Article

\title{
Convenient Synthesis and Physiological Activities of Flavonoids in Coreopsis lanceolata L. Petals and Their Related Compounds
}

\author{
Daisuke Nakabo, Yuka Okano, Naomi Kandori, Taisei Satahira, Naoya Kataoka, \\ Junpei Akamatsu and Yoshiharu Okada * (iD
}

Department of Biotechnology and Chemistry, Faculty of Engineering, Kindai University, Umenobe-1, Takaya, Higashi-hiroshima 739-2116 Japan; 1633850001b@hiro.kindai.ac.jp (D.N.); 1333850001@hiro.kindai.ac.jp (Y.O.); 1433850002@hiro.kindai.ac.jp (N.K.); 0910910069@hiro.kindai.ac.jp (T.S.); 1110910080@hiro.kindai.ac.jp (N.K.); 1410980093@hiro.kindai.ac.jp (J.A.)

* Correspondence: okadasan@hiro.kindai.ac.jp; Tel.: +81-82-434-7000

Received: 31 March 2018; Accepted: 6 July 2018; Published: 9 July 2018

\begin{abstract}
Chalcones, flavanones, and flavonols, including 8-methoxybutin isolated from Coreopsis lanceolata L. petals, were successfully synthesized with total yields of 2-59\% from O-methylpyrogallols using the Horner-Wadsworth-Emmons reaction as a key reaction. Aurones, including leptosidin, were also successfully synthesized with 5-36\% total yields using the Aldol condensation reaction as a key reaction. Each chalcone, flavanone, flavonol, and aurone with the 3,4-dihydroxy groups in the B-ring showed high antioxidant activity. Additionally, each of the chalcones, flavanones, flavonols, and aurones with the 2,4-dihydroxy groups in the B-ring showed an excellent whitening ability.
\end{abstract}

Keywords: Coreopsis lanceolata L.; chalcone; flavanone; flavonol; aurone; Horner-WadsworthEmmons reaction

\section{Introduction}

Coreopsis lanceolata L. is a plant native to North America with a yellow flower that blooms from May to June in Japan. We previously reported the isolation and physiological activities of lanceolin $\left(3,4,2^{\prime}, 4^{\prime}-\right.$ tetrahydroxy-3'-methoxychalcone-4'-glucoside), 8-methoxybutin ( $7,3^{\prime}, 4^{\prime}$-trihydroxy-8-methoxyflavanone), and leptosidin $\left(6,3^{\prime}, 4^{\prime}\right.$-trihydroxy-7-methoxyaurone) from C. lanceolata L. petals as shown in Figure 1 [1,2]. Koketsu et al. reported the isolation of lanceoletin $\left(3,4,2^{\prime}, 4^{\prime}\right.$-tetrahydroxy- $3^{\prime}$-methoxychalcone), okanin (3,4,2', $3^{\prime}, 4^{\prime}$-pentahydroxychalcone), 4-methoxylanceoletin (3,2', 4' -trihydroxy-4,3' -dimethoxychalcone), 8-methoxybutin, leptosidin, and leptosin $\left(6,3^{\prime}, 4^{\prime}\right.$-trihydroxy-7-methoxyaurone-6-glucoside) from C. lanceolata L., and the antileukemic activity of 4-methoxylanceoletin [3]. In this paper, we report the synthesis of the several kinds of flavonoids including C. lanceolata L. petals and their analogs, and the relationship between structure and physiological activities.

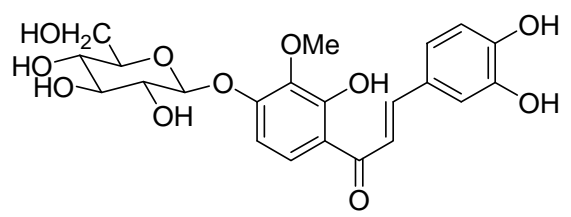

Lanceolin

(2',3,4,4'-tetrahydroxy-3'-methoxy chalcon-4'-glucoside)

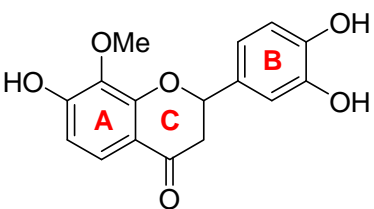

8-Methoxybutin (3',4',7-trihydroxy-8 methoxyflavanone)

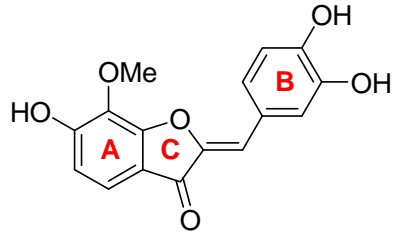

Leptosidin

((Z)-3', 4',6-trihydroxy-7methoxyaurone)

Figure 1. Isolated flavonoids from Coreopsis lenceolata L. petals. 


\section{Results and Discussion}

\subsection{Flavonoids Synthesis}

The process used to synthesize the chalcones, flavanones, and flavonols is shown in Scheme 1. The protection of $\mathbf{1} \mathbf{a}, \mathbf{b}$ with chloromethyl methyl ether ( $\mathrm{MOMCl}$ ) produced compound $\mathbf{2} \mathbf{a}, \mathbf{b}$. The lithiation at the 4-position of $\mathbf{2} \mathbf{a}, \mathbf{b}$ with $n$-BuLi, which was stabilized by the methoxymethoxy moiety and subsequent ethoxycarbonylation with ethyl chloroformate produced ethyl benzoates $\mathbf{3 a}, \mathbf{b}$ with 86 and 73\% yields, respectively. The reaction of $\mathbf{3 a} \mathbf{a} \mathbf{b}$ with dimethyl methylphosphonate in the presence of lithium diisopropylamide (LDA) produced $\beta$-keto phosphonates $4 \mathbf{a}, \mathbf{b}$ with 87 and $76 \%$ yields, respectively. The Horner-Wadsworth-Emmons (HWE) reaction, which is a key reaction in this process, of $\mathbf{4 a} \mathbf{a} \mathbf{b}$ with aromatic aldehydes $\mathbf{5 a - f}$ in the presence of 1,8-diazabicyclo[5.4.0] undec-7-ene (DBU) as a base produced the corresponding chalcone 6a-1 with 78-92\% yields. Subsequently, the deprotection of $\mathbf{6 a}-\mathbf{1}$ with $3 \mathrm{M} \mathrm{HCl}$ at reflux produced the MOM group deprotected chalcones $7 \mathbf{a}-\mathbf{1}$ with $41-98 \%$ yields. The structures of $7 \mathbf{a}-1$ were assigned based on their hydrogen and carbon nuclear magnetic resonance $\left({ }^{1} \mathrm{H}-\mathrm{NMR}\right.$ and $\left.{ }^{13} \mathrm{C}-\mathrm{NMR}\right)$ spectral data. The olefinic protons of $7 \mathrm{a}$ were observed at $\delta 7.43(\mathrm{~d}, J=15.9 \mathrm{~Hz})$ and $\delta 7.83(\mathrm{~d}, J=15.4 \mathrm{~Hz})$, respectively. Therefore, the geometry of the double bond of $7 \mathbf{a}-\mathbf{1}$ was assigned as the $(E)$-form. A solution of $7 \mathbf{a}-\mathbf{1}$ in methanol containing potassium fluoride was heated at reflux to produce flavanones $8 \mathbf{a}-\mathbf{1}$ with $46-98 \%$ yields [4]. The ${ }^{1} \mathrm{H}-\mathrm{NMR}$ spectrum of $\mathbf{8 a}$ shows a signal for the methine proton $(\mathrm{dd}, J=2.9$ and $12.9 \mathrm{~Hz})$ at $\delta 5.42$ and two methylene protons $(\mathrm{dd}, J=3.2$ and $17.1 \mathrm{~Hz})$ at $\delta 2.72$ and $(\mathrm{dd}, J=12.9$ and $16.9 \mathrm{~Hz})$ at $\delta 3.07$, respectively. These coupling constants of $2.9 \mathrm{~Hz}$ and $12.9 \mathrm{~Hz}$ were the vicinal coupling constants assigned to two methylene protons and a methine proton, respectively. Therefore, the structures of $\mathbf{8 a}-\mathbf{1}$ were determined as flavanones. Treatment of $\mathbf{6 a}-\mathbf{k}$ with $1.5 \mathrm{M} \mathrm{HCl}$ at room temperature produced the chalcones $\mathbf{9 a}-\mathbf{k}$ with $65-95 \%$ yields, which the 2'-MOM groups activated by the close carbonyl groups, which were selectively deprotected. Treatment of $\mathbf{9 a}-\mathbf{k}$ and $\mathbf{7 1}$ with basic $\mathrm{H}_{2} \mathrm{O}_{2}$ produced the corresponding flavonols $10 \mathrm{a}-\mathbf{1}$ with $17-65 \%$ yields [5]. ${ }^{13}$ C-NMR spectrum of 10a showed a signal for carbonyl carbon at $\delta 172.70$. However, a similar signal for flavanone 8a was observed at $\delta 193.21$. The carbonyl carbon of 10a shifted toward the upper field due to the influence of the double bond of flavonol. Therefore, the structures of $\mathbf{1 0 a}-\mathbf{1}$ were determined to be flavonols. Finally, the deprotection of the MOM groups of $10 a-1$ with $3 \mathrm{M}$ $\mathrm{HCl}$ produced compounds $\mathbf{1 1 a}-1$ with $38-98 \%$ yields.

The process used to synthesize the aurones is shown in Scheme 2. The Friedel-Crafts acylation of $\mathbf{1 a}, \mathbf{b}$ with chloroacetyl chloride produced compounds $\mathbf{1 2} \mathbf{a}, \mathbf{b}$ with 54 and $58 \%$ yields, respectively. The cyclization of $\mathbf{1 2} \mathbf{b}$ with potassium hydroxide as a base produced benzofuranone $\mathbf{1 3 b}$ with a low yield of $28 \%$ in a complex mixture since the intermolecular reaction of $\mathbf{1 2 b}$ due to high basicity. Using sodium acetate instead of potassium hydroxide as a base resulted in an increase in the yield to $83 \%$. A similar reaction of 12a produced 13a with a 77\% yield. The protection of the hydroxyl group of 13a with $\mathrm{MOMCl}$ produced compound $13 \mathrm{c}$ with a $58 \%$ yield. The aldol condensation reaction, which is a key reaction in this process, of $\mathbf{1 3 b} \mathbf{b}$ with aromatic aldehydes $\mathbf{5 a}-\mathbf{f}$ in the presence of aluminum oxide produced the corresponding aurones $14 a-1$ with $31-89 \%$ yields [6]. In this reaction, the use of 13a resulted in decreasing yields. The structures of $14 a-1$ were classified on the basis of their ${ }^{1} \mathrm{H}-\mathrm{NMR}$ and ${ }^{13} \mathrm{C}-\mathrm{NMR}$ spectral data. The ${ }^{1} \mathrm{H}-\mathrm{NMR}$ spectrum of 14 a showed a signal for an olefinic proton at $\delta 6.84$ (s). The olefinic carbon was observed at $\delta 112.16$. According to the ${ }^{13} \mathrm{C}-\mathrm{NMR}$ study of the aurones, a signal for the olefinic carbon of the Z-isomer was observed at about $110 \mathrm{ppm}$, whereas that of $E$-isomer was observed at about $120 \mathrm{ppm}$ [7]. Therefore, the structures of 14a-1 were classified as the (Z)-form. Finally, the deprotection of the MOM group of $\mathbf{1 4 a - k}$ with $3 \mathrm{M} \mathrm{HCl}$ produced compounds 15a-k with 51-97\% yields. 
<smiles>[R20]c1cccc(O)c1OC</smiles><smiles>[R20]c1ccc(C(=O)/C=C/c2ccc3cc2C(C)C[Se]3)c(OC)c1OC</smiles>

6a-I

7a-I

8a-I

$(7)$<smiles>[R20]c1ccc(C(=O)/C=C/c2ccccc2)c(O)c1OC</smiles>

9a-k
(8)<smiles>[R20]c1ccc2c(=O)c(O)c(-c3ccccc3)oc2c1OC</smiles>

(5)<smiles>[R10]c1ccc2c(=O)c(O)c(-c3ccccc3)oc2c1OC</smiles>

11a-I

Reagents and conditions: (1) $\mathrm{MOMCl}, \mathrm{NaH}, \mathrm{DMF}, 0^{\circ} \mathrm{C}$ to r.t.; (2) ${ }^{n} \mathrm{BuLi}, \mathrm{ClCO}_{2} \mathrm{Et}$, THF, $-70{ }^{\circ} \mathrm{C}$ to r.t.; (3) LDA, $\mathrm{CH}_{3} \mathrm{P}(\mathrm{O})(\mathrm{OMe})_{2}$, THF, $-70^{\circ} \mathrm{C}$ to r.t.; (4) DBU, ArCHO 5a-f, THF, r.t.; (5) $3 \mathrm{M} \mathrm{HCl}$, THF, reflux; (6) KF, MeOH, reflux; (7) $1.5 \mathrm{M} \mathrm{HCl}$, THF, r.t.; (8) $\mathrm{H}_{2} \mathrm{O}_{2}, 4 \mathrm{M} \mathrm{NaOH}$, $\mathrm{MeOH}$, r.t.

Scheme 1. Synthesis of chalcones 7a-1, flavanones 8a-1, and flavonols 11a-1.<smiles>[R10]c1ccc(C(=O)CC)c(O)c1OC</smiles>

$12 a, b$
(2)<smiles>[R20]c1ccc2c(c1OC)OC(C)C2=O</smiles>

$13 a, b$<smiles>[R20]c1ccc2c(c1OC)OC(C)C2=O</smiles>

$13 c$<smiles>[R20]c1ccc2c(c1OC)O/C(=C\c1ccccc1)C2=O</smiles>

$14 a-I$<smiles>[R10]Oc1ccc2c(c1OC)O/C(=C\c1ccccc1)C2=O</smiles>

15a-k

Reagents and conditions: (1) $\mathrm{AlCl}_{3}, \mathrm{ClCO}_{2} \mathrm{Et}, \mathrm{ClCH}_{2} \mathrm{CH}_{2} \mathrm{Cl}$, r.t.; (2) $\mathrm{NaOAc}, \mathrm{MeOH}$, reflux; (3) MOMCl, NaH, DMF, r.t.; (4) $\mathrm{Al}_{2} \mathrm{O}_{3}, \mathrm{ArCHO}_{5} \mathrm{a}$-f, $\mathrm{CH}_{2} \mathrm{Cl}_{2}$, r.t.; (5) $3 \mathrm{M} \mathrm{HCl}$, THF, reflux.

Scheme 2. Synthesis of aurones 15a-k.

\subsection{Antioxidant and Tyrosinase Inhibitory Activity of the Synthesized Flavonoids}

Next, the physiological activities of these synthesized compounds were investigated. The antioxidant activity and whitening effect were assessed based on the 2,2-diphenyl-1-picrylhydrazyl (DPPH) free radical scavenging assay [8] and tyrosinase inhibition assay [9], respectively. The results are summarized in Tables 1 and 3-4. The antioxidant activity was evaluated based on the scavenging rate of the DPPH radical under the condition where the final concentration of the samples and DPPH radical were prepared at $0.040 \mathrm{mM}$ and $0.040 \mathrm{mM}$, respectively. A correlation was found between the physiological activity and 
structures of the A-ring and B-ring of the chalcones, flavanones, flavonols, and aurones. On the chalcones, the hydroxyl group at the 4-position on the A-ring was confirmed to be important for the antioxidant activity since the chalcones $7 \mathrm{~g}-\mathbf{l}$ with a methoxy group instead of a hydroxyl group at the 4-position displayed decreased activity. The flavanones $\mathbf{8 a}-\mathbf{f}$ showed lower antioxidant activity than chalcones $\mathbf{7 a}-\mathbf{f}$, since the hydroxyl group at 2-position of the A-ring of chalcone was lost during the conversion into flavanone. For the aurones, $\mathbf{1 5} \mathbf{g}-\mathbf{k}$ with a methoxy substituent at the 6-position on the A-ring showed similar behavior. However, on the flavonols, the compounds 101 and $11 \mathbf{g}-\mathbf{k}$ with methoxy groups at the 7-position on the A-ring showed a higher antioxidant activity than with hydroxyl groups. Each of the chalcones $7 \mathbf{b}, \mathbf{h}$, flavanones $8 \mathbf{b}, \mathbf{h}$, flavonols $11 \mathbf{b}, \mathbf{h}$, and aurones $15 b$, $\mathbf{h}$ with 3,4 -dihydroxy groups on the B-ring had high antioxidant activity. In addition, each with a 4-hydroxy-3-methoxy placement on the B-ring $(\mathbf{7 d}, \mathbf{j}, \mathbf{8 d}, \mathbf{j}, \mathbf{1 1} \mathbf{d}, \mathbf{j}$, and $\mathbf{1 5 d}, \mathbf{j})$ had superior antioxidant effects compared with those with the 3-hydroxy-4-methoxy placement (7e,k, 8e,k, 11e,k, and 15e,k). Moreover, the 4-hydroxyl group on the B-ring $(\mathbf{7 j}, \mathbf{8 j}, \mathbf{1 1} \mathbf{j}$, and $\mathbf{1 5} \mathbf{j})$ seemed to have more influence on the antioxidant activity than a hydroxyl group on the A-ring (7f, $\mathbf{8 f}, \mathbf{1 1 f}$, and $\mathbf{1 5 f})$. The flavanones and aurones showed low antioxidant activity; the correlation between the substitution groups and activity was recorded.

Although each of the chalcones $7 \mathrm{c}, \mathbf{i}$ and aurones $\mathbf{1 5 c}, \mathbf{i}$ with the 2,4-dihydroxy groups on the B-ring showed lower antioxidant activity, flavonols 11c,i with those groups had a high activity due to an apparent enhancement by the hydroxyl group at the 3-position on the C-ring. Since flavanones showed lower radical scavenging activity overall, the double bond in the structure of the flavonoid was thought to strongly influence antioxidant activity. The antioxidant activity in decreasing order was flavonol, chalcone, aurone, and flavanone.

The whitening effect was evaluated by inhibition of tyrosinase activity under the condition where the final concentration of samples and tyrosinase were prepared in $0.10 \mathrm{mM}$ and 20 units $/ \mathrm{mL}$, respectively. Each of chalcones $7 \mathbf{b}, \mathbf{h}$, flavanones $8 \mathbf{b}, \mathbf{h}$, flavonol $\mathbf{1 1 h}$, and aurones $\mathbf{1 5 b}$,h with 3,4-dihydroxy groups on the B-ring displayed a low inhibition rate. In addition, each with a 3-hydroxy-4-methoxy placement on the B-ring $(\mathbf{7 e}, \mathbf{k}, \mathbf{8 e}, \mathbf{k}, \mathbf{1 1 e}, \mathbf{k}$, and $\mathbf{1 5 e}, \mathbf{k})$ had a superior inhibition activity compared to those with the 4-hydroxy-3-methoxy placement (7d,j, 8d, j, 11d, j, and $\mathbf{1 5 d}, \mathbf{j})$.

The chalcones $\mathbf{7 c , i}$ and aurones $\mathbf{1 5 c}$, $\mathbf{i}$ bearing 2,4-dihydroxy groups on the B-ring demonstrated high inhibitory activity potential. Ramsden et al. explained that the reductive elimination and loss of copper atoms from the active site of tyrosinase via the resorcinol (1,3-dihydroxybenzene) moiety resulted in the inactivation of tyrosinase [10]. However, the flavonol 11c,i bearing a similar group did not inhibit tyrosinase activity. This tendency could potentially be due to the steric hindrance of the hydroxyl group at the 3-position of the flavonol against the 2,4-dihydroxy groups on the B-ring. The whitening effect in decreasing order was chalcone, aurone. flavonol, and flavanone.

Table 1. The DPPH radical scavenging assay and tyrosinase inhibition activity assay of chalcones $\mathbf{7 a - 1 .}$

Entry Compound


Table 1. Cont.

\begin{tabular}{|c|c|c|c|c|}
\hline Entry & Compound & $\mathbf{R}^{1}$ & $\begin{array}{l}\text { DPPH Radical } \\
\text { Scavenging Assay }\end{array}$ & $\begin{array}{c}\text { Tyrosinase Inhibition } \\
\text { Activity Assay }\end{array}$ \\
\hline & & & Scavenging Rate (\%) ${ }^{a}$ & Inhibition Rate $(\%) b$ \\
\hline 3 & $7 \mathrm{c}$ & $\mathrm{H}$ & 31.6 & 85.7 \\
\hline 4 & $7 d$ & $\mathrm{H}$ & 56.7 & 0.0 \\
\hline 5 & $7 e$ & $\mathrm{H}$ & 20.5 & 30.3 \\
\hline 6 & $7 f$ & $\mathrm{H}$ & 11.4 & 5.1 \\
\hline 7 & $7 \mathrm{~g}$ & $\mathrm{Me}$ & 1.0 & 40.7 \\
\hline 8 & $7 \mathrm{~h}$ & $\mathrm{Me}$ & 94.0 & 18.7 \\
\hline 9 & $7 \mathbf{i}$ & $\mathrm{Me}$ & 6.9 & 80.3 \\
\hline 10 & $7 \mathbf{j}$ & $\mathrm{Me}$ & 48.8 & 0.0 \\
\hline 11 & $7 \mathbf{k}$ & $\mathrm{Me}$ & 0.1 & 22.5 \\
\hline 12 & 71 & $\mathrm{Me}$ & 4.2 & 7.2 \\
\hline 13 & Lanceolin & & $94.2^{\mathrm{c}}$ & \\
\hline 14 & $\alpha$-Tocopherol & & 95.0 & \\
\hline 15 & Arbutin & & & 9.3 \\
\hline
\end{tabular}

Table 2. The DPPH radical scavenging assay and tyrosinase inhibition activity assay of flavanones 8a-1.

Entry Compound


Table 2. Cont.

\begin{tabular}{|c|c|c|c|c|}
\hline \multirow[t]{2}{*}{ Entry } & \multirow[t]{2}{*}{ Compound } & \multirow[t]{2}{*}{$\mathbf{R}^{1}$} & \multirow{2}{*}{$\begin{array}{c}\text { DPPH Radical } \\
\text { Scavenging Assay } \\
\text { Scavenging Rate }(\%)^{a}\end{array}$} & \multirow{2}{*}{$\begin{array}{c}\begin{array}{c}\text { Tyrosinase Inhibition } \\
\text { Activity Assay }\end{array} \\
\text { Inhibition Rate }(\%)^{b}\end{array}$} \\
\hline & & & & \\
\hline 4 & $8 e$ & $\mathrm{H}$ & 16.2 & 0.0 \\
\hline 5 & $8 f$ & $\mathrm{H}$ & 4.7 & 0.0 \\
\hline 6 & $8 g$ & $\mathrm{Me}$ & 0.6 & 27.4 \\
\hline 7 & $8 h$ & $\mathrm{Me}$ & 94.2 & 23.1 \\
\hline 8 & $8 j$ & $\mathrm{Me}$ & 15.6 & 0.0 \\
\hline 9 & $8 k$ & $\mathrm{Me}$ & 7.2 & 0.0 \\
\hline 10 & 81 & $\mathrm{Me}$ & 0.0 & 1.8 \\
\hline 11 & 8-Methoxybu & & $94.3^{c}$ & \\
\hline 12 & $\alpha$-Tocopherol & & 95.0 & \\
\hline 13 & Arbutin & & & 9.3 \\
\hline
\end{tabular}

Table 3. The DPPH radical scavenging assay and tyrosinase inhibition activity assay of flavonols 11a-1.

Entry Compound


Table 3. Cont.

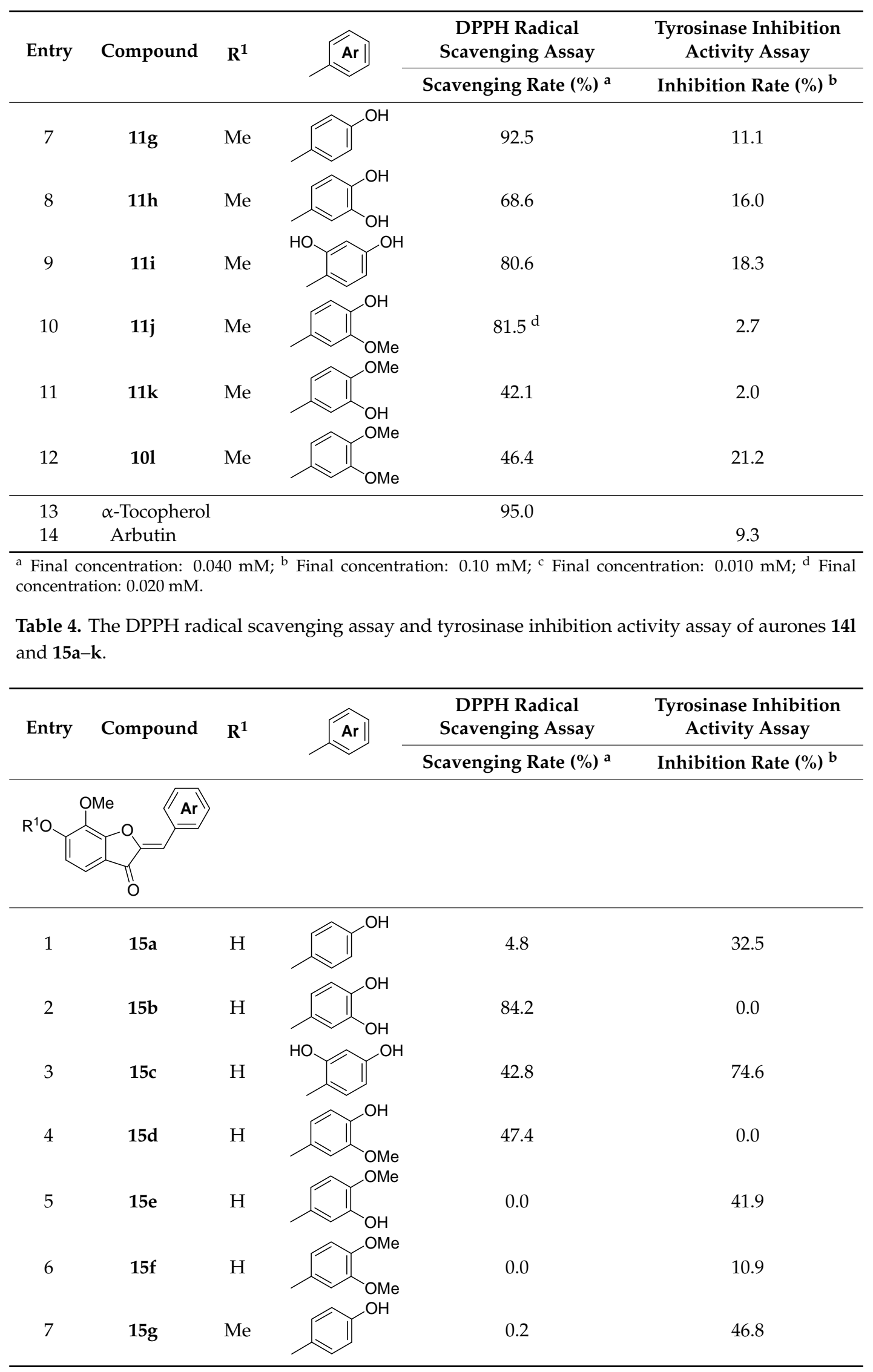


Table 4. Cont.

\begin{tabular}{|c|c|c|c|c|}
\hline \multirow[t]{2}{*}{ Entry } & \multirow[t]{2}{*}{ Compound } & \multirow[t]{2}{*}{$\mathbf{R}^{1}$} & \multirow{2}{*}{$\begin{array}{c}\text { DPPH Radical } \\
\text { Scavenging Assay }\end{array}$} & \multirow{2}{*}{$\begin{array}{c}\begin{array}{c}\text { Tyrosinase Inhibition } \\
\text { Activity Assay }\end{array} \\
\text { Inhibition Rate (\%) }^{\mathbf{b}}\end{array}$} \\
\hline & & & & \\
\hline 8 & $15 \mathrm{~h}$ & $\mathrm{Me}$ & 85.8 & 0.0 \\
\hline 9 & $15 i$ & $\mathrm{Me}$ & 13.3 & 56.6 \\
\hline 10 & $15 j$ & $\mathrm{Me}$ & 32.8 & 13.8 \\
\hline 11 & $15 k$ & $\mathrm{Me}$ & 8.9 & 23.2 \\
\hline 12 & 141 & $\mathrm{Me}$ & 0.5 & 10.1 \\
\hline 13 & Leptosidin & & $93.4^{\mathrm{c}}$ & \\
\hline 14 & $\alpha$-Tocopherol & & 95.0 & \\
\hline 15 & Arbutin & & & 9.3 \\
\hline
\end{tabular}

\section{Materials and Methods}

\subsection{General Methods}

${ }^{1} \mathrm{H}-\mathrm{NMR}$ and ${ }^{13} \mathrm{C}$-NMR spectra were obtained on a JEOL JNM-EX400 (Tokyo, Japan) spectrometer in $\mathrm{CDCl}_{3}, \mathrm{CD}_{3} \mathrm{OD}$, or dimethyl sulfoxide (DMSO)- $d_{6}$ operating at $400 \mathrm{MHz}$ and $100 \mathrm{MHz}$, respectively, with $\mathrm{Me}_{4} \mathrm{Si}$ as the internal standard. The absorbance was measured with a microplate reader Corona MTP-300 (Tokyo, Japan). The absorbance was recorded in the 200-600 nm range at room temperature with Jasco V630 (Tokyo, Japan). The mass spectra were obtained on a Shimadzu gas chromatograph mass spectrometer (GCMS)-QP5000 (Kyoto, Japan) with a column temperature of $240{ }^{\circ} \mathrm{C}$, injection temperature of $200{ }^{\circ} \mathrm{C}$, and interface temperature of $230^{\circ} \mathrm{C}$, with $\mathrm{He}$ as the carrier gas at a flow rate of $1.3 \mathrm{~mL} / \mathrm{min}$. Tetrahydrofuran (THF) was purified by distillation over benzophenone ketyl under an argon atmosphere before use. The melting points were measured in open capillary tubes and were uncorrected.

\subsection{The General Procedure for the Protection of 2-O-Methylpyrogallol 1a,b with Chloromethyl Methyl Ether}

A solution of $\mathbf{1 a}, \mathbf{b}(100.0 \mathrm{mmol})$ in $\mathrm{N}, \mathrm{N}$-dimethylformamide (DMF) $(50 \mathrm{~mL})$ was added to a suspension of sodium hydride $(60 \%$ in mineral oil, $9.60 \mathrm{~g}, 240.0 \mathrm{mmol}$ or $4.80 \mathrm{~g}, 120.0 \mathrm{mmol})$ in DMF $(150 \mathrm{~mL})$ at $0{ }^{\circ} \mathrm{C}$. After being stirred at room temperature for $30 \mathrm{~min}$, chloromethyl methyl ether $(15.2 \mathrm{~mL}, 200.0 \mathrm{mmol}$ or $11.4 \mathrm{~mL}, 150.0 \mathrm{mmol})$ was added to the mixture at $0{ }^{\circ} \mathrm{C}$. After being stirred at room temperature for $6 \mathrm{~h}, 100 \mathrm{~mL} \mathrm{Et}_{2} \mathrm{O}$ was added to the mixture. The reaction mixture was poured into ice water $(400 \mathrm{~mL})$. The mixture was extracted with $\mathrm{Et}_{2} \mathrm{O}$. The organic layer was washed with water and brine and dried over anhydrous $\mathrm{MgSO}_{4}$. The solvent was evaporated in vacuo and the residue was chromatographed on silica gel with $\mathrm{CHCl}_{3}-\mathrm{Et}_{2} \mathrm{O}(9: 1)$ to produce $\mathbf{2 a}, \mathbf{b}$.

2-Methoxy-1,3-di(methoxymethoxy)benzene (2a): (22.14 g, $97.0 \mathrm{mmol}, 97 \%$ yield); ${ }^{1} \mathrm{H}-\mathrm{NMR}\left(\mathrm{CDCl}_{3}\right)$ $3.52\left(\mathrm{~s}, 6 \mathrm{H}, \mathrm{OCH}_{3}\right), 3.89\left(\mathrm{~s}, 3 \mathrm{H}, \mathrm{OCH}_{3}\right), 5.22\left(\mathrm{~s}, 4 \mathrm{H}, \mathrm{OCH}_{2}\right), 6.85(\mathrm{~d}, J=8.1 \mathrm{~Hz}, 2 \mathrm{H}, \mathrm{H}-4$ and $\mathrm{H}-6), 6.95$ $(\mathrm{t}, J=8.3 \mathrm{~Hz}, 1 \mathrm{H}, \mathrm{H}-5)$. 
1,2-Dimethoxy-3-(methoxymethoxy)benzene (2b): (18.63 g, $94.0 \mathrm{mmol}, 94 \%$ yield); ${ }^{1} \mathrm{H}-\mathrm{NMR}\left(\mathrm{CDCl}_{3}\right)$ $3.52\left(\mathrm{~s}, 3 \mathrm{H}, \mathrm{OCH}_{3}\right), 3.87\left(\mathrm{~s}, 3 \mathrm{H}, \mathrm{OCH}_{3}\right), 3.87\left(\mathrm{~s}, 3 \mathrm{H}, \mathrm{OCH}_{3}\right), 5.23\left(\mathrm{~s}, 2 \mathrm{H}, \mathrm{OCH}_{2}\right), 6.63(\mathrm{~d}, J=8.1 \mathrm{~Hz}, 1 \mathrm{H}$, H-6), 6.80 (d, $J=7.6 \mathrm{~Hz}, 1 \mathrm{H}, \mathrm{H}-4), 6.98$ (t, $J=8.3 \mathrm{~Hz}, 1 \mathrm{H}, \mathrm{H}-5)$.

\subsection{The General Procedure for the Preparation of Ethyl Benzoates $\mathbf{3 a}, \mathbf{b}$}

n-BuLi (1.55 M hexane solution, $23.2 \mathrm{~mL}, 36.0 \mathrm{mmol})$ was added to a solution of $\mathbf{2 a}, \mathbf{b}(30.0 \mathrm{mmol})$ in THF $(150 \mathrm{~mL})$ at $-70^{\circ} \mathrm{C}$. The reaction mixture was warmed to $0{ }^{\circ} \mathrm{C}$ and stirred for $90 \mathrm{~min}$ at the same temperature. The mixture was cooled to $-70{ }^{\circ} \mathrm{C}$ and a solution of ethyl chloroformate $(14.3 \mathrm{~mL}$, $150.0 \mathrm{mmol})$ in THF $(15 \mathrm{~mL})$ was added dropwise to the mixture. After being stirred for $30 \mathrm{~min}$ at $-70{ }^{\circ} \mathrm{C}$, the mixture was stirred at room temperature for $2 \mathrm{~h}$. The mixture was poured into an ice-saturated ammonium chloride aqueous solution. The mixture was extracted with $\mathrm{Et}_{2} \mathrm{O}$. The organic layer was washed with water and brine and dried over anhydrous $\mathrm{MgSO}_{4}$. The solvent was evaporated in vacuo and the residue was chromatographed on silica gel with $\mathrm{CHCl}_{3}-\mathrm{Et}_{2} \mathrm{O}(9: 1)$ to produce $\mathbf{3 a}, \mathbf{b}$.

Ethyl 3-methoxy-2,4-di(methoxymethoxy)benzoate (3a): (7.75 g, $25.8 \mathrm{mmol}, 86 \%$ yield); ${ }^{1} \mathrm{H}-\mathrm{NMR}$ $\left(\mathrm{CDCl}_{3}\right) \delta 1.38\left(\mathrm{t}, J=7.1 \mathrm{~Hz}, 3 \mathrm{H}, \mathrm{CH}_{3}\right), 3.52\left(\mathrm{~s}, 3 \mathrm{H}, \mathrm{OCH}_{3}\right), 3.62\left(\mathrm{~s}, 3 \mathrm{H}, \mathrm{OCH}_{3}\right), 3.89\left(\mathrm{~s}, 3 \mathrm{H}, \mathrm{OCH}_{3}\right)$, $4.37\left(\mathrm{q}, J=7.1 \mathrm{~Hz}, 1 \mathrm{H}, \mathrm{OCH}_{2} \mathrm{CH}_{3}\right), 5.18\left(\mathrm{~s}, 2 \mathrm{H}, \mathrm{OCH}_{2}\right), 5.28\left(\mathrm{~s}, 2 \mathrm{H}, \mathrm{OCH}_{2}\right), 6.97(\mathrm{~d}, J=9.0 \mathrm{~Hz}, 1 \mathrm{H}, \mathrm{H}-5)$, $7.60(\mathrm{~d}, J=8.8 \mathrm{~Hz}, 1 \mathrm{H}, \mathrm{H}-6) ;{ }^{13} \mathrm{C}-\mathrm{NMR}\left(\mathrm{CDCl}_{3}\right) \delta 14.3,56.4,57.4,60.8,61.0,94.6,100.1,110.6,119.3$, $126.7,143.2,151.3,154.4,165.1$.

Ethyl 3,4-dimethoxy-2-(methoxymethoxy)benzoate (3b): (5.92 g, $21.9 \mathrm{mmol}, 73 \%$ yield); ${ }^{1} \mathrm{H}-\mathrm{NMR}$ $\left(\mathrm{CDCl}_{3}\right) \delta 1.38\left(\mathrm{t}, J=7.1 \mathrm{~Hz}, 3 \mathrm{H}, \mathrm{CH}_{3}\right), 3.61\left(\mathrm{~s}, 3 \mathrm{H}, \mathrm{OCH}_{3}\right), 3.87\left(\mathrm{~s}, 3 \mathrm{H}, \mathrm{OCH}_{3}\right), 3.91\left(\mathrm{~s}, 3 \mathrm{H}, \mathrm{OCH}_{3}\right)$, $4.35\left(\mathrm{q}, J=7.1 \mathrm{~Hz}, 1 \mathrm{H}, \mathrm{OCH}_{2} \mathrm{CH}_{3}\right), 5.17\left(\mathrm{~s}, 2 \mathrm{H}, \mathrm{OCH}_{2}\right), 6.72(\mathrm{~d}, J=9.0 \mathrm{~Hz}, 1 \mathrm{H}, \mathrm{H}-5), 7.65(\mathrm{~d}, J=8.8 \mathrm{~Hz}, 1 \mathrm{H}$, H-6); ${ }^{13} \mathrm{C}-\mathrm{NMR}\left(\mathrm{CDCl}_{3}\right) \delta 14.3,56.0,57.4,60.7,60.9,100.0,106.9,118.2,127.0,142.5,151.2,156.8,165.2$.

\subsection{The General Procedure for the Synthesis of $\alpha$-(Dimethylphosphono)acetylbenzenes $\mathbf{4 a}, \mathbf{b}$}

$n$-BuLi (1.55 M hexane solution, $42.6 \mathrm{~mL}, 66 \mathrm{mmol}$ ) was added to a solution of diisopropylamine $(8.4 \mathrm{~mL}, 60.0 \mathrm{mmol})$ in THF $(100 \mathrm{~mL})$ at $-70{ }^{\circ} \mathrm{C}$. After being stirred for $30 \mathrm{~min}$ at the same temperature, a solution of dimethyl methylphosphonate $(4.47 \mathrm{~g}, 36.0 \mathrm{mmol})$ in THF $(15 \mathrm{~mL})$ was added dropwise to the mixture. The reaction mixture was stirred for $15 \mathrm{~min}$ at $-70{ }^{\circ} \mathrm{C}$ and a solution of $3 \mathbf{a}, \mathbf{b}(30.0 \mathrm{mmol})$ in THF $(15 \mathrm{~mL})$ was added to the mixture. The mixture was stirred for $1 \mathrm{~h}$ at $-70{ }^{\circ} \mathrm{C}$ and for $12 \mathrm{~h}$ at room temperature. The mixture was poured into ice and a $2 \mathrm{M}$ hydrochloric acid aqueous solution. The mixture was extracted with EtOAc. The organic layer was washed with water and brine and dried over anhydrous $\mathrm{MgSO}_{4}$. The solvent was evaporated in vacuo and the residue was chromatographed on silica gel with $\mathrm{CHCl}_{3}-\mathrm{Et}_{2} \mathrm{O}-\mathrm{MeOH}(8: 2: 0.05)$ to produce $4 \mathbf{a}, \mathbf{b}$.

$\alpha$-(Dimethylphosphono)-3-methoxy-2,4-di(methoxymethoxy)acetophenone (4a): (9.87 g, $26.1 \mathrm{mmol}$, $87 \%$ yield); reddish brown viscous oil; ${ }^{1} \mathrm{H}-\mathrm{NMR}\left(\mathrm{CDCl}_{3}\right) \delta 3.52\left(\mathrm{~s}, 6 \mathrm{H}, \mathrm{OCH}_{3}\right), 3.77(\mathrm{~d}, J=11.2 \mathrm{~Hz}, 6 \mathrm{H}$, $\left.\mathrm{P}(\mathrm{O}) \mathrm{OCH}_{3}\right), 3.86\left(\mathrm{~d}, \mathrm{~J}=21.5 \mathrm{~Hz}, 2 \mathrm{H}, \mathrm{P}(\mathrm{O}) \mathrm{CH}_{2}\right), 3.88\left(\mathrm{~s}, 3 \mathrm{H}, \mathrm{OCH}_{3}\right), 5.23\left(\mathrm{~s}, 2 \mathrm{H}, \mathrm{OCH}_{2}\right), 5.28(\mathrm{~s}, 2 \mathrm{H}$, $\left.\mathrm{OCH}_{2}\right), 6.98(\mathrm{~d}, J=8.8 \mathrm{~Hz}, 1 \mathrm{H}, \mathrm{H}-5), 7.48(\mathrm{~d}, J=9.0 \mathrm{~Hz}, 1 \mathrm{H}, \mathrm{H}-6) ;{ }^{13} \mathrm{C}-\mathrm{NMR}\left(\mathrm{CDCl}_{3}\right) \delta 40.3(\mathrm{~d}, J=131.0 \mathrm{~Hz}$, $\left.\mathrm{P}(\mathrm{O}) \mathrm{CH}_{2}\right), 52.9\left(\mathrm{~d}, \mathrm{~J}=5.8 \mathrm{~Hz}, \mathrm{P}(\mathrm{O}) \mathrm{OCH}_{3}\right), 56.5,58.0,61.0,94.7,100.2,110.9,126.0,126.9(\mathrm{~d}, J=3.3 \mathrm{~Hz}$, Ar), 142.0, 150.6, 155.1, $191.9(\mathrm{~d}, J=6.6 \mathrm{~Hz}, \mathrm{CO})$.

$\alpha$-(Dimethylphosphono)-3,4-dimethoxy-2-(methoxymethoxy)acetophenone (4b): (7.94 g, $22.8 \mathrm{mmol}$, $76 \%$ yield); reddish brown viscous oil; ${ }^{1} \mathrm{H}-\mathrm{NMR}\left(\mathrm{CDCl}_{3}\right) \delta 3.51\left(\mathrm{~s}, 3 \mathrm{H}, \mathrm{OCH}_{3}\right), 3.77(\mathrm{~d}, J=11.0 \mathrm{~Hz}, 6 \mathrm{H}$, $\left.\mathrm{OCH}_{3}\right), 3.86\left(\mathrm{~s}, 3 \mathrm{H}, \mathrm{OCH}_{3}\right), 3.87\left(\mathrm{~d}, \mathrm{~J}=21.7 \mathrm{~Hz}, 2 \mathrm{H}, \mathrm{P}(\mathrm{O}) \mathrm{CH}_{2}\right), 3.92\left(\mathrm{~s}, 3 \mathrm{H}, \mathrm{OCH}_{3}\right), 5.23\left(\mathrm{~s}, 2 \mathrm{H}, \mathrm{OCH}_{2}\right)$, $6.76(\mathrm{~d}, J=8.8 \mathrm{~Hz}, 1 \mathrm{H}, \mathrm{H}-5), 7.54(\mathrm{~d}, J=8.8 \mathrm{~Hz}, 1 \mathrm{H}, \mathrm{H}-6) ;{ }^{13} \mathrm{C}-\mathrm{NMR}\left(\mathrm{CDCl}_{3}\right) \delta 40.9(\mathrm{~d}, J=131.0 \mathrm{~Hz}$, $\left.\mathrm{P}(\mathrm{O}) \mathrm{CH}_{2}\right), 52.8\left(\mathrm{~d}, J=6.6 \mathrm{~Hz}, \mathrm{P}(\mathrm{O}) \mathrm{OCH}_{3}\right), 56.1,58.0,60.8,100.2,107.3,125.9(\mathrm{~d}, J=3.3 \mathrm{~Hz}, \mathrm{Ar}), 126.2$, $141.4,150.6,157.5,191.7(\mathrm{~d}, J=6.6 \mathrm{~Hz}, \mathrm{CO})$. 


\subsection{The General Procedure for the Synthesis of Chalcones 6a-1}

A solution of benzaldehydes $\mathbf{5 a}-\mathbf{f}(1.2 \mathrm{mmol})$ in THF $(1 \mathrm{~mL})$ was added to a solution of $\mathbf{4 a}, \mathbf{b}$ $(1.0 \mathrm{mmol})$ and DBU $(0.30 \mathrm{~g}, 2.0 \mathrm{mmol})$ in THF $(4 \mathrm{~mL})$ at room temperature. The reaction mixture was poured into an ice-saturated ammonium chloride aqueous solution and extracted with $\mathrm{Et}_{2} \mathrm{O}$. The organic layer was washed with water and brine and dried over anhydrous $\mathrm{MgSO}_{4}$. The solvent was evaporated in vacuo and the residue was chromatographed on a preparative thin layer chromatography (hexane:EtOAc $=3: 2$ ) to produce chalcones $\mathbf{6 a}-\mathbf{1}$.

$3^{\prime}$-Methoxy-4,2' $4^{\prime}$-tri(methoxymethoxy)chalcone (6a): ( $0.35 \mathrm{~g}, 0.78 \mathrm{mmol}, 78 \%$ yield); yellow viscous oil; ${ }^{1} \mathrm{H}-\mathrm{NMR}\left(\mathrm{CDCl}_{3}\right) \delta 3.45\left(\mathrm{~s}, 3 \mathrm{H}, \mathrm{OCH}_{3}\right), 3.49\left(\mathrm{~s}, 3 \mathrm{H}, \mathrm{OCH}_{3}\right), 3.53\left(\mathrm{~s}, 3 \mathrm{H}, \mathrm{OCH}_{3}\right), 3.93\left(\mathrm{~s}, 3 \mathrm{H}, \mathrm{OCH}_{3}\right)$, $5.15\left(\mathrm{~s}, 2 \mathrm{H}, \mathrm{OCH}_{2}\right), 5.21\left(\mathrm{~s}, 2 \mathrm{H}, \mathrm{OCH}_{2}\right), 5.28\left(\mathrm{~s}, 2 \mathrm{H}, \mathrm{OCH}_{2}\right), 7.00\left(\mathrm{~d}, J=8.8 \mathrm{~Hz}, 1 \mathrm{H}, \mathrm{H}-5^{\prime}\right), 7.06(\mathrm{~d}, J=8.5$ $\mathrm{Hz}, 2 \mathrm{H}, \mathrm{H}-3$ and H-5), $7.34(\mathrm{~d}, J=15.9 \mathrm{~Hz}, 1 \mathrm{H}, \mathrm{H}-\alpha), 7.37\left(\mathrm{~d}, J=8.8 \mathrm{~Hz}, 1 \mathrm{H}, \mathrm{H}-6^{\prime}\right), 7.57(\mathrm{~d}, J=8.8 \mathrm{~Hz}$, 2H, H-2 and H-6), $7.64(\mathrm{~d}, J=15.6 \mathrm{~Hz}, 1 \mathrm{H}, \mathrm{H}-\beta) ;{ }^{13} \mathrm{C}-\mathrm{NMR}\left(\mathrm{CDCl}_{3}\right) \delta 56.0,56.3,57.5,60.9,94.0,94.7$, 99.9, 111.1, 116.2, 124.7, 125.0, 128.5, 128.8, 129.8, 142.4, 142.9, 149.8, 153.7, 158.7, 190.9.

3'-Methoxy-3,4,2', $4^{\prime}$-tetra(methoxymethoxy)chalcone (6b): (0.44 g, $0.91 \mathrm{mmol}, 91 \%$ yield); yellow viscous oil; ${ }^{1} \mathrm{H}-\mathrm{NMR}\left(\mathrm{CDCl}_{3}\right) \delta 3.46\left(\mathrm{~s}, 3 \mathrm{H}, \mathrm{OCH}_{3}\right), 3.52\left(\mathrm{~s}, 3 \mathrm{H}, \mathrm{OCH}_{3}\right), 3.54\left(\mathrm{~s}, 6 \mathrm{H}, \mathrm{OCH}_{3}\right), 3.93(\mathrm{~s}, 3 \mathrm{H}$, $\left.\mathrm{OCH}_{3}\right), 5.16\left(\mathrm{~s}, 2 \mathrm{H}, \mathrm{OCH}_{2}\right), 5.27\left(\mathrm{~s}, 2 \mathrm{H}, \mathrm{OCH}_{2}\right), 5.28\left(\mathrm{~s}, 2 \mathrm{H}, \mathrm{OCH}_{2}\right), 5.28\left(\mathrm{~s}, 2 \mathrm{H}, \mathrm{OCH}_{2}\right), 7.00(\mathrm{~d}, J=8.8$ $\left.\mathrm{Hz}, 1 \mathrm{H}, \mathrm{H}-5^{\prime}\right), 7.17(\mathrm{~d}, J=8.5 \mathrm{~Hz}, 1 \mathrm{H}, \mathrm{H}-5), 7.26(\mathrm{dd}, J=2.0$ and $8.3 \mathrm{~Hz}, 1 \mathrm{H}, \mathrm{H}-6), 7.31(\mathrm{~d}, J=15.9 \mathrm{~Hz}$, $1 \mathrm{H}, \mathrm{H}-\alpha), 7.36\left(\mathrm{~d}, J=8.8 \mathrm{~Hz}, 1 \mathrm{H}, \mathrm{H}-6^{\prime}\right), 7.43(\mathrm{~d}, J=2.0 \mathrm{~Hz}, \mathrm{H}-2), 7.58(\mathrm{~d}, J=15.9 \mathrm{~Hz}, 1 \mathrm{H}, \mathrm{H}-\beta) ;{ }^{13} \mathrm{C}-\mathrm{NMR}$ $\left(\mathrm{CDCl}_{3}\right) \delta 56.1,56.2,56.3,57.5,60.9,94.7,94.9,95.3,99.8,111.1,116.0,116.0,123.5,124.9,125.2,128.6$, $129.2,142.4,143.1,147.0,149.0,149.7,153.7,190.9$.

$3^{\prime}$-Methoxy-2,4,2', $4^{\prime}$-tetra(methoxymethoxy)chalcone (6c): (0.43 g, $0.89 \mathrm{mmol}, 89 \%$ yield); yellow viscous oil; ${ }^{1} \mathrm{H}-\mathrm{NMR}\left(\mathrm{CDCl}_{3}\right) \delta 3.47\left(\mathrm{~s}, 3 \mathrm{H}, \mathrm{OCH}_{3}\right), 3.49\left(\mathrm{~s}, 3 \mathrm{H}, \mathrm{OCH}_{3}\right), 3.50\left(\mathrm{~s}, 3 \mathrm{H}, \mathrm{OCH}_{3}\right), 3.53(\mathrm{~s}, 3 \mathrm{H}$, $\left.\mathrm{OCH}_{3}\right), 3.93\left(\mathrm{~s}, 3 \mathrm{H}, \mathrm{OCH}_{3}\right), 5.14\left(\mathrm{~s}, 2 \mathrm{H}, \mathrm{OCH}_{2}\right), 5.20\left(\mathrm{~s}, 2 \mathrm{H}, \mathrm{OCH}_{2}\right), 5.25\left(\mathrm{~s}, 2 \mathrm{H}, \mathrm{OCH}_{2}\right), 5.29(\mathrm{~s}, 2 \mathrm{H}$, $\left.\mathrm{OCH}_{2}\right), 6.73(\mathrm{dd}, J=2.2 \mathrm{~Hz}$ and $8.5 \mathrm{~Hz}, 1 \mathrm{H}, \mathrm{H}-5), 6.84(\mathrm{~d}, J=2.2 \mathrm{~Hz}, 1 \mathrm{H}, \mathrm{H}-3), 7.00(\mathrm{~d}, J=8.8 \mathrm{~Hz}, 1 \mathrm{H}$, H- $\left.5^{\prime}\right), 7.38\left(\mathrm{~d}, J=8.3 \mathrm{~Hz}, 1 \mathrm{H}, \mathrm{H}-6^{\prime}\right), 7.41(\mathrm{~d}, J=14.6 \mathrm{~Hz}, 1 \mathrm{H}, \mathrm{H}-\alpha), 7.60(\mathrm{~d}, J=8.5 \mathrm{~Hz}, 1 \mathrm{H}, \mathrm{H}-6), 8.02$ $(\mathrm{d}, J=15.9 \mathrm{~Hz}, 1 \mathrm{H}, \mathrm{H}-\beta) ;{ }^{13} \mathrm{C}-\mathrm{NMR}\left(\mathrm{CDCl}_{3}\right) \delta 56.3,56.4,56.5,57.7,61.1,94.1,94.5,94.8,100.0,103.1$, 109.2, 111.1, 118.4, 124.9, 125.2, 129.2, 129.3, 138.3, 142.5, 149.9, 153.7, 157.4, 160.0, 191.3 .

3, $3^{\prime}$-Dimethoxy-4, $2^{\prime}, 4^{\prime}$-tri(methoxymethoxy)chalcone (6d): (0.37 g, $0.82 \mathrm{mmol}, 82 \%$ yield); ${ }^{1} \mathrm{H}-\mathrm{NMR}$ $\left(\mathrm{CDCl}_{3}\right) \delta 3.46\left(\mathrm{~s}, 3 \mathrm{H}, \mathrm{OCH}_{3}\right), 3.52\left(\mathrm{~s}, 3 \mathrm{H}, \mathrm{OCH}_{3}\right), 3.54\left(\mathrm{~s}, 3 \mathrm{H}, \mathrm{OCH}_{3}\right), 3.93\left(\mathrm{~s}, 6 \mathrm{H}, \mathrm{OCH}_{3}\right), 5.16(\mathrm{~s}, 2 \mathrm{H}$, $\left.\mathrm{OCH}_{2}\right), 5.28\left(\mathrm{~s}, 2 \mathrm{H}, \mathrm{OCH}_{2}\right), 5.29\left(\mathrm{~s}, 2 \mathrm{H}, \mathrm{OCH}_{2}\right), 7.00\left(\mathrm{~d}, J=8.8 \mathrm{~Hz}, 1 \mathrm{H}, \mathrm{H}-5^{\prime}\right), 7.16-7.17(\mathrm{~m}, 3 \mathrm{H}, \mathrm{H}-2$, H-5 and H-6), $7.36(\mathrm{~d}, J=15.9 \mathrm{~Hz}, 1 \mathrm{H}, \mathrm{H}-\alpha), 7.37\left(\mathrm{~d}, J=8.5 \mathrm{~Hz}, 1 \mathrm{H}, \mathrm{H}-6^{\prime}\right), 7.61(\mathrm{~d}, J=15.9 \mathrm{~Hz}, 1 \mathrm{H}, \mathrm{H}-\beta)$; ${ }^{13} \mathrm{C}-\mathrm{NMR}\left(\mathrm{CDCl}_{3}\right) \delta 55.8,56.2,56.3,57.5,60.9,94.7,95.0,99.8,110.6,111.1,115.6,122.3,124.9,125.0$, $128.6,129.1,142.4,143.2,148.3,149.5,149.7,153.7,190.9$.

4,3'-Dimethoxy-3,2 $2^{\prime}, 4^{\prime}$-tri(methoxymethoxy)chalcone (6e): (0.36 g, $0.80 \mathrm{mmol}, 80 \%$ yield); ${ }^{1} \mathrm{H}-\mathrm{NMR}$ $\left(\mathrm{CDCl}_{3}\right) \delta 3.46\left(\mathrm{~s}, 3 \mathrm{H}, \mathrm{OCH}_{3}\right), 3.53\left(\mathrm{~s}, 6 \mathrm{H}, \mathrm{OCH}_{3}\right), 3.92\left(\mathrm{~s}, 3 \mathrm{H}, \mathrm{OCH}_{3}\right), 3.93\left(\mathrm{~s}, 3 \mathrm{H}, \mathrm{OCH}_{3}\right), 5.16(\mathrm{~s}, 2 \mathrm{H}$, $\left.\mathrm{OCH}_{2}\right), 5.26\left(\mathrm{~s}, 2 \mathrm{H}, \mathrm{OCH}_{2}\right), 5.28\left(\mathrm{~s}, 2 \mathrm{H}, \mathrm{OCH}_{2}\right), 6.91(\mathrm{~d}, J=8.3 \mathrm{~Hz}, 1 \mathrm{H}, \mathrm{H}-5), 7.00(\mathrm{~d}, J=8.8 \mathrm{~Hz}, 1 \mathrm{H}$, $\left.\mathrm{H}-5^{\prime}\right), 7.26(\mathrm{dd}, J=1.7 \mathrm{~Hz}$ and $8.3 \mathrm{~Hz}, 1 \mathrm{H}, \mathrm{H}-6), 7.29(\mathrm{~d}, J=15.6 \mathrm{~Hz}, 1 \mathrm{H}, \mathrm{H}-\alpha), 7.35(\mathrm{~d}, J=8.8 \mathrm{~Hz}, 1 \mathrm{H}$, H-6 $\left.{ }^{\prime}\right), 7.43(\mathrm{~d}, J=1.7 \mathrm{~Hz}, 1 \mathrm{H}, \mathrm{H}-2), 7.59$ (d, $\left.J=15.6 \mathrm{~Hz}, 1 \mathrm{H}, \mathrm{H}-\beta\right) ;{ }^{13} \mathrm{C}-\mathrm{NMR}\left(\mathrm{CDCl}_{3}\right) \delta$ 55.9, 56.3, 56.4, 57.6, 61.0, 94.9, 95.5, 99.9, 111.2, 111.5, 115.6, 124.1, 124.9, 125.1, 128.0, 128.9, 142.6, 143.5, 146.6, 149.9, $151.7,153.8,191.3$.

3,4, $3^{\prime}$-Trimethoxy-2' ${ }^{\prime} 4^{\prime}$-di(methoxymethoxy)chalcone (6f): (0.35 g, $0.83 \mathrm{mmol}, 83 \%$ yield); ${ }^{1} \mathrm{H}-\mathrm{NMR}$ $\left(\mathrm{CDCl}_{3}\right) \delta 3.47\left(\mathrm{~s}, 3 \mathrm{H}, \mathrm{OCH}_{3}\right), 3.54\left(\mathrm{~s}, 3 \mathrm{H}, \mathrm{OCH}_{3}\right), 3.93\left(\mathrm{~s}, 3 \mathrm{H}, \mathrm{OCH}_{3}\right), 3.93\left(\mathrm{~s}, 6 \mathrm{H}, \mathrm{OCH}_{3}\right), 5.17(\mathrm{~s}, 2 \mathrm{H}$, $\left.\mathrm{OCH}_{2}\right), 5.29\left(\mathrm{~s}, 2 \mathrm{H}, \mathrm{OCH}_{2}\right), 6.88(\mathrm{~d}, J=8.3 \mathrm{~Hz}, 1 \mathrm{H}, \mathrm{H}-5), 7.00\left(\mathrm{~d}, J=8.8 \mathrm{~Hz}, \mathrm{H}-5^{\prime}\right), 7.15(\mathrm{~d}, J=2.0 \mathrm{~Hz}$, $1 \mathrm{H}, \mathrm{H}-2), 7.20(\mathrm{dd}, J=2.0 \mathrm{~Hz}$ and $8.3 \mathrm{~Hz}, 1 \mathrm{H}, \mathrm{H}-6), 7.32(\mathrm{~d}, J=15.9 \mathrm{~Hz}, 1 \mathrm{H}, \mathrm{H}-\alpha), 7.37(\mathrm{~d}, J=8.5 \mathrm{~Hz}, 1 \mathrm{H}$, H-6 $\left.{ }^{\prime}\right), 7.62(\mathrm{~d}, J=15.9 \mathrm{~Hz}, 1 \mathrm{H}, \mathrm{H}-\beta) ;{ }^{13} \mathrm{C}-\mathrm{NMR}\left(\mathrm{CDCl}_{3}\right) \delta 55.9,56.0,56.5,57.7,61.1,94.9,100.0,110.0$, $111.0,111.3,123.1,124.7,125.2,127.9,128.9,143.7,149.1,150.0,151.2,153.9,191.2$. 
$3^{\prime}, 4^{\prime}$-Dimethoxy-4,2'-di(methoxymethoxy)chalcone (6g): (0.35 g, $0.89 \mathrm{mmol}, 89 \%$ yield); yellow viscous oil; ${ }^{1} \mathrm{H}-\mathrm{NMR}\left(\mathrm{CDCl}_{3}\right) \delta 3.45\left(\mathrm{~s}, 3 \mathrm{H}, \mathrm{OCH}_{3}\right), 3.49\left(\mathrm{~s}, 3 \mathrm{H}, \mathrm{OCH}_{3}\right), 3.91\left(\mathrm{~s}, 3 \mathrm{H}, \mathrm{OCH}_{3}\right), 3.93\left(\mathrm{~s}, 3 \mathrm{H}, \mathrm{OCH}_{3}\right)$, $5.15\left(\mathrm{~s}, 2 \mathrm{H}, \mathrm{OCH}_{2}\right), 5.22\left(\mathrm{~s}, 2 \mathrm{H}, \mathrm{OCH}_{2}\right), 6.78\left(\mathrm{~d}, J=8.8 \mathrm{~Hz}, 1 \mathrm{H}, \mathrm{H}-5^{\prime}\right), 7.06(\mathrm{~d}, J=8.5 \mathrm{~Hz}, 2 \mathrm{H}, \mathrm{H}-3$ and H-5), $7.39(\mathrm{~d}, J=15.9 \mathrm{~Hz}, 1 \mathrm{H}, \mathrm{H}-\alpha), 7.45\left(\mathrm{~d}, J=8.5 \mathrm{~Hz}, 1 \mathrm{H}, \mathrm{H}-6^{\prime}\right), 7.58(\mathrm{~d}, J=8.8 \mathrm{~Hz}, 2 \mathrm{H}, \mathrm{H}-2$ and H-6), $7.66(\mathrm{~d}, J=15.9 \mathrm{~Hz}, 1 \mathrm{H}, \mathrm{H}-\beta) ;{ }^{13} \mathrm{C}-\mathrm{NMR}\left(\mathrm{CDCl}_{3}\right) \delta 56.1,56.2,57.7,61.0,94.1,100.1,107.4,116.3,124.8$, $125.5,127.8,128.7,129.9,141.7,142.8,150.0,156.4,158.8,190.8$.

$3^{\prime}, 4^{\prime}$-Dimethoxy-3,4,2'-tri(methoxymethoxy)chalcone (6h): (0.35 g, $0.79 \mathrm{mmol}, 79 \%$ yield); ${ }^{1} \mathrm{H}-\mathrm{NMR}$ $\left(\mathrm{CDCl}_{3}\right) \delta 3.46\left(\mathrm{~s}, 3 \mathrm{H}, \mathrm{OCH}_{3}\right), 3.52\left(\mathrm{~s}, 3 \mathrm{H}, \mathrm{OCH}_{3}\right), 3.54\left(\mathrm{~s}, 3 \mathrm{H}, \mathrm{OCH}_{3}\right), 3.91\left(\mathrm{~s}, 3 \mathrm{H}, \mathrm{OCH}_{3}\right), 3.93(\mathrm{~s}, 3 \mathrm{H}$, $\left.\mathrm{OCH}_{3}\right), 5.16\left(\mathrm{~s}, 2 \mathrm{H}, \mathrm{OCH}_{2}\right), 5.28\left(\mathrm{~s}, 2 \mathrm{H}, \mathrm{OCH}_{2}\right), 5.29\left(\mathrm{~s}, 2 \mathrm{H}, \mathrm{OCH}_{2}\right), 6.78\left(\mathrm{~d}, J=8.8 \mathrm{~Hz}, 1 \mathrm{H}, \mathrm{H}-5^{\prime}\right), 7.18$ $(\mathrm{d}, J=8.5 \mathrm{~Hz}, 1 \mathrm{H}, \mathrm{H}-5), 7.26(\mathrm{dd}, J=2.0 \mathrm{~Hz}$ and $8.5 \mathrm{~Hz}, 1 \mathrm{H}, \mathrm{H}-6), 7.36(\mathrm{~d}, J=15.9 \mathrm{~Hz}, 1 \mathrm{H}, \mathrm{H}-\alpha), 7.44$ $\left(\mathrm{d}, J=8.5 \mathrm{~Hz}, 1 \mathrm{H}, \mathrm{H}-6^{\prime}\right), 7.44(\mathrm{~d}, J=2.0 \mathrm{~Hz}, 1 \mathrm{H}, \mathrm{H}-2), 7.60(\mathrm{~d}, J=15.6 \mathrm{~Hz}, 1 \mathrm{H}, \mathrm{H}-\beta) ;{ }^{13} \mathrm{C}-\mathrm{NMR}\left(\mathrm{CDCl}_{3}\right)$ ס 56.0, 56.2, 56.3, 57.6, 60.9, 94.9, 95.3, 99.9, 107.3, 116.0, 116.0, 123.6, 125.3, 125.4, 127.6, 129.3, 141.7, 143.0, 147.1, 149.0, 150.0, 156.4, 191.0.

$3^{\prime}, 4^{\prime}$-Dimethoxy-2,4,2'-tri(methoxymethoxy)chalcone (6i): $(0.37 \mathrm{~g}, 0.83 \mathrm{mmol}, 83 \%$ yield); yellow viscous oil; ${ }^{1} \mathrm{H}-\mathrm{NMR}\left(\mathrm{CDCl}_{3}\right) \delta 3.46\left(\mathrm{~s}, 3 \mathrm{H}, \mathrm{OCH}_{3}\right), 3.49\left(\mathrm{~s}, 3 \mathrm{H}, \mathrm{OCH}_{3}\right), 3.50\left(\mathrm{~s}, 3 \mathrm{H}, \mathrm{OCH}_{3}\right), 3.91(\mathrm{~s}, 3 \mathrm{H}$, $\left.\mathrm{OCH}_{3}\right), 3.93\left(\mathrm{~s}, 3 \mathrm{H}, \mathrm{OCH}_{3}\right), 5.14\left(\mathrm{~s}, 2 \mathrm{H}, \mathrm{OCH}_{2}\right), 5.20\left(\mathrm{~s}, 2 \mathrm{H}, \mathrm{OCH}_{2}\right), 5.25\left(\mathrm{~s}, 2 \mathrm{H}, \mathrm{OCH}_{2}\right), 6.73(\mathrm{dd}, J=2.2$ and $8.5 \mathrm{~Hz}, 1 \mathrm{H}, \mathrm{H}-5), 6.77\left(\mathrm{~d}, J=8.8 \mathrm{~Hz}, 1 \mathrm{H}, \mathrm{H}-5^{\prime}\right), 6.84(\mathrm{~d}, J=2.2 \mathrm{~Hz}, 1 \mathrm{H}, \mathrm{H}-3), 7.45(\mathrm{~d}, J=15.9 \mathrm{~Hz}$, $1 \mathrm{H}, \mathrm{H}-\alpha), 7.45\left(\mathrm{~d}, J=8.8 \mathrm{~Hz}, 1 \mathrm{H}, \mathrm{H}-6^{\prime}\right), 7.61(\mathrm{~d}, J=8.5 \mathrm{~Hz}, 1 \mathrm{H}, \mathrm{H}-6), 8.03(\mathrm{~d}, J=15.9 \mathrm{~Hz}, 1 \mathrm{H}, \mathrm{H}-\beta)$; ${ }^{13} \mathrm{C}-\mathrm{NMR}\left(\mathrm{CDCl}_{3}\right) \delta 55.9,56.1,56.2,57.5,60.8,94.0,94.4,99.8,103.0,107.2,109.1,118.4,124.8,125.3$, $127.9,129.1,137.9,141.6,149.7,156.1,157.3,159.8,191.0$.

3, $3^{\prime}, 4^{\prime}$-Trimethoxy-4,2'-di(methoxymethoxy)chalcone $(6 \mathbf{j})$ : $(0.33 \mathrm{~g}, 0.78 \mathrm{mmol}, 78 \%$ yield); yellow viscous oil; ${ }^{1} \mathrm{H}-\mathrm{NMR}\left(\mathrm{CDCl}_{3}\right) \delta 3.46\left(\mathrm{~s}, 3 \mathrm{H}, \mathrm{OCH}_{3}\right), 3.52\left(\mathrm{~s}, 3 \mathrm{H}, \mathrm{OCH}_{3}\right), 3.91\left(\mathrm{~s}, 3 \mathrm{H}, \mathrm{OCH}_{3}\right), 3.93(\mathrm{~s}, 6 \mathrm{H}$, $\left.\mathrm{OCH}_{3}\right), 5.17\left(\mathrm{~s}, 2 \mathrm{H}, \mathrm{OCH}_{2}\right), 5.28\left(\mathrm{~s}, 2 \mathrm{H}, \mathrm{OCH}_{2}\right), 6.78\left(\mathrm{~d}, J=8.8 \mathrm{~Hz}, 1 \mathrm{H}, \mathrm{H}-5^{\prime}\right), 7.17(\mathrm{br} \mathrm{s}, 3 \mathrm{H}, \mathrm{H}-2, \mathrm{H}-5$, and H-6), $7.39(\mathrm{~d}, J=15.6 \mathrm{~Hz}, 1 \mathrm{H}, \mathrm{H}-\alpha), 7.45\left(\mathrm{~d}, J=8.8 \mathrm{~Hz}, 1 \mathrm{H}, \mathrm{H}-6^{\prime}\right), 7.63(\mathrm{~d}, J=15.9 \mathrm{~Hz}, 1 \mathrm{H}, \mathrm{H}-\beta)$; ${ }^{13} \mathrm{C}-\mathrm{NMR}\left(\mathrm{CDCl}_{3}\right) \delta 55.9,56.0,56.3,57.6,60.9,95.1,100.0,107.4,110.7,115.6,122.5,125.1,125.5,127.6$, $129.3,141.7,143.1,148.4,149.6,150.0,156.5,190.8$.

4,3' $4^{\prime}$-Trimethoxy-3,2'-di(methoxymethoxy)chalcone (6k): (0.37 g, $0.89 \mathrm{mmol}, 89 \%$ yield); yellow viscous oil; ${ }^{1} \mathrm{H}-\mathrm{NMR}\left(\mathrm{CDCl}_{3}\right) \delta 3.46\left(\mathrm{~s}, 3 \mathrm{H}, \mathrm{OCH}_{3}\right), 3.53\left(\mathrm{~s}, 3 \mathrm{H}, \mathrm{OCH}_{3}\right), 3.91\left(\mathrm{~s}, 3 \mathrm{H}, \mathrm{OCH}_{3}\right), 3.92(\mathrm{~s}, 3 \mathrm{H}$, $\left.\mathrm{OCH}_{3}\right), 3.93\left(\mathrm{~s}, 3 \mathrm{H}, \mathrm{OCH}_{3}\right), 5.16\left(\mathrm{~s}, 2 \mathrm{H}, \mathrm{OCH}_{2}\right), 5.26\left(\mathrm{~s}, 2 \mathrm{H}, \mathrm{OCH}_{2}\right), 6.77\left(\mathrm{~d}, J=8.8 \mathrm{~Hz}, 1 \mathrm{H}, \mathrm{H}-5^{\prime}\right), 6.91$ $(\mathrm{d}, J=8.5 \mathrm{~Hz}, 1 \mathrm{H}, \mathrm{H}-5), 7.27(\mathrm{dd}, J=2.0 \mathrm{~Hz}$ and $8.3 \mathrm{~Hz}, 1 \mathrm{H}, \mathrm{H}-6), 7.34(\mathrm{~d}, J=15.9 \mathrm{~Hz}, 1 \mathrm{H}, \mathrm{H}-\alpha), 7.43$ $\left(\mathrm{d}, J=8.5 \mathrm{~Hz}, 1 \mathrm{H}, \mathrm{H}-6^{\prime}\right), 7.44(\mathrm{~d}, J=1.7 \mathrm{~Hz}, 1 \mathrm{H}, \mathrm{H}-2), 7.60(\mathrm{~d}, J=15.6 \mathrm{~Hz}, 1 \mathrm{H}, \mathrm{H}-\beta) ;{ }^{13} \mathrm{C}-\mathrm{NMR}\left(\mathrm{CDCl}_{3}\right)$ 反 55.9, 56.0, 56.2, 57.5, 60.8, 95.3, 99.8, 107.2, 111.4, 115.5, 123.9, 124.7, 125.2, 127.6, 127.9, 141.6, 143.0, $146.3,149.7,151.5,156.2,190.7$.

3,4, $3^{\prime}, 4^{\prime}$-Tetramethoxy-2' -(methoxymethoxy)chalcone (61): (0.36 g, $0.92 \mathrm{mmol}, 92 \%$ yield); ${ }^{1} \mathrm{H}-\mathrm{NMR}$ $\left(\mathrm{CDCl}_{3}\right) \delta 3.46\left(\mathrm{~s}, 3 \mathrm{H}, \mathrm{OCH}_{3}\right), 3.91\left(\mathrm{~s}, 3 \mathrm{H}, \mathrm{OCH}_{3}\right), 3.93\left(\mathrm{~s}, 3 \mathrm{H}, \mathrm{OCH}_{3}\right), 3.93\left(\mathrm{~s}, 3 \mathrm{H}, \mathrm{OCH}_{3}\right), 3.93(\mathrm{~s}, 3 \mathrm{H}$, $\left.\mathrm{OCH}_{3}\right), 5.17\left(\mathrm{~s}, 2 \mathrm{H}, \mathrm{OCH}_{2}\right), 6.78\left(\mathrm{~d}, J=8.8 \mathrm{~Hz}, 1 \mathrm{H}, \mathrm{H}-5^{\prime}\right), 6.89(\mathrm{~d}, J=8.3 \mathrm{~Hz}, 1 \mathrm{H}, \mathrm{H}-5), 7.16(\mathrm{~d}, J=2.0$ $\mathrm{Hz}, 1 \mathrm{H}, \mathrm{H}-2), 7.20(\mathrm{dd}, J=2.0 \mathrm{~Hz}$ and $8.3 \mathrm{~Hz}, 1 \mathrm{H}, \mathrm{H}-6), 7.37(\mathrm{~d}, J=15.9 \mathrm{~Hz}, 1 \mathrm{H}, \mathrm{H}-\alpha), 7.44(\mathrm{~d}, J=8.5$ $\left.\mathrm{Hz}, 1 \mathrm{H}, \mathrm{H}-6^{\prime}\right), 7.63$ (d, $\left.J=15.9 \mathrm{~Hz}, 1 \mathrm{H}, \mathrm{H}-\beta\right) ;{ }^{13} \mathrm{C}-\mathrm{NMR}\left(\mathrm{CDCl}_{3}\right) \delta 55.8,55.9,56.0,57.6,60.9,100.0,107.4$, $109.9,110.9,123.0,124.6,125.4,127.7,127.9,141.7,143.3,149.0,149.9,151.0,156.4,190.9$.

\subsection{The General Procedure for the Deprotection of $\mathbf{6 a - 1}$}

A solution of $\mathbf{6 a - 1}(1.0 \mathrm{mmol})$ in methanol $(5 \mathrm{~mL})$ and $3 \mathrm{M}$ hydrochloric acid $(5 \mathrm{~mL})$ was refluxed for $1 \mathrm{~h}$. The mixture was extracted with EtOAc. The organic layer was washed with water and brine and dried over anhydrous $\mathrm{MgSO}_{4}$. The solvent was evaporated in vacuo and the residue was chromatographed on preparative thin layer chromatography (hexane:EtOAc $=2: 3$ ) to produce aurones $7 a-1$. 
4,2' $4^{\prime}$-Trihydroxy-3'-methoxychalcone (7a): (0.22 $\mathrm{g}, 0.76 \mathrm{mmol}, 76 \%$ yield); yellowish brown solid, 204-209 ${ }^{\circ} \mathrm{C} ;{ }^{1} \mathrm{H}-\mathrm{NMR}\left(\mathrm{CDCl}_{3}: \mathrm{DMSO}_{-} d_{6}=9: 1\right) \delta 3.93\left(\mathrm{~s}, 3 \mathrm{H}, \mathrm{OCH}_{3}\right), 6.53\left(\mathrm{~d}, J=8.8 \mathrm{~Hz}, 1 \mathrm{H}, \mathrm{H}-5^{\prime}\right), 6.90$ $(\mathrm{d}, J=7.8 \mathrm{~Hz}, 2 \mathrm{H}, \mathrm{H}-3$ and H-5), $7.43(\mathrm{~d}, J=15.9 \mathrm{~Hz}, 1 \mathrm{H}, \mathrm{H}-\alpha), 7.54(\mathrm{~d}, J=8.1 \mathrm{~Hz}, 2 \mathrm{H}, \mathrm{H}-2$ and H-6), $7.61\left(\mathrm{~d}, J=8.8 \mathrm{~Hz}, 1 \mathrm{H}, \mathrm{H}-6^{\prime}\right), 7.83(\mathrm{~d}, J=15.4 \mathrm{~Hz}, 1 \mathrm{H}, \mathrm{H}-\beta), 9.25(\mathrm{~s}, 1 \mathrm{H}, \mathrm{OH}), 9.57(\mathrm{~s}, 1 \mathrm{H}, \mathrm{OH}), 13.76$ $(\mathrm{s}, 1 \mathrm{H}, \mathrm{OH}) ;{ }^{13} \mathrm{C}-\mathrm{NMR}\left(\mathrm{CDCl}_{3}: \mathrm{DMSO}-d_{6}=9: 1\right) \delta 60.3,107.4,114.0,115.9,116.4,125.7,125.7,130.2,134.6$, $144.3,156.2,158.3,159.9,191.7 ;$ UV/Vis $\left(3.0 \times 10^{-5} \mathrm{M}, \mathrm{DMSO}\right) ; \lambda=380.0 \mathrm{~nm}\left(\varepsilon, 3.0 \times 10^{4}\right)$.

3,4,2' $4^{\prime}$-Tetrahydroxy-3'-methoxychalcone (7b): $(0.25 \mathrm{~g}, 0.84 \mathrm{mmol}, 84 \%$ yield); yellow solid, $191-195$ ${ }^{\circ} \mathrm{C} ;{ }^{1} \mathrm{H}-\mathrm{NMR}\left(\mathrm{DMSO}-\mathrm{d}_{6}\right) \delta 3.74\left(\mathrm{~s}, 3 \mathrm{H}, \mathrm{OCH}_{3}\right), 6.48\left(\mathrm{~d}, J=9.3 \mathrm{~Hz}, 1 \mathrm{H}, \mathrm{H}-5^{\prime}\right), 6.82(\mathrm{~d}, J=8.3 \mathrm{~Hz}, 1 \mathrm{H}$, $\mathrm{H}-5), 7.22(\mathrm{dd}, J=2.0 \mathrm{~Hz}$ and $8.3 \mathrm{~Hz}, 1 \mathrm{H}, \mathrm{H}-6), 7.29(\mathrm{~d}, J=2.0 \mathrm{~Hz}, 1 \mathrm{H}, \mathrm{H}-2), 7.65(\mathrm{~d}, J=15.1 \mathrm{~Hz}, 1 \mathrm{H}$, $\mathrm{H}-\alpha), 7.69(\mathrm{~d}, J=15.1 \mathrm{~Hz}, 1 \mathrm{H}, \mathrm{H}-\beta), 7.93\left(\mathrm{~d}, J=9.3 \mathrm{~Hz}, 1 \mathrm{H}, \mathrm{H}-6^{\prime}\right), 9.12(\mathrm{~s}, 1 \mathrm{H}, \mathrm{OH}), 9.71(\mathrm{~s}, 1 \mathrm{H}, \mathrm{OH})$, $10.40(\mathrm{~s}, 1 \mathrm{H}, \mathrm{OH}), 13.74(\mathrm{~s}, 1 \mathrm{H}, \mathrm{OH}) ;{ }^{13} \mathrm{C}-\mathrm{NMR}$ (DMSO- $\left.d_{6}\right) \delta 59.7,107.9,113.7,115.7,115.9,117.2,122.4$, $126.2,126.8,134.7,144.9,145.6,149.0,157.1,158.5,192.0 ;$ UV/Vis $\left(2.6 \times 10^{-5} \mathrm{M}, \mathrm{DMSO}\right) ; \lambda=400.5 \mathrm{~nm}$ $\left(\varepsilon, 2.1 \times 10^{4}\right)$.

2,4,2' ' $^{\prime}$-Tetrahydroxy-3'-methoxychalcone (7c): $(0.14 \mathrm{~g}, 0.47 \mathrm{mmol}, 47 \%$ yield); reddish orange solid, 189-193 ${ }^{\circ} \mathrm{C} ;{ }^{1} \mathrm{H}-\mathrm{NMR}\left(\mathrm{CD}_{3} \mathrm{OD}\right) \delta 3.85\left(\mathrm{~s}, 3 \mathrm{H}, \mathrm{OCH}_{3}\right), 6.34(\mathrm{~d}, J=2.2 \mathrm{~Hz}, 1 \mathrm{H}, \mathrm{H}-3), 6.36(\mathrm{dd}, J=2.2 \mathrm{~Hz}$ and $9.5 \mathrm{~Hz}, 1 \mathrm{H}, \mathrm{H}-5), 6.46\left(\mathrm{~d}, J=8.8 \mathrm{~Hz}, 1 \mathrm{H}, \mathrm{H}-5^{\prime}\right), 7.51(\mathrm{~d}, J=8.3 \mathrm{~Hz}, 1 \mathrm{H}, \mathrm{H}-6), 7.68(\mathrm{~d}, J=9.5 \mathrm{~Hz}$, $\left.1 \mathrm{H}, \mathrm{H}-6^{\prime}\right), 7.69(\mathrm{~d}, J=15.1 \mathrm{~Hz}, 1 \mathrm{H}, \mathrm{H}-\alpha), 8.10(\mathrm{~d}, J=15.4 \mathrm{~Hz}, 1 \mathrm{H}, \mathrm{H}-\beta) ;{ }^{13} \mathrm{C}-\mathrm{NMR}(\mathrm{CD} 3 \mathrm{OD}) \delta 60.8$, 103.4, 108.6, 109.0, 115.4, 115.5, 117.4, 127.2, 132.3, 136.0, 142.2, 157.6, 159.3, 160.6, 162.6, 194.3; UV/Vis $\left(2.8 \times 10^{-5} \mathrm{M}, \mathrm{DMSO}\right) ; \lambda=399.0 \mathrm{~nm}\left(\varepsilon, 3.0 \times 10^{4}\right)$.

4,2' , $^{\prime}$-Trihydroxy-3,3'-dimethoxychalcone (7d): $\left(0.30 \mathrm{~g}, 0.95 \mathrm{mmol}, 95 \%\right.$ yield); orange solid, $158-163{ }^{\circ} \mathrm{C}$; ${ }^{1} \mathrm{H}-\mathrm{NMR}\left(\mathrm{DMSO}_{-} \mathrm{d}_{6}\right) \delta 3.76\left(\mathrm{~s}, 3 \mathrm{H}, \mathrm{OCH}_{3}\right), 3.89\left(\mathrm{~s}, 3 \mathrm{H}, \mathrm{OCH}_{3}\right), 6.51\left(\mathrm{~d}, J=9.0 \mathrm{~Hz}, 1 \mathrm{H}, \mathrm{H}-5^{\prime}\right), 6.86$ $(\mathrm{d}, J=8.1 \mathrm{~Hz}, 1 \mathrm{H}, \mathrm{H}-5), 7.30(\mathrm{~d}, J=8.3 \mathrm{~Hz}, 1 \mathrm{H}, \mathrm{H}-6), 7.56(\mathrm{br} \mathrm{s}, 1 \mathrm{H}, \mathrm{H}-2), 7.76(\mathrm{~d}, J=15.1 \mathrm{~Hz}, 1 \mathrm{H}, \mathrm{H}-\alpha)$, $7.81(\mathrm{~d}, J=15.4 \mathrm{~Hz}, 1 \mathrm{H}, \mathrm{H}-\beta), 8.01\left(\mathrm{~d}, J=8.8 \mathrm{~Hz}, 1 \mathrm{H}, \mathrm{H}-6^{\prime}\right), 9.77(\mathrm{~s}, 1 \mathrm{H}, \mathrm{OH}), 10.46(\mathrm{~s}, 1 \mathrm{H}, \mathrm{OH}), 13.83$ $(\mathrm{s}, 1 \mathrm{H}, \mathrm{OH}) ;{ }^{13} \mathrm{C}-\mathrm{NMR}\left(\mathrm{DMSO}-d_{6}\right) \delta 55.8,59.7,107.7,111.5,113.5,115.4,117.2,124.4,125.9,126.7,134.5$, 144.6, 147.7, 149.7, 156.9, 158.2, 191.7; UV/Vis $\left(2.5 \times 10^{-5} \mathrm{M}\right.$, DMSO $) ; \lambda=397.5 \mathrm{~nm}\left(\varepsilon, 2.8 \times 10^{4}\right)$.

$3,2^{\prime}, 4^{\prime}$-Trihydroxy-4,3'-dimethoxychalcone (7e): (0.29 g, $0.90 \mathrm{mmol}, 90 \%$ yield); yellowish brown solid, 180-185 ${ }^{\circ} \mathrm{C} ;{ }^{1} \mathrm{H}-\mathrm{NMR}\left(\mathrm{DMSO}-d_{6}\right) \delta 3.77\left(\mathrm{~s}, 3 \mathrm{H}, \mathrm{OCH}_{3}\right), 3.87\left(\mathrm{~s}, 3 \mathrm{H}, \mathrm{OCH}_{3}\right), 6.52\left(\mathrm{~d}, J=8.8 \mathrm{~Hz}, 1 \mathrm{H}, \mathrm{H}-5^{\prime}\right)$, $7.02(\mathrm{~d}, J=8.5 \mathrm{~Hz}, 1 \mathrm{H}, \mathrm{H}-5), 7.34(\mathrm{dd}, J=1.7 \mathrm{~Hz}$ and $8.3 \mathrm{~Hz}, 1 \mathrm{H}, \mathrm{H}-6), 7.39(\mathrm{~d}, J=1.5 \mathrm{~Hz}, 1 \mathrm{H}, \mathrm{H}-2)$, $7.73(\mathrm{~d}, J=15.4 \mathrm{~Hz}, 1 \mathrm{H}, \mathrm{H}-\alpha), 7.78(\mathrm{~d}, J=15.4 \mathrm{~Hz}, 1 \mathrm{H}, \mathrm{H}-\beta), 8.00(\mathrm{~d}, J=9.0 \mathrm{~Hz}, 1 \mathrm{H}, \mathrm{H}-6), 9.24(\mathrm{~s}, 1 \mathrm{H}$, $\mathrm{OH}), 10.54(\mathrm{~s}, 1 \mathrm{H}, \mathrm{OH}), 13.76(\mathrm{~s}, 1 \mathrm{H}, \mathrm{OH}) ;{ }^{13} \mathrm{C}-\mathrm{NMR}$ (DMSO-d $\left.d_{6}\right) \delta 55.7,59.8,107.9,111.7,113.6,114.9$, $118.1,122.2,126.8,127.3,134.5,144.3,146.4,150.2,157.0,158.3,191.7$; UV/Vis (2.7 × 10 $0^{-5} \mathrm{M}$, DMSO); $\lambda=400.0 \mathrm{~nm}\left(\varepsilon, 2.2 \times 10^{4}\right)$.

2', 4'-Dihydroxy-3,4,3'-trimethoxychalcone (7f): (0.32 g, $0.98 \mathrm{mmol}, 98 \%$ yield); orange-yellow solid, 140-144 ${ }^{\circ} \mathrm{C} ;{ }^{1} \mathrm{H}-\mathrm{NMR}\left(\mathrm{DMSO}-d_{6}\right) \delta 3.75\left(\mathrm{~s}, 3 \mathrm{H}, \mathrm{OCH}_{3}\right), 3.83\left(\mathrm{~s}, 3 \mathrm{H}, \mathrm{OCH}_{3}\right), 3.88\left(\mathrm{~s}, 3 \mathrm{H}, \mathrm{OCH}_{3}\right), 6.51(\mathrm{~d}$, $\left.J=9.0 \mathrm{~Hz}, 1 \mathrm{H}, \mathrm{H}-5^{\prime}\right), 7.04(\mathrm{~d}, J=8.3 \mathrm{~Hz}, 1 \mathrm{H}, \mathrm{H}-5), 7.57(\mathrm{~d}, J=2.0 \mathrm{~Hz}, 1 \mathrm{H}, \mathrm{H}-2), 7.41(\mathrm{dd}, J=2.0 \mathrm{~Hz}$ and $8.3 \mathrm{~Hz}, 1 \mathrm{H}, \mathrm{H}-6), 7.78(\mathrm{~d}, J=15.4 \mathrm{~Hz}, 1 \mathrm{H}, \mathrm{H}-\alpha), 7.86(\mathrm{~d}, J=15.4 \mathrm{~Hz}, 1 \mathrm{H}, \mathrm{H}-\beta), 8.02(\mathrm{~d}, J=9.0 \mathrm{~Hz}, 1 \mathrm{H}$, H-6') 10.48 (s, $1 \mathrm{H}, \mathrm{OH}), 13.76(\mathrm{~s}, 1 \mathrm{H}, \mathrm{OH}) ;{ }^{13} \mathrm{C}-\mathrm{NMR}$ (DMSO- $\left.d_{6}\right) \delta 55.6,55.7,59.7,107.7,110.6,111.3$, $113.5,118.2,124.2,126.8,127.1,134.5,144.2,148.7,151.2,157.0,158.2,191.7 ; \mathrm{UV} / \mathrm{Vis}\left(3.3 \times 10^{-5} \mathrm{M}\right.$, DMSO); $\lambda=394.0 \mathrm{~nm}\left(\varepsilon, 2.3 \times 10^{4}\right)$.

4,2'-Dihydroxy-3' $4^{\prime}$-dimethoxychalcone $(7 \mathrm{~g})$ : $(0.25 \mathrm{~g}, 0.84 \mathrm{mmol}, 84 \%$ yield $)$; yellow solid, $152-156{ }^{\circ} \mathrm{C}$; ${ }^{1} \mathrm{H}-\mathrm{NMR}\left(\mathrm{CDCl}_{3}\right) \delta 3.93\left(\mathrm{~s}, 3 \mathrm{H}, \mathrm{OCH}_{3}\right), 3.96\left(\mathrm{~s}, 3 \mathrm{H}, \mathrm{OCH}_{3}\right), 5.75(\mathrm{~s}, 1 \mathrm{H}, \mathrm{OH}), 6.54(\mathrm{~d}, J=9.0 \mathrm{~Hz}, 1 \mathrm{H}$, H-5 $5^{\prime}, 6.90(\mathrm{~d}, J=8.5 \mathrm{~Hz}, 2 \mathrm{H}, \mathrm{H}-3$ and H-5), $7.45(\mathrm{~d}, J=15.4 \mathrm{~Hz}, 1 \mathrm{H}, \mathrm{H}-\alpha), 7.57(\mathrm{~d}, J=8.5 \mathrm{~Hz}, 2 \mathrm{H}, \mathrm{H}-2$ and H-6), 7.69 (d, $\left.J=9.0 \mathrm{~Hz}, 1 \mathrm{H}, \mathrm{H}-6^{\prime}\right), 7.86(\mathrm{~d}, J=15.4 \mathrm{~Hz}, 1 \mathrm{H}, \mathrm{H}-\beta), 13.35(\mathrm{~s}, 1 \mathrm{H}, \mathrm{OH}) ;{ }^{13} \mathrm{C}-\mathrm{NMR}$ $\left(\mathrm{CDCl}_{3}\right) \delta 56.0,60.6,102.6,115.4,115.8,117.4,125.6,127.2,130.3,136.3,144.3,157.8,157.9,158.0,192.1$.

3,4,2'-Trihydroxy-3' $4^{\prime}$-dimethoxychalcone $(7 \mathrm{~h})$ : $(0.16 \mathrm{~g}, 0.51 \mathrm{mmol}, 51 \%$ yield); green-yellow solid, 147-151 ${ }^{\circ} \mathrm{C} ;{ }^{1} \mathrm{H}-\mathrm{NMR}\left(\mathrm{CDCl}_{3}\right) \delta 3.93\left(\mathrm{~s}, 3 \mathrm{H}, \mathrm{OCH}_{3}\right), 3.95\left(\mathrm{~s}, 3 \mathrm{H}, \mathrm{OCH}_{3}\right), 5.91(\mathrm{~s}, 1 \mathrm{H}, \mathrm{OH}), 6.01(\mathrm{~s}, 1 \mathrm{H}$, $\mathrm{OH}), 6.54\left(\mathrm{~d}, J=9.0 \mathrm{~Hz}, 1 \mathrm{H}, \mathrm{H}-5^{\prime}\right), 6.92(\mathrm{~d}, J=8.1 \mathrm{~Hz}, 1 \mathrm{H}, \mathrm{H}-5), 7.14(\mathrm{~d}, J=8.3 \mathrm{~Hz}, 1 \mathrm{H}, \mathrm{H}-6), 7.18(\mathrm{~s}, 1 \mathrm{H}$, 
H-2), 7.39 (d, $J=15.1 \mathrm{~Hz}, 1 \mathrm{H}, \mathrm{H}-\alpha), 7.67\left(\mathrm{~d}, J=9.0 \mathrm{~Hz}, 1 \mathrm{H}, \mathrm{H}-6^{\prime}\right), 7.77(\mathrm{~d}, J=15.4 \mathrm{~Hz}, 1 \mathrm{H}, \mathrm{H}-\beta), 13.39$ (s, 1H, OH); ${ }^{13} \mathrm{C}-\mathrm{NMR}(\mathrm{CD} 3 \mathrm{OD}) \delta 56.5,60.8,104.2,115.8,116.5,116.7,117.9,123.7,127.6,128.1,137.3$, 146.6, 146.7, 150.0, 158.5, 159.6, 193.9.

2,4,2'-Trihydroxy-3' ' $^{\prime}$-methoxychalcone (7i): $(0.13 \mathrm{~g}, 0.41 \mathrm{mmol}, 41 \%$ yield); reddish orange solid, 120-125 ${ }^{\circ} \mathrm{C} ;{ }^{1} \mathrm{H}-\mathrm{NMR}$ (DMSO- $\left.d_{6}\right) \delta 3.69\left(\mathrm{~s}, 3 \mathrm{H}, \mathrm{OCH}_{3}\right), 3.87\left(\mathrm{~s}, 3 \mathrm{H}, \mathrm{OCH}_{3}\right), 6.33(\mathrm{dd}, J=1.7 \mathrm{~Hz}$ and $8.8 \mathrm{~Hz}, 1 \mathrm{H}, \mathrm{H}-5), 6.38(\mathrm{~d}, J=1.7 \mathrm{~Hz}, 1 \mathrm{H}, \mathrm{H}-3), 6.68\left(\mathrm{~d}, J=8.8 \mathrm{~Hz}, 1 \mathrm{H}, \mathrm{H}-5^{\prime}\right), 7.70(\mathrm{~d}, J=14.9 \mathrm{~Hz}, 1 \mathrm{H}$, $\mathrm{H}-\alpha), 7.73\left(\mathrm{~d}, J=7.6 \mathrm{~Hz}, 1 \mathrm{H}, \mathrm{H}-6^{\prime}\right), 7.95(\mathrm{~d}, J=9.0 \mathrm{~Hz}, 1 \mathrm{H}, \mathrm{H}-6), 8.09(\mathrm{~d}, J=15.4 \mathrm{~Hz}, 1 \mathrm{H}, \mathrm{H}-\beta), 10.33$ (br s, $2 \mathrm{H}, \mathrm{OH}), 13.57$ (s, $1 \mathrm{H}, \mathrm{OH}) ;{ }^{13} \mathrm{C}-\mathrm{NMR}\left(\mathrm{DMSO}-d_{6}\right) \delta 56.2,59.9,102.4,103.5,108.2,113.2,115.2$, 115.4, 126.5, 130.6, 135.7, 140.5, 157.1, 157.9, 159.3, 161.8, 192.4.

4,2'-Dihydroxy-3,3', $4^{\prime}$-trimethoxychalcone (7j): $(0.25 \mathrm{~g}, 0.77 \mathrm{mmol}, 77 \%$ yield); yellowish brown solid, 117-124 ${ }^{\circ} \mathrm{C} ;{ }^{1} \mathrm{H}-\mathrm{NMR}\left(\mathrm{CDCl}_{3}\right) \delta 3.93\left(\mathrm{~s}, 3 \mathrm{H}, \mathrm{OCH}_{3}\right), 3.96\left(\mathrm{~s}, 3 \mathrm{H}, \mathrm{OCH}_{3}\right), 3.98\left(\mathrm{~s}, 3 \mathrm{H}, \mathrm{OCH}_{3}\right), 5.96(\mathrm{~s}, 1 \mathrm{H}$, $\mathrm{OH}), 6.54\left(\mathrm{~d}, J=9.0 \mathrm{~Hz}, 1 \mathrm{H}, \mathrm{H}-5^{\prime}\right), 6.97(\mathrm{~d}, J=8.3 \mathrm{~Hz}, 1 \mathrm{H}, \mathrm{H}-5), 7.13(\mathrm{~d}, J=1.7 \mathrm{~Hz}, 1 \mathrm{H}, \mathrm{H}-2), 7.25$ $(\mathrm{dd}, J=1.7 \mathrm{~Hz}$ and $8.5 \mathrm{~Hz}, 1 \mathrm{H}, \mathrm{H}-6), 7.43(\mathrm{~d}, J=15.4 \mathrm{~Hz}, 1 \mathrm{H}, \mathrm{H}-\alpha), 7.70\left(\mathrm{~d}, J=9.0 \mathrm{~Hz}, 1 \mathrm{H}, \mathrm{H}-6^{\prime}\right), 7.85$ $(\mathrm{d}, J=15.4 \mathrm{~Hz}, 1 \mathrm{H}, \mathrm{H}-\beta), 13.32(\mathrm{~s}, 1 \mathrm{H}, \mathrm{OH}) ;{ }^{13} \mathrm{C}-\mathrm{NMR}\left(\mathrm{CDCl}_{3}\right) \delta 56.0,56.1,60.6,102.6,110.3,114.8$, 115.6, 117.6, 123.2, 125.7, 127.2, 136.6, 144.9, 146.6, 148.3, 158.1, 158.2, 192.2.

3,2'-Dihydroxy-4,3' $4^{\prime}$-trimethoxychalcone (7k): ( $0.24 \mathrm{~g}, 0.73 \mathrm{mmol}, 73 \%$ yield); yellowish brown solid, 107-110 ${ }^{\circ} \mathrm{C} ;{ }^{1} \mathrm{H}-\mathrm{NMR}\left(\mathrm{CDCl}_{3}\right) \delta 3.92\left(\mathrm{~s}, 3 \mathrm{H}, \mathrm{OCH}_{3}\right), 3.95\left(\mathrm{~s}, 3 \mathrm{H}, \mathrm{OCH}_{3}\right), 3.96\left(\mathrm{~s}, 3 \mathrm{H}, \mathrm{OCH}_{3}\right), 5.73(\mathrm{~s}, 1 \mathrm{H}$, $\mathrm{OH}), 6.54\left(\mathrm{~d}, J=9.0 \mathrm{~Hz}, 1 \mathrm{H}, \mathrm{H}-5^{\prime}\right), 6.89(\mathrm{~d}, J=8.3 \mathrm{~Hz}, 1 \mathrm{H}, \mathrm{H}-5), 7.14(\mathrm{dd}, J=2.2 \mathrm{~Hz}$ and $8.3 \mathrm{~Hz} 1 \mathrm{H}, \mathrm{H}-6)$, $7.30(\mathrm{~d}, J=2.2 \mathrm{~Hz}, 1 \mathrm{H}, \mathrm{H}-2), 7.44(\mathrm{~d}, J=15.4 \mathrm{~Hz}, 1 \mathrm{H}, \mathrm{H}-\alpha), 7.68\left(\mathrm{~d}, J=9.0 \mathrm{~Hz}, 1 \mathrm{H}, \mathrm{H}-6^{\prime}\right), 7.82(\mathrm{~d}, J=15.4$ $\mathrm{Hz}, 1 \mathrm{H}, \mathrm{H}-\beta), 13.32(\mathrm{~s}, 1 \mathrm{H}, \mathrm{OH}) ;{ }^{13} \mathrm{C}-\mathrm{NMR}\left(\mathrm{CDCl}_{3}\right) \delta 55.9,56.0,60.5,102.6,110.3,112.6,115.4,118.0$, $122.9,125.6,128.1,136.4,144.3,145.6,148.7,157.9,158.0,192.0$.

2'-Hydroxy-3,4,3' $4^{\prime}$-tetramethoxychalcone (71): (0.28 g, $0.80 \mathrm{mmol}, 80 \%$ yield); orange-yellow solid, 117-120 ${ }^{\circ} \mathrm{C} ;{ }^{1} \mathrm{H}-\mathrm{NMR}\left(\mathrm{CDCl}_{3}\right) \delta 3.93\left(\mathrm{~s}, 3 \mathrm{H}, \mathrm{OCH}_{3}\right), 3.95\left(\mathrm{~s}, 3 \mathrm{H}, \mathrm{OCH}_{3}\right), 3.96\left(\mathrm{~s}, 3 \mathrm{H}, \mathrm{OCH}_{3}\right), 3.98(\mathrm{~s}, 3 \mathrm{H}$, $\left.\mathrm{OCH}_{3}\right), 6.55\left(\mathrm{~d}, J=9.3 \mathrm{~Hz}, 1 \mathrm{H}, \mathrm{H}-5^{\prime}\right), 6.92(\mathrm{~d}, J=8.3 \mathrm{~Hz}, 1 \mathrm{H}, \mathrm{H}-5), 7.17(\mathrm{~d}, J=2.0 \mathrm{~Hz}, 1 \mathrm{H}, \mathrm{H}-2), 7.27$ $(\mathrm{dd}, J=2.0 \mathrm{~Hz}$ and $8.3 \mathrm{~Hz} 1 \mathrm{H}, \mathrm{H}-6), 7.45(\mathrm{~d}, J=15.4 \mathrm{~Hz}, 1 \mathrm{H}, \mathrm{H}-\alpha), 7.72\left(\mathrm{~d}, J=9.3 \mathrm{~Hz}, 1 \mathrm{H}, \mathrm{H}-6^{\prime}\right), 7.87$ $(\mathrm{d}, J=15.4 \mathrm{~Hz}, 1 \mathrm{H}, \mathrm{H}-\beta), 13.34(\mathrm{~s}, 1 \mathrm{H}, \mathrm{OH}) ;{ }^{13} \mathrm{C}-\mathrm{NMR}\left(\mathrm{CDCl}_{3}\right) \delta 55.9,55.9,56.0,60.5,102.4,109.9,110.8$, $115.3,117.6,123.1,125.6,127.3,136.4,144.5,148.9,151.2,157.9,158.0,191.9$.

\subsection{The General Procedure for the Synthesis of Flavanones 8a-1}

A solution of $7 \mathrm{a}-1 \mathrm{l}(1.0 \mathrm{mmol})$ and potassium fluoride $(0.29 \mathrm{~g}, 5.0 \mathrm{mmol})$ in methanol $(5 \mathrm{~mL})$ was refluxed for $24 \mathrm{~h}$. The water was added to a mixture solution and the mixture was extracted with EtOAc. The organic layer was washed with water and brine and dried over anhydrous $\mathrm{MgSO}_{4}$. The solvent was evaporated in vacuo and the residue was chromatographed on a preparative thin layer chromatography (hexane:toluene:EtOAc $=1: 1: 1$ ) to produce flavanones $\mathbf{8 a}-\mathbf{l}$.

7,4'-Dihydroxy-8-methoxyflavanone (8a): (0.28 g, $0.98 \mathrm{mmol}, 98 \%$ yield); pale yellow solid, $195-200{ }^{\circ} \mathrm{C}$; ${ }^{1} \mathrm{H}-\mathrm{NMR}\left(\mathrm{CD}_{3} \mathrm{OD}\right) \delta 2.72(\mathrm{dd}, J=2.9 \mathrm{~Hz}$ and $17.1 \mathrm{~Hz}, 1 \mathrm{H}, \mathrm{H}-3 \mathrm{ax}), 3.07(\mathrm{dd}, J=12.9 \mathrm{~Hz}$ and $17.1 \mathrm{~Hz}$, $1 \mathrm{H}, \mathrm{H}-3 \mathrm{eq}), 3.79\left(\mathrm{~s}, 3 \mathrm{H}, \mathrm{OCH}_{3}\right), 5.42(\mathrm{dd}, J=2.9 \mathrm{~Hz}$ and $12.9 \mathrm{~Hz}, 1 \mathrm{H}, \mathrm{H}-2), 6.55(\mathrm{~d}, J=8.8 \mathrm{~Hz}, 1 \mathrm{H}, \mathrm{H}-6)$, $6.82\left(\mathrm{td}, J=2.0 \mathrm{~Hz}\right.$ and $8.5 \mathrm{~Hz}, 2 \mathrm{H}, \mathrm{H}-3^{\prime}$ and $\left.\mathrm{H}-5^{\prime}\right), 7.35\left(\mathrm{td}, J=1.7 \mathrm{~Hz}\right.$ and $8.3 \mathrm{~Hz}, 2 \mathrm{H}, \mathrm{H}-2^{\prime}$ and $\left.\mathrm{H}-6^{\prime}\right)$, $7.51(\mathrm{~d}, J=8.8 \mathrm{~Hz}, 1 \mathrm{H}, \mathrm{H}-5) ;{ }^{13} \mathrm{C}-\mathrm{NMR}\left(\mathrm{CD}_{3} \mathrm{OD}\right) \delta 44.8,61.2,81.3,111.4,115.9,116.2,123.7,128.8,131.0$, 136.4, 157.4, 158.5, 158.7, 193.2; UV/Vis $\left(1.5 \times 10^{-3} \mathrm{M}, \mathrm{DMSO}\right) ; \lambda=376.4 \mathrm{~nm}\left(\varepsilon, 1.2 \times 10^{2}\right)$.

7, $3^{\prime}, 4^{\prime}$-Trihydroxy-8-methoxyflavanone ( $\left.8 \mathbf{b}\right):(0.20 \mathrm{~g}, 0.65 \mathrm{mmol}, 65 \%$ yield); yellowish brown solid, 188-193 ${ }^{\circ} \mathrm{C} ;{ }^{1} \mathrm{H}-\mathrm{NMR}\left(\mathrm{CD}_{3} \mathrm{OD}\right) \delta 2.72(\mathrm{dd}, J=2.9 \mathrm{~Hz}$ and $17.1 \mathrm{~Hz}, 1 \mathrm{H}, \mathrm{H}-3 \mathrm{ax}), 3.01(\mathrm{dd}, J=12.9 \mathrm{~Hz}$ and $17.1 \mathrm{~Hz}, 1 \mathrm{H}, \mathrm{H}-3 \mathrm{eq}), 3.81\left(\mathrm{~s}, 3 \mathrm{H}, \mathrm{OCH}_{3}\right), 5.35(\mathrm{dd}, J=2.9 \mathrm{~Hz}$ and $12.9 \mathrm{~Hz}, 1 \mathrm{H}, \mathrm{H}-2), 6.54(\mathrm{~d}, J=8.8 \mathrm{~Hz}$, $1 \mathrm{H}, \mathrm{H}-6), 6.78\left(\mathrm{~d}, J=8.1 \mathrm{~Hz}, 1 \mathrm{H}, \mathrm{H}-5^{\prime}\right), 6.82\left(\mathrm{dd}, J=1.7 \mathrm{~Hz}\right.$ and $\left.8.3 \mathrm{~Hz}, 1 \mathrm{H}, \mathrm{H}-6^{\prime}\right), 6.97(\mathrm{~d}, J=1.7 \mathrm{~Hz}$, $\left.1 \mathrm{H}, \mathrm{H}-2^{\prime}\right), 7.50$ (d, J = 8.8 Hz, 1H, H-5); ${ }^{13} \mathrm{C}-\mathrm{NMR}$ (CD3OD) $\delta 44.9,61.3,81.3,111.3,114.5,115.9,116.1$, 119.0, 123.6, 131.7, 136.4, 146.2, 146.6, 157.3, 158.4, 193.2; UV/Vis $\left(2.6 \times 10^{-5} \mathrm{M}, \mathrm{CH}_{3} \mathrm{OH}\right) ; \lambda=392.0 \mathrm{~nm}$ $\left(\varepsilon, 2.7 \times 10^{3}\right)$. 
7,4'-Dihydroxy-8,3'-dimethoxyflavanone (8d): (0.28 g, $0.90 \mathrm{mmol}, 90 \%$ yield); yellow solid, $193-195{ }^{\circ} \mathrm{C}$; ${ }^{1} \mathrm{H}-\mathrm{NMR}\left(\mathrm{CD}_{3} \mathrm{OD}\right) \delta 2.67(\mathrm{dd}, J=2.7 \mathrm{~Hz}$ and $16.8 \mathrm{~Hz}, 1 \mathrm{H}, \mathrm{H}-3 \mathrm{ax}), 3.16(\mathrm{dd}, J=12.7 \mathrm{~Hz}$ and $16.6 \mathrm{~Hz}$, $1 \mathrm{H}, \mathrm{H}-3 \mathrm{eq}), 3.69\left(\mathrm{~s}, 3 \mathrm{H}, \mathrm{OCH}_{3}\right), 3.77\left(\mathrm{~s}, 3 \mathrm{H}, \mathrm{OCH}_{3}\right), 5.46(\mathrm{dd}, J=2.4 \mathrm{~Hz}$ and $12.9 \mathrm{~Hz}, 1 \mathrm{H}, \mathrm{H}-2), 6.57$ $(\mathrm{d}, J=8.8 \mathrm{~Hz}, 1 \mathrm{H}, \mathrm{H}-6), 6.79\left(\mathrm{~d}, J=8.8 \mathrm{~Hz}, 1 \mathrm{H}, \mathrm{H}-6^{\prime}\right), 6.93\left(\mathrm{~d}, J=8.8 \mathrm{~Hz}, 1 \mathrm{H}, \mathrm{H}-5^{\prime}\right), 7.11\left(\mathrm{~s}, 1 \mathrm{H}, \mathrm{H}-2^{\prime}\right), 7.40$ $(\mathrm{d}, J=8.8 \mathrm{~Hz}, 1 \mathrm{H}, \mathrm{H}-5) ;{ }^{13} \mathrm{C}-\mathrm{NMR}\left(\mathrm{CD}_{3} \mathrm{OD}\right) \delta 43.2,55.7,60.2,79.4,110.4,111.0,114.4,115.1,119.3,122.0$, $129.9,135.1,146.7,147.4,155.7,156.9,190.2 ; \mathrm{UV} / \mathrm{Vis}\left(2.7 \times 10^{-5} \mathrm{M}, \mathrm{CH}_{3} \mathrm{OH}\right) ; \lambda=383.8 \mathrm{~nm}\left(\varepsilon, 1.7 \times 10^{4}\right)$.

7,3'-Dihydroxy-8, $4^{\prime}$-dimethoxyflavanone (8e): $(0.27 \mathrm{~g}, 0.85 \mathrm{mmol}, 85 \%$ yield); yellowish brown solid, 180-185 ${ }^{\circ} \mathrm{C} ;{ }^{1} \mathrm{H}-\mathrm{NMR}$ (DMSO- $d_{6}$ ) $\delta 2.69(\mathrm{dd}, J=2.9 \mathrm{~Hz}$ and $16.8 \mathrm{~Hz}, 1 \mathrm{H}, \mathrm{H}-3 \mathrm{ax}$ ), 3.06 (dd, $J=12.5 \mathrm{~Hz}$ and $16.8 \mathrm{~Hz}, 1 \mathrm{H}, \mathrm{H}-3 \mathrm{eq}), 3.71\left(\mathrm{~s}, 3 \mathrm{H}, \mathrm{OCH}_{3}\right), 3.78\left(\mathrm{~s}, 3 \mathrm{H}, \mathrm{OCH}_{3}\right), 5.48(\mathrm{dd}, J=2.9 \mathrm{~Hz} \mathrm{~Hz}$ and $12.5 \mathrm{~Hz}, 1 \mathrm{H}$, $\mathrm{H}-2), 6.58(\mathrm{~d}, J=8.8 \mathrm{~Hz}, 1 \mathrm{H}, \mathrm{H}-6), 6.91\left(\mathrm{dd}, J=1.7 \mathrm{~Hz}\right.$ and $\left.8.3 \mathrm{~Hz}, 1 \mathrm{H}, \mathrm{H}-6^{\prime}\right), 6.95\left(\mathrm{~d}, J=8.5 \mathrm{~Hz}, 1 \mathrm{H}, \mathrm{H}-5^{\prime}\right)$, $6.97\left(\mathrm{~d}, J=2.4 \mathrm{~Hz}, 1 \mathrm{H}, \mathrm{H}-2^{\prime}\right), 7.41$ (d, $\left.J=8.8 \mathrm{~Hz}, 1 \mathrm{H}, \mathrm{H}-5\right) ;{ }^{13} \mathrm{C}-\mathrm{NMR}$ (DMSO- $d_{6}$ ) $\delta 43.1,55.6,60.1,78.9$, 110.2, 111.8, 113.8, 114.3, 117.3, 121.8, 131.4, 134.9, 146.2, 147.5, 155.4, 156.6, 189.8; UV/Vis $\left(2.9 \times 10^{-5} \mathrm{M}\right.$, $\mathrm{DMSO}) ; \lambda=363.6 \mathrm{~nm}\left(\varepsilon, 2.2 \times 10^{3}\right)$.

7-Hydroxy-8, $3^{\prime}, 4^{\prime}$-trimethoxyflavanone (8f): ( $0.30 \mathrm{~g}, 0.90 \mathrm{mmol}, 90 \%$ yield); yellow solid, $143-145^{\circ} \mathrm{C}$; ${ }^{1} \mathrm{H}-\mathrm{NMR}\left(\mathrm{CDCl}_{3}\right) \delta 2.87(\mathrm{dd}, J=2.9 \mathrm{~Hz}$ and $16.8 \mathrm{~Hz}, 1 \mathrm{H}, \mathrm{H}-3 \mathrm{ax}), 3.06(\mathrm{dd}, J=12.9 \mathrm{~Hz}$ and $16.8 \mathrm{~Hz}, 1 \mathrm{H}$, $\mathrm{H}-3 \mathrm{eq}), 3.91\left(\mathrm{~s}, 6 \mathrm{H}, \mathrm{OCH}_{3}\right), 3.95\left(\mathrm{~s}, 3 \mathrm{H}, \mathrm{OCH}_{3}\right), 5.46(\mathrm{dd}, J=2.7 \mathrm{~Hz}$ and $12.9 \mathrm{~Hz}, 1 \mathrm{H}, \mathrm{H}-2), 6.59(\mathrm{~s}, 1 \mathrm{H}$, $\mathrm{OH}), 6.68(\mathrm{~d}, J=8.8 \mathrm{~Hz}, 1 \mathrm{H}, \mathrm{H}-6), 6.91\left(\mathrm{~d}, J=8.8 \mathrm{~Hz}, 1 \mathrm{H}, \mathrm{H}-5^{\prime}\right), 7.02-7.03\left(\mathrm{~m}, 2 \mathrm{H}, \mathrm{H}-2^{\prime}\right.$ and H-6 $\left.{ }^{\prime}\right), 7.65$ $(\mathrm{d}, J=8.5 \mathrm{~Hz}, 1 \mathrm{H}, \mathrm{H}-5) ;{ }^{13} \mathrm{C}-\mathrm{NMR}\left(\mathrm{CDCl}_{3}\right) \delta 44.2,55.8,61.1,80.0,109.1,109.3,110.9,115.4,118.4,122.9$, 130.9, 134.1, 148.8, 149.0, 154.2, 155.0, 190.2; UV/Vis $\left(2.3 \times 10^{-5} \mathrm{M}, \mathrm{CHCl}_{3}\right) ; \lambda=392.6 \mathrm{~nm}\left(\varepsilon, 1.4 \times 10^{3}\right)$.

4'-Hydroxy-7,8-dimethoxyflavanone (8g): $\left(0.26 \mathrm{~g}, 0.87 \mathrm{mmol}, 87 \%\right.$ yield); yellow solid, $165-170{ }^{\circ} \mathrm{C}$; ${ }^{1} \mathrm{H}-\mathrm{NMR}\left(\mathrm{CDCl}_{3}\right) \delta 2.88(\mathrm{dd}, J=2.9 \mathrm{~Hz}$ and $16.8 \mathrm{~Hz}, 1 \mathrm{H}, \mathrm{H}-3 \mathrm{ax}), 3.07(\mathrm{dd}, J=12.2 \mathrm{~Hz}$ and $16.8 \mathrm{~Hz}, 1 \mathrm{H}$, $\mathrm{H}$-eq), $3.88\left(\mathrm{~s}, 3 \mathrm{H}, \mathrm{OCH}_{3}\right), 3.94\left(\mathrm{~s}, 3 \mathrm{H}, \mathrm{OCH}_{3}\right), 5.45(\mathrm{dd}, J=2.9 \mathrm{~Hz}$ and $12.2 \mathrm{~Hz}, 1 \mathrm{H}, \mathrm{H}-2), 6.39(\mathrm{~s}, 1 \mathrm{H}, \mathrm{OH})$, $6.67(\mathrm{~d}, J=9.0 \mathrm{~Hz}, 1 \mathrm{H}, \mathrm{H}-6), 6.87\left(\mathrm{~d}, J=8.5 \mathrm{~Hz}, 2 \mathrm{H}, \mathrm{H}-3^{\prime}\right.$ and $\left.\mathrm{H}-5^{\prime}\right), 7.31\left(\mathrm{~d}, J=8.8 \mathrm{~Hz}, 2 \mathrm{H}, \mathrm{H}-2^{\prime}\right.$ and $\left.\mathrm{H}-6^{\prime}\right)$, $7.73(\mathrm{~d}, J=9.0 \mathrm{~Hz}, 1 \mathrm{H}, \mathrm{H}-5) ;{ }^{13} \mathrm{C}-\mathrm{NMR}\left(\mathrm{CDCl}_{3}\right) \delta 44.0,56.3,61.1,79.7,105.7,115.5,116.0,123.1,127.8$, 130.3, 136.7, 155.4, 156.2, 158.8, 191.6; UV/Vis $\left(3.1 \times 10^{-5} \mathrm{M}_{1} \mathrm{CHCl}_{3}\right) ; \lambda=391.2 \mathrm{~nm}\left(\varepsilon, 1.2 \times 10^{3}\right)$.

$3^{\prime}, 4^{\prime}$-Dihydroxy-7,8-dimethoxyflavanone ( $\left.8 \mathbf{h}\right)(0.20 \mathrm{~g}, 0.63 \mathrm{mmol}, 63 \%$ yield); yellowish brown solid, 175-177 ${ }^{\circ} \mathrm{C} ;{ }^{1} \mathrm{H}-\mathrm{NMR}$ (DMSO-d $\left.{ }_{6}\right) \delta 2.71(\mathrm{dd}, J=2.9 \mathrm{~Hz}$ and $16.8 \mathrm{~Hz}, 1 \mathrm{H}, \mathrm{H}-3 \mathrm{ax}), 3.11(\mathrm{dd}, J=12.5 \mathrm{~Hz}$ and $16.8 \mathrm{~Hz}, 1 \mathrm{H}, \mathrm{H}-3 \mathrm{eq}), 3.69\left(\mathrm{~s}, 3 \mathrm{H}, \mathrm{OCH}_{3}\right), 3.87\left(\mathrm{~s}, 3 \mathrm{H}, \mathrm{OCH}_{3}\right), 5.45(\mathrm{dd}, J=2.9 \mathrm{~Hz}$ and $12.5 \mathrm{~Hz}, 1 \mathrm{H}$, H-2), 6.76-6.77 (m, 2H, H-6 and H-6 $\left.{ }^{\prime}\right), 6.84\left(\mathrm{~d}, J=8.8 \mathrm{~Hz}, 1 \mathrm{H}, \mathrm{H}-5^{\prime}\right), 6.92\left(\mathrm{~d}, J=1.7 \mathrm{~Hz}, 1 \mathrm{H}, \mathrm{H}-2^{\prime}\right), 7.55$ $(\mathrm{d}, J=8.8 \mathrm{~Hz}, 1 \mathrm{H}, \mathrm{H}-5) ;{ }^{13} \mathrm{C}-\mathrm{NMR}$ (DMSO- $\left.d_{6}\right) \delta 43.2,56.1,60.2,79.1,105.8,114.1,115.1,115.6,117.6$, $121.9,129.6,136.2,144.9,145.4,154.7,158.0,190.3$.

4'-Hydroxy-7,8,3'-trimethoxyflavanone (8j): (0.30 g, $0.91 \mathrm{mmol}, 91 \%$ yield); yellow solid, $145-146{ }^{\circ} \mathrm{C}$; ${ }^{1} \mathrm{H}-\mathrm{NMR}\left(\mathrm{CDCl}_{3}\right) \delta 2.88(\mathrm{dd}, J=2.9 \mathrm{~Hz}$ and $16.8 \mathrm{~Hz}, 1 \mathrm{H}, \mathrm{H}-3 \mathrm{ax}), 3.06(\mathrm{dd}, J=12.5 \mathrm{~Hz}$ and $16.8 \mathrm{~Hz}, 1 \mathrm{H}$, $\mathrm{H}-3 \mathrm{eq}), 3.87\left(\mathrm{~s}, 3 \mathrm{H}, \mathrm{OCH}_{3}\right), 3.91\left(\mathrm{~s}, 3 \mathrm{H}, \mathrm{OCH}_{3}\right), 3.93\left(\mathrm{~s}, 3 \mathrm{H}, \mathrm{OCH}_{3}\right), 5.44(\mathrm{dd}, J=2.9 \mathrm{~Hz}$ and $12.5 \mathrm{~Hz}, 1 \mathrm{H}$, $\mathrm{H}-2), 5.78(\mathrm{~s}, 1 \mathrm{H}, \mathrm{OH}), 6.67(\mathrm{~d}, J=8.8 \mathrm{~Hz}, 1 \mathrm{H}, \mathrm{H}-6), 6.92-6.99\left(\mathrm{~m}, 2 \mathrm{H}, \mathrm{H}-5^{\prime}\right.$ and H-6 $\left.{ }^{\prime}\right), 7.02(\mathrm{~d}, J=1.5 \mathrm{~Hz}$, $\left.1 \mathrm{H}, \mathrm{H}-2^{\prime}\right), 7.71(\mathrm{~d}, J=9.0 \mathrm{~Hz}, 1 \mathrm{H}, \mathrm{H}-5) ;{ }^{13} \mathrm{C}-\mathrm{NMR}\left(\mathrm{CDCl}_{3}\right) \delta 44.1,55.8,56.1,60.9,79.7,105.4,108.6$, 114.2, 115.9, 119.1, 122.6, 130.4, 136.7, 145.6, 146.3, 155.0, 158.4, 190.6; UV/Vis $\left(6.1 \times 10^{-4} \mathrm{M} \mathrm{CHCl}_{3}\right)$; $\lambda=370.0 \mathrm{~nm}\left(\varepsilon, 1.9 \times 10^{3}\right)$.

$3^{\prime}$-Hydroxy-7,8,4'-trimethoxyflavanone (8k): (0.30 g, $0.90 \mathrm{mmol}, 90 \%$ yield); ${ }^{1} \mathrm{H}-\mathrm{NMR}\left(\mathrm{CDCl}_{3}\right) \delta 2.85$ $(\mathrm{dd}, J=2.9 \mathrm{~Hz}$ and $16.8 \mathrm{~Hz}, 1 \mathrm{H}, \mathrm{H}-3 \mathrm{ax}), 3.02(\mathrm{dd}, J=12.5 \mathrm{~Hz}$ and $16.8 \mathrm{~Hz}, 1 \mathrm{H}, \mathrm{H}-3 \mathrm{eq}), 3.87(\mathrm{~s}, 3 \mathrm{H}$, $\left.\mathrm{OCH}_{3}\right), 3.89\left(\mathrm{~s}, 3 \mathrm{H}, \mathrm{OCH}_{3}\right), 3.93\left(\mathrm{~s}, 3 \mathrm{H}, \mathrm{OCH}_{3}\right), 5.41(\mathrm{dd}, J=2.9 \mathrm{~Hz}$ and $12.5 \mathrm{~Hz}, 1 \mathrm{H}, \mathrm{H}-2), 5.94(\mathrm{~s}, 1 \mathrm{H}$, $\mathrm{OH}), 6.66(\mathrm{~d}, J=9.0 \mathrm{~Hz}, 1 \mathrm{H}, \mathrm{H}-6), 6.87\left(\mathrm{~d}, J=8.3 \mathrm{~Hz}, 1 \mathrm{H}, \mathrm{H}-5^{\prime}\right), 6.95(\mathrm{dd}, J=2.0 \mathrm{~Hz}$ and $8.3 \mathrm{~Hz}, 1 \mathrm{H}$, H-6 $\left.{ }^{\prime}\right), 7.08\left(\mathrm{~d}, J=2.0 \mathrm{~Hz}, 1 \mathrm{H}, \mathrm{H}-2^{\prime}\right), 7.70(\mathrm{~d}, J=9.0 \mathrm{~Hz}, 1 \mathrm{H}, \mathrm{H}-5) ;{ }^{13} \mathrm{C}-\mathrm{NMR}\left(\mathrm{CDCl}_{3}\right) \delta 44.1,55.9,56.1$, $60.9,79.4,105.4,110.4,112.4,115.9,117.7,122.6,131.6,136.7,145.5,146.5,155.0,158.4,190.7$.

$3^{\prime}, 4^{\prime}, 7,8$-Tetramethoxyflavanone (81): (0.16 g, $0.46 \mathrm{mmol}, 46 \%$ yield); yellow solid, $141-143{ }^{\circ} \mathrm{C} ;{ }^{1} \mathrm{H}-\mathrm{NMR}$ $\left(\mathrm{CDCl}_{3}\right) \delta 2.90(\mathrm{dd}, J=3.2 \mathrm{~Hz}$ and $16.8 \mathrm{~Hz}, 1 \mathrm{H}, \mathrm{H}-3 \mathrm{ax}), 3.07(\mathrm{dd}, J=12.2 \mathrm{~Hz}$ and $16.8 \mathrm{~Hz}, 1 \mathrm{H}, \mathrm{H}-\mathrm{eq}), 3.88$ $\left(\mathrm{s}, 3 \mathrm{H}, \mathrm{OCH}_{3}\right), 3.90\left(\mathrm{~s}, 3 \mathrm{H}, \mathrm{OCH}_{3}\right), 3.91\left(\mathrm{~s}, 3 \mathrm{H}, \mathrm{OCH}_{3}\right), 3.94\left(\mathrm{~s}, 3 \mathrm{H}, \mathrm{OCH}_{3}\right), 5.48(\mathrm{dd}, J=2.9 \mathrm{~Hz}$ and 12.2 
$\mathrm{Hz}, 1 \mathrm{H}, \mathrm{H}-2), 6.67(\mathrm{~d}, J=9.0 \mathrm{~Hz}, 1 \mathrm{H}, \mathrm{H}-6), 6.90\left(\mathrm{~d}, J=8.1 \mathrm{~Hz}, 1 \mathrm{H}, \mathrm{H}-5^{\prime}\right), 7.01-7.04\left(\mathrm{~m}, 2 \mathrm{H}, \mathrm{H}-2^{\prime}\right.$ and $\left.\mathrm{H}-6^{\prime}\right)$, $7.71(\mathrm{~d}, J=8.8 \mathrm{~Hz}, 1 \mathrm{H}, \mathrm{H}-5) ;{ }^{13} \mathrm{C}-\mathrm{NMR}\left(\mathrm{CDCl}_{3}\right) \delta 44.1,55.8,55.8,56.1,60.9,79.5,105.4,109.2,110.8,116.0$, 118.4, 122.6, 131.0, 136.7, 148.8, 148.9, 154.9, 158.4, 190.5; GC-MS 344 (M+, 44), 180 (35), 164 (100).

\subsection{The General Procedure for the Synthesis of Chalcones $\mathbf{9 a - k}$ by the Selective Deprotection of the} 2'-Methoxymethyl Group

A solution of $\mathbf{6 a}-\mathbf{k}(1.0 \mathrm{mmol})$ and $1.5 \mathrm{M}$ hydrochloric acid aqueous solution $(5 \mathrm{~mL})$ in THF $(5 \mathrm{~mL})$ was stirred at room temperature for $45 \mathrm{~min}$. The mixture was extracted with $\mathrm{Et}_{2} \mathrm{O}$. The organic layer was washed with water and brine and dried over anhydrous $\mathrm{MgSO}_{4}$. The solvent was evaporated in vacuo and the residue was chromatographed on a preparative thin layer chromatography (hexane:EtOAc $=3: 2$ ) to produce chalcones $\mathbf{9 a}-\mathbf{k}$.

2'-Hydroxy-3'-methoxy-4,4'-di(methoxymethoxy)chalcone (9a): $(0.29 \mathrm{~g}, 0.77 \mathrm{mmol}, 77 \%$ yield); ${ }^{1} \mathrm{H}-\mathrm{NMR}\left(\mathrm{CDCl}_{3}\right) \delta 3.50\left(\mathrm{~s}, 3 \mathrm{H}, \mathrm{OCH}_{3}\right), 3.53\left(\mathrm{~s}, 3 \mathrm{H}, \mathrm{OCH}_{3}\right), 3.94\left(\mathrm{~s}, 3 \mathrm{H}, \mathrm{OCH}_{3}\right), 5.23\left(\mathrm{~s}, 2 \mathrm{H}, \mathrm{OCH}_{2}\right), 5.32$ $\left(\mathrm{s}, 2 \mathrm{H}, \mathrm{OCH}_{2}\right), 6.75\left(\mathrm{~d}, J=9.0 \mathrm{~Hz}, 1 \mathrm{H}, \mathrm{H}-5^{\prime}\right), 7.09(\mathrm{~d}, J=8.8 \mathrm{~Hz}, 2 \mathrm{H}, \mathrm{H}-3$ and $\mathrm{H}-5), 7.47(\mathrm{~d}, J=15.4 \mathrm{~Hz}$, $1 \mathrm{H}, \mathrm{H}-\alpha), 7.61\left(\mathrm{~d}, J=8.8 \mathrm{~Hz}, 2 \mathrm{H}, \mathrm{H}-2\right.$ and H-6), $7.64\left(\mathrm{~d}, J=9.0 \mathrm{~Hz}, 1 \mathrm{H}, \mathrm{H}-6^{\prime}\right), 7.88(\mathrm{~d}, J=15.4 \mathrm{~Hz}, 1 \mathrm{H}$, $\mathrm{H}-\beta), 13.33(\mathrm{~s}, 1 \mathrm{H}, \mathrm{OH}) ;{ }^{13} \mathrm{C}-\mathrm{NMR}\left(\mathrm{CDCl}_{3}\right) \delta 56.1,56.4,60.6,94.0,94.5,106.0,116.0,116.3,117.9,125.2$, $128.1,130.0,144.3,155.6,158.2,159.1,192.1$.

2'-Hydroxy-3'-methoxy-3,4,4'-tri(methoxymethoxy)chalcone (9b): $(0.38 \mathrm{~g}, 0.87 \mathrm{mmol}, 87 \%$ yield); orange solid, $84-88^{\circ} \mathrm{C} ;{ }^{1} \mathrm{H}-\mathrm{NMR}\left(\mathrm{CDCl}_{3}\right) \delta 3.53\left(\mathrm{~s}, 3 \mathrm{H}, \mathrm{OCH}_{3}\right), 3.53\left(\mathrm{~s}, 3 \mathrm{H}, \mathrm{OCH}_{3}\right), 3.56\left(\mathrm{~s}, 3 \mathrm{H}, \mathrm{OCH}_{3}\right)$, $3.95\left(\mathrm{~s}, 3 \mathrm{H}, \mathrm{OCH}_{3}\right), 5.30\left(\mathrm{~s}, 2 \mathrm{H}, \mathrm{OCH}_{2}\right), 5.30\left(\mathrm{~s}, 2 \mathrm{H}, \mathrm{OCH}_{2}\right), 5.32\left(\mathrm{~s}, 2 \mathrm{H}, \mathrm{OCH}_{2}\right), 6.76(\mathrm{~d}, J=9.0 \mathrm{~Hz}, 1 \mathrm{H}$, $\left.\mathrm{H}-5^{\prime}\right), 7.21(\mathrm{~d}, J=8.5 \mathrm{~Hz}, 1 \mathrm{H}, \mathrm{H}-5), 7.29(\mathrm{dd}, J=2.0 \mathrm{~Hz}$ and $8.5 \mathrm{~Hz}, 1 \mathrm{H}, \mathrm{H}-6), 7.44(\mathrm{~d}, J=15.4 \mathrm{~Hz}, 1 \mathrm{H}$, $\mathrm{H}-\alpha), 7.48(\mathrm{~d}, J=2.0 \mathrm{~Hz}, 1 \mathrm{H}, \mathrm{H}-2), 7.66\left(\mathrm{~d}, J=9.0 \mathrm{~Hz}, \mathrm{H}-6^{\prime}\right), 7.84(\mathrm{~d}, J=15.4 \mathrm{~Hz}, 1 \mathrm{H}, \mathrm{H}-\beta), 13.31(\mathrm{~s}, 1 \mathrm{H}$, $\mathrm{OH}) ;{ }^{13} \mathrm{C}-\mathrm{NMR}\left(\mathrm{CDCl}_{3}\right) \delta 56.3,56.3,56.4,60.7,94.6,95.0,95.5,106.2,116.1,116.1,118.6,124.1,125.5$, 129.0, 137.4, 144.3, 144.5, 147.3, 149.6, 155.8, 158.4, 192.3.

2'-Hydroxy-3'-methoxy-2,4,4'-tri(methoxymethoxy)chalcone (9c): $(0.32 \mathrm{~g}, 0.73 \mathrm{mmol}, 73 \%$ yield); ${ }^{1} \mathrm{H}-\mathrm{NMR}\left(\mathrm{CDCl}_{3}\right) \delta 3.50\left(\mathrm{~s}, 3 \mathrm{H}, \mathrm{OCH}_{3}\right), 3.53\left(\mathrm{~s}, 3 \mathrm{H}, \mathrm{OCH}_{3}\right), 3.53\left(\mathrm{~s}, 3 \mathrm{H}, \mathrm{OCH}_{3}\right), 3.94\left(\mathrm{~s}, 3 \mathrm{H}, \mathrm{OCH}_{3}\right), 5.21$ $\left(\mathrm{s}, 2 \mathrm{H}, \mathrm{OCH}_{2}\right), 5.29\left(\mathrm{~s}, 2 \mathrm{H}, \mathrm{OCH}_{2}\right), 5.32\left(\mathrm{~s}, 2 \mathrm{H}, \mathrm{OCH}_{2}\right), 6.75\left(\mathrm{~d}, J=9.0 \mathrm{~Hz}, 1 \mathrm{H}, \mathrm{H}-5^{\prime}\right), 6.76(\mathrm{dd}, J=2.2 \mathrm{~Hz}$ and $8.5 \mathrm{~Hz}, 1 \mathrm{H}, \mathrm{H}-5), 6.87(\mathrm{~d}, J=2.2 \mathrm{~Hz}, 1 \mathrm{H}, \mathrm{H}-3), 7.59(\mathrm{~d}, J=15.6 \mathrm{~Hz}, 1 \mathrm{H}, \mathrm{H}-\alpha), 7.61(\mathrm{~d}, J=8.5 \mathrm{~Hz}, 1 \mathrm{H}$, H-6), $7.64\left(\mathrm{~d}, J=9.3 \mathrm{~Hz}, 1 \mathrm{H}, \mathrm{H}-6^{\prime}\right), 8.21(\mathrm{~d}, J=15.4 \mathrm{~Hz}, 1 \mathrm{H}, \mathrm{H}-\beta), 13.46(\mathrm{~s}, 1 \mathrm{H}, \mathrm{OH}) ;{ }^{13} \mathrm{C}-\mathrm{NMR}\left(\mathrm{CDCl}_{3}\right)$ $\delta 56.2,56.3,56.4,60.6,94.1,94.4,94.5,103.1,105.9,109.2,116.1,118.1,118.3,125.2,129.8,137.2,139.8$, $155.4,157.6,158.2,160.3,192.6$.

2'-Hydroxy-3,3'-dimethoxy-4,4'-di(methoxymethoxy)chalcone (9d): (0.35 g, $0.87 \mathrm{mmol}, 87 \%$ yield); ${ }^{1} \mathrm{H}-\mathrm{NMR}\left(\mathrm{CDCl}_{3}\right) \delta 3.53\left(\mathrm{~s}, 6 \mathrm{H}, \mathrm{OCH}_{3}\right), 3.95\left(\mathrm{~s}, 3 \mathrm{H}, \mathrm{OCH}_{3}\right), 3.97\left(\mathrm{~s}, 3 \mathrm{H}, \mathrm{OCH}_{3}\right), 5.30\left(\mathrm{~s}, 2 \mathrm{H}, \mathrm{OCH}_{2}\right), 5.33$ $\left(\mathrm{s}, 2 \mathrm{H}, \mathrm{OCH}_{2}\right), 6.77\left(\mathrm{~d}, J=9.3 \mathrm{~Hz}, 1 \mathrm{H}, \mathrm{H}-5^{\prime}\right), 7.17(\mathrm{~d}, J=1.7 \mathrm{~Hz}, 1 \mathrm{H}, \mathrm{H}-2), 7.20(\mathrm{~d}, J=8.3 \mathrm{~Hz}, 1 \mathrm{H}, \mathrm{H}-5)$, $7.25(\mathrm{dd}, J=1.7 \mathrm{~Hz}$ and $8.3 \mathrm{~Hz}, 1 \mathrm{H}, \mathrm{H}-6), 7.46(\mathrm{~d}, J=15.4 \mathrm{~Hz}, 1 \mathrm{H}, \mathrm{H}-\alpha), 7.67\left(\mathrm{~d}, J=9.3 \mathrm{~Hz}, 1 \mathrm{H}, \mathrm{H}-6^{\prime}\right)$, $7.86(\mathrm{~d}, J=15.4 \mathrm{~Hz}, 1 \mathrm{H}, \mathrm{H}-\beta), 13.34$ (s, $1 \mathrm{H}, \mathrm{OH}) ;{ }^{13} \mathrm{C}-\mathrm{NMR}\left(\mathrm{CDCl}_{3}\right) \delta 55.9,56.3,56.4,60.6,94.4,94.9$, $105.9,110.8,115.5,115.9,118.1,122.5,125.2,128.6,137.2,144.5,148.7,149.4,155.6,158.2,192.0$.

2'-Hydroxy-4,3'-dimethoxy-3,4'-di(methoxymethoxy)chalcone (9e): (0.26 g, $0.65 \mathrm{mmol}, 65 \%$ yield); ${ }^{1} \mathrm{H}-\mathrm{NMR}\left(\mathrm{CDCl}_{3}\right) \delta 3.53\left(\mathrm{~s}, 3 \mathrm{H}, \mathrm{OCH}_{3}\right), 3.56\left(\mathrm{~s}, 3 \mathrm{H}, \mathrm{OCH}_{3}\right), 3.95\left(\mathrm{~s}, 6 \mathrm{H}, \mathrm{OCH}_{3}\right), 5.30\left(\mathrm{~s}, 2 \mathrm{H}, \mathrm{OCH}_{2}\right)$, $5.33\left(\mathrm{~s}, 2 \mathrm{H}, \mathrm{OCH}_{2}\right), 6.76\left(\mathrm{~d}, J=9.0 \mathrm{~Hz}, 1 \mathrm{H}, \mathrm{H}-5^{\prime}\right), 6.94(\mathrm{~d}, J=8.3 \mathrm{~Hz}, 1 \mathrm{H}, \mathrm{H}-5), 7.31(\mathrm{dd}, J=2.0 \mathrm{~Hz}$ and $8.3 \mathrm{~Hz}, 1 \mathrm{H}, \mathrm{H}-6), 7.43(\mathrm{~d}, J=15.4 \mathrm{~Hz}, 1 \mathrm{H}, \mathrm{H}-\alpha), 7.49(\mathrm{~d}, J=2.2 \mathrm{~Hz}, 1 \mathrm{H}, \mathrm{H}-2), 7.67$ (d, $J=9.3 \mathrm{~Hz}, 1 \mathrm{H}$, H-6' $), 7.85(\mathrm{~d}, J=15.4 \mathrm{~Hz}, 1 \mathrm{H}, \mathrm{H}-\beta), 13.36(\mathrm{~s}, 1 \mathrm{H}, \mathrm{OH}){ }^{13}{ }^{13} \mathrm{C}-\mathrm{NMR}\left(\mathrm{CDCl}_{3}\right) \delta 55.9,56.2,56.4,60.6,94.4$, $95.3,105.9,111.3,115.0,115.9,117.8,124.5,125.3,127.4,137.1,144.5,146.5,151.9,155.5,158.2,192.0$.

2'-Hydroxy-3,4,3'-trimethoxy-4'-(methoxymethoxy)chalcone (9f): $(0.36 \mathrm{~g}, 0.95 \mathrm{mmol}, 95 \%$ yield); ${ }^{1} \mathrm{H}-\mathrm{NMR}\left(\mathrm{CDCl}_{3}\right) \delta 3.53\left(\mathrm{~s}, 3 \mathrm{H}, \mathrm{OCH}_{3}\right), 3.95\left(\mathrm{~s}, 6 \mathrm{H}, \mathrm{OCH}_{3}\right), 3.97\left(\mathrm{~s}, 3 \mathrm{H}, \mathrm{OCH}_{3}\right), 5.33\left(\mathrm{~s}, 2 \mathrm{H}, \mathrm{OCH}_{2}\right), 6.76$ $\left(\mathrm{d}, J=9.0 \mathrm{~Hz}, 1 \mathrm{H}, \mathrm{H}-5^{\prime}\right), 6.92(\mathrm{~d}, J=8.5 \mathrm{~Hz}, \mathrm{H}-5), 7.16(\mathrm{~d}, J=1.7 \mathrm{~Hz}, 1 \mathrm{H}, \mathrm{H}-2), 7.26(\mathrm{dd}, J=1.7 \mathrm{~Hz}$ and $8.3 \mathrm{~Hz}, 1 \mathrm{H}, \mathrm{H}-6), 7.44(\mathrm{~d}, J=15.4 \mathrm{~Hz}, 1 \mathrm{H}, \mathrm{H}-\alpha), 7.67\left(\mathrm{~d}, J=9.0 \mathrm{~Hz}, 1 \mathrm{H}, \mathrm{H}-6^{\prime}\right), 7.87(\mathrm{~d}, J=15.4 \mathrm{~Hz}, 1 \mathrm{H}$, 
$\mathrm{H}-\beta), 13.37(\mathrm{~s}, 1 \mathrm{H}, \mathrm{OH}) ;{ }^{13} \mathrm{C}-\mathrm{NMR}\left(\mathrm{CDCl}_{3}\right) \delta 55.8,55.9,56.4,60.6,94.4,105.9,109.9,110.8,115.9,117.5$, $123.1,125.2,127.3,137.2,144.7,148.9,151.3,155.5,158.2,192.0$.

2'-Hydroxy-3' , 4'-dimethoxy-4-(methoxymethoxy)chalcone (9g): $(0.32 \mathrm{~g}, 0.93 \mathrm{mmol}, 93 \%$ yield); yellow solid, 92-95 ${ }^{\circ} \mathrm{C} ;{ }^{1} \mathrm{H}-\mathrm{NMR}\left(\mathrm{CDCl}_{3}\right) \delta 3.50\left(\mathrm{~s}, 3 \mathrm{H}, \mathrm{OCH}_{3}\right), 3.93\left(\mathrm{~s}, 3 \mathrm{H}, \mathrm{OCH}_{3}\right), 3.96\left(\mathrm{~s}, 3 \mathrm{H}, \mathrm{OCH}_{3}\right), 5.23$ $\left(\mathrm{s}, 2 \mathrm{H}, \mathrm{OCH}_{2}\right), 6.54\left(\mathrm{~d}, J=9.0 \mathrm{~Hz}, 1 \mathrm{H}, \mathrm{H}-5^{\prime}\right), 7.09(\mathrm{~d}, J=8.8 \mathrm{~Hz}, 2 \mathrm{H}, \mathrm{H}-3$ and H-5), $7.48(\mathrm{~d}, J=15.4 \mathrm{~Hz}$, $1 \mathrm{H}, \mathrm{H}-\alpha), 7.61\left(\mathrm{~d}, J=8.8 \mathrm{~Hz}, 2 \mathrm{H}, \mathrm{H}-2\right.$ and H-6), $7.69\left(\mathrm{~d}, J=9.0 \mathrm{~Hz}, 1 \mathrm{H}, \mathrm{H}-6^{\prime}\right), 7.87(\mathrm{~d}, J=15.4 \mathrm{~Hz}, 1 \mathrm{H}$, $\mathrm{H}-\beta), 13.31$ (s, $1 \mathrm{H}, \mathrm{OH}) ;{ }^{13} \mathrm{C}-\mathrm{NMR}\left(\mathrm{CDCl}_{3}\right) \delta 56.0,56.1,60.5,94.0,102.5,115.4,116.3,117.9,125.6,128.1$, 130.0, 136.4, 144.1, 157.9, 158.0, 159.0, 192.0.

2'-Hydroxy-3', $4^{\prime}$-dimethoxy-3,4-di(methoxymethoxy)chalcone (9h): $(0.38 \mathrm{~g}, 0.93 \mathrm{mmol}, 93 \%$ yield); ${ }^{1} \mathrm{H}-\mathrm{NMR}\left(\mathrm{CDCl}_{3}\right) \delta 3.53\left(\mathrm{~s}, 3 \mathrm{H}, \mathrm{OCH}_{3}\right), 3.56\left(\mathrm{~s}, 3 \mathrm{H}, \mathrm{OCH}_{3}\right), 3.93\left(\mathrm{~s}, 3 \mathrm{H}, \mathrm{OCH}_{3}\right), 3.96\left(\mathrm{~s}, 3 \mathrm{H}, \mathrm{OCH}_{3}\right)$, $5.30\left(\mathrm{~s}, 2 \mathrm{H}, \mathrm{OCH}_{2}\right), 5.31\left(\mathrm{~s}, 2 \mathrm{H}, \mathrm{OCH}_{2}\right), 6.55\left(\mathrm{~d}, J=9.0 \mathrm{~Hz}, 1 \mathrm{H}, \mathrm{H}-5^{\prime}\right), 7.21(\mathrm{~d}, J=8.3 \mathrm{~Hz}, 1 \mathrm{H}, \mathrm{H}-5), 7.29$ $(\mathrm{dd}, J=2.0 \mathrm{~Hz}$ and $8.5 \mathrm{~Hz}, 1 \mathrm{H}, \mathrm{H}-6), 7.45(\mathrm{~d}, J=15.4 \mathrm{~Hz}, 1 \mathrm{H}, \mathrm{H}-\alpha), 7.48(\mathrm{~d}, J=2.0 \mathrm{~Hz}, 1 \mathrm{H}, \mathrm{H}-2), 7.70$ $\left(\mathrm{d}, J=9.0 \mathrm{~Hz}, 1 \mathrm{H}, \mathrm{H}-6^{\prime}\right), 7.84(\mathrm{~d}, J=15.4 \mathrm{~Hz}, 1 \mathrm{H}, \mathrm{H}-\beta), 13.28(\mathrm{~s}, 1 \mathrm{H}, \mathrm{OH}) ;{ }^{13} \mathrm{C}-\mathrm{NMR}\left(\mathrm{CDCl}_{3}\right) \delta 56.0$, 56.2, 60.5, 94.9, 95.3, 102.5, 115.4, 115.8, 115.9, 118.4, 123.9, 125.7, 128.8, 136.4, 144.1, 147.1, 149.3, 157.9, $158.1,191.9$.

2'-Hydroxy-3' , 4'-dimethoxy-2,4-di(methoxymethoxy)chalcone (9i): (0.38 g, $0.93 \mathrm{mmol}, 93 \%$ yield); light yellow solid, $93-95^{\circ} \mathrm{C} ;{ }^{1} \mathrm{H}-\mathrm{NMR}\left(\mathrm{CDCl}_{3}\right) \delta 3.50\left(\mathrm{~s}, 3 \mathrm{H}, \mathrm{OCH}_{3}\right), 3.53\left(\mathrm{~s}, 3 \mathrm{H}, \mathrm{OCH}_{3}\right), 3.93(\mathrm{~s}, 3 \mathrm{H}$, $\left.\mathrm{OCH}_{3}\right), 3.96\left(\mathrm{~s}, 3 \mathrm{H}, \mathrm{OCH}_{3}\right), 5.22\left(\mathrm{~s}, 2 \mathrm{H}, \mathrm{OCH}_{2}\right), 5.29\left(\mathrm{~s}, 2 \mathrm{H}, \mathrm{OCH}_{2}\right), 6.54\left(\mathrm{~d}, J=9.0 \mathrm{~Hz}, 1 \mathrm{H}, \mathrm{H}-5^{\prime}\right), 6.76$ $(\mathrm{dd}, J=2.4 \mathrm{~Hz}$ and $8.8 \mathrm{~Hz}, 1 \mathrm{H}, \mathrm{H}-5), 6.87(\mathrm{~d}, J=2.2 \mathrm{~Hz}, 1 \mathrm{H}, \mathrm{H}-3), 7.59(\mathrm{~d}, J=15.6 \mathrm{~Hz}, 1 \mathrm{H}, \mathrm{H}-\alpha), 7.62$ $(\mathrm{d}, J=8.8 \mathrm{~Hz}, 1 \mathrm{H}, \mathrm{H}-6), 7.69\left(\mathrm{~d}, J=9.0 \mathrm{~Hz}, 1 \mathrm{H}, \mathrm{H}-6^{\prime}\right), 8.22(\mathrm{~d}, J=15.4 \mathrm{~Hz}, 1 \mathrm{H}, \mathrm{H}-\beta), 13.43(\mathrm{~s}, 1 \mathrm{H}, \mathrm{OH})$; ${ }^{13} \mathrm{C}-\mathrm{NMR}\left(\mathrm{CDCl}_{3}\right) \delta 56.0,56.2,56.3,60.5,94.0,94.4,102.4,103.0,109.1,115.5,118.1,118.3,125.5,129.6$, $136.4,139.5,157.6,157.9,157.9,160.2,192.4$.

2'-Hydroxy-3,3' 2 $^{\prime}$-trimethoxy-4-(methoxymethoxy)chalcone $(9 \mathbf{j}):(0.34 \mathrm{~g}, 0.90 \mathrm{mmol}, 90 \%$ yield); ${ }^{1} \mathrm{H}-\mathrm{NMR}\left(\mathrm{CDCl}_{3}\right) \delta 3.53\left(\mathrm{~s}, 3 \mathrm{H}, \mathrm{OCH}_{3}\right), 3.93\left(\mathrm{~s}, 3 \mathrm{H}, \mathrm{OCH}_{3}\right), 3.96\left(\mathrm{~s}, 3 \mathrm{H}, \mathrm{OCH}_{3}\right), 3.97\left(\mathrm{~s}, 3 \mathrm{H}, \mathrm{OCH}_{3}\right), 5.30$ $\left(\mathrm{s}, 2 \mathrm{H}, \mathrm{OCH}_{2}\right), 6.54\left(\mathrm{~d}, J=9.0 \mathrm{~Hz}, 1 \mathrm{H}, \mathrm{H}-5^{\prime}\right), 7.17(\mathrm{~d}, J=2.0 \mathrm{~Hz}, 1 \mathrm{H}, \mathrm{H}-2), 7.20(\mathrm{~d}, J=8.5 \mathrm{~Hz}, 1 \mathrm{H}, \mathrm{H}-5)$, $7.24(\mathrm{dd}, J=1.7 \mathrm{~Hz}$ and $8.3 \mathrm{~Hz}, 1 \mathrm{H}, \mathrm{H}-6), 7.46(\mathrm{~d}, J=15.4 \mathrm{~Hz}, 1 \mathrm{H}, \mathrm{H}-\alpha), 7.70\left(\mathrm{~d}, J=9.0 \mathrm{~Hz}, 1 \mathrm{H}, \mathrm{H}-6^{\prime}\right)$, $7.85(\mathrm{~d}, J=15.4 \mathrm{~Hz}, 1 \mathrm{H}, \mathrm{H}-\beta), 13.30(\mathrm{~s}, 1 \mathrm{H}, \mathrm{OH}) ;{ }^{13} \mathrm{C}-\mathrm{NMR}\left(\mathrm{CDCl}_{3}\right) \delta 55.9,56.0,56.3,60.5,94.9,102.5$, 111.0, 115.4, 115.6, 118.2, 122.4, 125.6, 128.7, 136.4, 144.3, 148.7, 149.5, 157.9, 158.1, 191.9.

2'-Hydroxy-4,3', 4'-trimethoxy-3-(methoxymethoxy)chalcone (9k): (0.36 g, $0.95 \mathrm{mmol}, 95 \%$ yield); ${ }^{1} \mathrm{H}-\mathrm{NMR}\left(\mathrm{CDCl}_{3}\right) \delta 3.57\left(\mathrm{~s}, 3 \mathrm{H}, \mathrm{OCH}_{3}\right), 3.93\left(\mathrm{~s}, 3 \mathrm{H}, \mathrm{OCH}_{3}\right), 3.95\left(\mathrm{~s}, 3 \mathrm{H}, \mathrm{OCH}_{3}\right), 3.96\left(\mathrm{~s}, 3 \mathrm{H}, \mathrm{OCH}_{3}\right), 5.30$ $\left(\mathrm{s}, 2 \mathrm{H}, \mathrm{OCH}_{2}\right), 6.55\left(\mathrm{~d}, J=9.3 \mathrm{~Hz}, 1 \mathrm{H}, \mathrm{H}-5^{\prime}\right), 6.94(\mathrm{~d}, J=8.3 \mathrm{~Hz}, 1 \mathrm{H}, \mathrm{H}-5), 7.31(\mathrm{dd}, J=2.2 \mathrm{~Hz}$ and 8.3 $\mathrm{Hz}, 1 \mathrm{H}, \mathrm{H}-6), 7.44$ (d, J = 15.4 Hz, 1H, H- $\alpha), 7.49(\mathrm{~d}, J=2.2 \mathrm{~Hz}, 1 \mathrm{H}, \mathrm{H}-2), 7.71$ (d, J = 9.0 Hz, 1H, H-6'), $7.85(\mathrm{~d}, J=15.4 \mathrm{~Hz}, 1 \mathrm{H}, \mathrm{H}-\beta), 13.32(\mathrm{~s}, 1 \mathrm{H}, \mathrm{OH}) ;{ }^{13} \mathrm{C}-\mathrm{NMR}\left(\mathrm{CDCl}_{3}\right) \delta 55.9,56.0,56.2,60.5,95.4,102.5$, $111.4,115.0,115.4,117.8,124.5,125.7,127.5,136.4,144.3,146.5,151.9,157.9,158.0,191.9$.

\subsection{The General Procedure for the Synthesis of Flavonols 10a-1}

To a solution of $\mathbf{7 1}$ and $\mathbf{9 a}-\mathbf{k}(1.0 \mathrm{mmol})$ in methanol $(25 \mathrm{~mL})$, a $4 \mathrm{M}$ sodium hydroxide aqueous solution $(0.3 \mathrm{~mL}, 1.2 \mathrm{mmol})$ and a $30 \%$ hydrogen peroxide solution $(0.5 \mathrm{~mL}, 5.0 \mathrm{mmol})$ were added at room temperature. After being stirred at room temperature for $12 \mathrm{~h}$, the mixture was poured into ice and a $2 \mathrm{M}$ hydrochloric acid aqueous solution. The precipitate was filtered, washed with water, and dried in vacuo to produce flavonols 10a-1.

8-Methoxy-7,4'-di(methoxymethoxy)flavonol (10a): (0.20 g, $0.51 \mathrm{mmol}, 51 \%$ yield); ${ }^{1} \mathrm{H}-\mathrm{NMR}\left(\mathrm{CDCl}_{3}\right)$ $\delta 3.51\left(\mathrm{~s}, 3 \mathrm{H}, \mathrm{OCH}_{3}\right), 3.56\left(\mathrm{~s}, 3 \mathrm{H}, \mathrm{OCH}_{3}\right), 4.07\left(\mathrm{~s}, 3 \mathrm{H}, \mathrm{OCH}_{3}\right), 5.26\left(\mathrm{~s}, 2 \mathrm{H}, \mathrm{OCH}_{2}\right), 5.36\left(\mathrm{~s}, 2 \mathrm{H}, \mathrm{OCH}_{2}\right)$, $7.20\left(\mathrm{~d}, J=9.0 \mathrm{~Hz}, 2 \mathrm{H}, \mathrm{H}-3^{\prime}\right.$ and H-5'), $7.26(\mathrm{~d}, J=9.0 \mathrm{~Hz}, 1 \mathrm{H}, \mathrm{H}-6), 7.93(\mathrm{~d}, J=9.0 \mathrm{~Hz}, 1 \mathrm{H}, \mathrm{H}-5), 8.26$ $\left(\mathrm{d}, J=9.0 \mathrm{~Hz}, 2 \mathrm{H}, \mathrm{H}-2^{\prime}\right.$ and $\left.\mathrm{H}-6^{\prime}\right) ;{ }^{13} \mathrm{C}-\mathrm{NMR}\left(\mathrm{CDCl}_{3}\right) \delta 56.1,56.5,61.6,94.1,95.1,113.6,116.0,116.1$, $116.5,120.5,124.7,129.2,129.2,137.2,137.7,144.8,149.7,153.9,158.4,172.7$. 
8-Methoxy-7, $3^{\prime}, 4^{\prime}$-tri(methoxymethoxy)flavonol (10b): (0.16 g, $0.36 \mathrm{mmol}, 36 \%$ yield); ${ }^{1} \mathrm{H}-\mathrm{NMR}\left(\mathrm{CDCl}_{3}\right)$ $\delta 3.55\left(\mathrm{~s}, 3 \mathrm{H}, \mathrm{OCH}_{3}\right), 3.56\left(\mathrm{~s}, 3 \mathrm{H}, \mathrm{OCH}_{3}\right), 3.58\left(\mathrm{~s}, 3 \mathrm{H}, \mathrm{OCH}_{3}\right), 4.08\left(\mathrm{~s}, 3 \mathrm{H}, \mathrm{OCH}_{3}\right), 5.33\left(\mathrm{~s}, 2 \mathrm{H}, \mathrm{OCH}_{2}\right)$, $5.34\left(\mathrm{~s}, 2 \mathrm{H}, \mathrm{OCH}_{2}\right), 5.36\left(\mathrm{~s}, 2 \mathrm{H}, \mathrm{OCH}_{2}\right), 7.09(\mathrm{~s}, 1 \mathrm{H}, \mathrm{OH}), 7.26(\mathrm{~d}, J=9.0 \mathrm{~Hz}, 1 \mathrm{H}, \mathrm{H}-6), 7.32(\mathrm{~d}, J=8.8 \mathrm{~Hz}$, $\left.1 \mathrm{H}, \mathrm{H}-5^{\prime}\right), 7.92(\mathrm{~d}, J=9.3 \mathrm{~Hz}, 1 \mathrm{H}, \mathrm{H}-5), 7.99\left(\mathrm{dd}, J=2.0 \mathrm{~Hz}\right.$ and $\left.8.8 \mathrm{~Hz}, 1 \mathrm{H}, \mathrm{H}-6^{\prime}\right), 8.18(\mathrm{~d}, J=2.0 \mathrm{~Hz}, 1 \mathrm{H}$, $\left.\mathrm{H}-2^{\prime}\right) ;{ }^{13} \mathrm{C}-\mathrm{NMR}\left(\mathrm{CDCl}_{3}\right) \delta 56.2,56.2,56.4,61.5,94.9,95.0,95.5,109.7,113.5,115.8,116.2,120.3,122.5$, $125.1,137.1,137.5,143.9,146.7,148.5,149.6,153.7,172.4$.

8-Methoxy-7, $2^{\prime}, 4^{\prime}$-tri(methoxymethoxy)flavonol (10c): (0.15 g, $0.33 \mathrm{mmol}, 33 \%$ yield); ${ }^{1} \mathrm{H}-\mathrm{NMR}\left(\mathrm{CDCl}_{3}\right)$ $\delta 3.48\left(\mathrm{~s}, 3 \mathrm{H}, \mathrm{OCH}_{3}\right), 3.51\left(\mathrm{~s}, 3 \mathrm{H}, \mathrm{OCH}_{3}\right), 3.55\left(\mathrm{~s}, 3 \mathrm{H}, \mathrm{OCH}_{3}\right), 3.98\left(\mathrm{~s}, 3 \mathrm{H}, \mathrm{OCH}_{3}\right), 5.20\left(\mathrm{~s}, 2 \mathrm{H}, \mathrm{OCH}_{2}\right)$, $5.23\left(\mathrm{~s}, 2 \mathrm{H}, \mathrm{OCH}_{2}\right), 5.34\left(\mathrm{~s}, 2 \mathrm{H}, \mathrm{OCH}_{2}\right), 6.43(\mathrm{~s}, 1 \mathrm{H}, \mathrm{OH}), 6.85\left(\mathrm{dd}, J=2.2 \mathrm{~Hz}\right.$ and $\left.8.5 \mathrm{~Hz}, 1 \mathrm{H}, \mathrm{H}-6^{\prime}\right), 7.00$ $\left(\mathrm{d}, J=2.2 \mathrm{~Hz}, 1 \mathrm{H}, \mathrm{H}-2^{\prime}\right), 7.27(\mathrm{~d}, J=9.0 \mathrm{~Hz}, 1 \mathrm{H}, \mathrm{H}-6), 7.54\left(\mathrm{~d}, J=8.5 \mathrm{~Hz}, 1 \mathrm{H}, \mathrm{H}-5^{\prime}\right), 7.96(\mathrm{~d}, J=9.0 \mathrm{~Hz}$, $1 \mathrm{H}, \mathrm{H}-5) ;{ }^{13} \mathrm{C}-\mathrm{NMR}\left(\mathrm{CDCl}_{3}\right) \delta 56.1,56.4,61.4,94.1,94.9,95.0,104.0,108.8,113.4,114.0,117.0,120.3$, $131.4,137.5,137.8,145.1,150.2,153.4,156.2,159.8,172.4$.

8,3'-Dimethoxy-7,4'-di(methoxymethoxy)flavonol (10d): $\left(0.11 \mathrm{~g}, 0.26 \mathrm{mmol}, 26 \%\right.$ yield); ${ }^{1} \mathrm{H}-\mathrm{NMR}$ $\left(\mathrm{CDCl}_{3}\right) \delta 3.55\left(\mathrm{~s}, 3 \mathrm{H}, \mathrm{OCH}_{3}\right), 3.56\left(\mathrm{~s}, 3 \mathrm{H}, \mathrm{OCH}_{3}\right), 4.00\left(\mathrm{~s}, 3 \mathrm{H}, \mathrm{OCH}_{3}\right), 4.07\left(\mathrm{~s}, 3 \mathrm{H}, \mathrm{OCH}_{3}\right), 5.33(\mathrm{~s}, 2 \mathrm{H}$, $\left.\mathrm{OCH}_{2}\right), 5.36\left(\mathrm{~s}, 2 \mathrm{H}, \mathrm{OCH}_{2}\right), 7.00(\mathrm{~s}, 1 \mathrm{H}, \mathrm{OH}), 7.27(\mathrm{~d}, J=9.0 \mathrm{~Hz}, 1 \mathrm{H}, \mathrm{H}-6), 7.32\left(\mathrm{~d}, J=8.5 \mathrm{~Hz}, 1 \mathrm{H}, \mathrm{H}-5^{\prime}\right)$, $7.90\left(\mathrm{dd}, J=2.0 \mathrm{~Hz}\right.$ and $\left.8.8 \mathrm{~Hz}, 1 \mathrm{H}, \mathrm{H}-6^{\prime}\right), 7.93(\mathrm{~d}, J=9.0 \mathrm{~Hz}, 1 \mathrm{H}, \mathrm{H}-5), 7.95\left(\mathrm{~d}, J=2.0 \mathrm{~Hz}, 1 \mathrm{H}, \mathrm{H}-2^{\prime}\right)$; ${ }^{13} \mathrm{C}-\mathrm{NMR}\left(\mathrm{CDCl}_{3}\right) \delta 55.8,56.2,56.5,61.5,95.0,110.8,113.5,115.5,116.2,120.4,120.8,125.1,137.1,137.4$, $144.1,147.7,149.1,149.5,153.7,172.4$.

8, $4^{\prime}$-Dimethoxy-7, $3^{\prime}$-di(methoxymethoxy)flavonol (10e): $\left(0.27 \mathrm{~g}, 0.65 \mathrm{mmol}, 65 \%\right.$ yield); ${ }^{1} \mathrm{H}-\mathrm{NMR}$ $\left(\mathrm{CDCl}_{3}\right) \delta 3.56\left(\mathrm{~s}, 3 \mathrm{H}, \mathrm{OCH}_{3}\right), 3.58\left(\mathrm{~s}, 3 \mathrm{H}, \mathrm{OCH}_{3}\right), 3.98\left(\mathrm{~s}, 3 \mathrm{H}, \mathrm{OCH}_{3}\right), 4.08\left(\mathrm{~s}, 3 \mathrm{H}, \mathrm{OCH}_{3}\right), 5.34(\mathrm{~s}, 2 \mathrm{H}$, $\left.\mathrm{OCH}_{2}\right), 5.36\left(\mathrm{~s}, 2 \mathrm{H}, \mathrm{OCH}_{2}\right), 6.98(\mathrm{~s}, 1 \mathrm{H}, \mathrm{OH}), 7.06\left(\mathrm{~d}, J=8.8 \mathrm{~Hz}, 1 \mathrm{H}, \mathrm{H}-5^{\prime}\right), 7.26(\mathrm{~d}, J=9.0 \mathrm{~Hz}, 1 \mathrm{H}, \mathrm{H}-6)$, $7.92(\mathrm{~d}, J=9.0 \mathrm{~Hz}, 1 \mathrm{H}, \mathrm{H}-5), 8.04\left(\mathrm{dd}, J=2.2 \mathrm{~Hz}\right.$ and $\left.8.5 \mathrm{~Hz}, 1 \mathrm{H}, \mathrm{H}-6^{\prime}\right), 8.17\left(\mathrm{~d}, J=2.2 \mathrm{~Hz}, 1 \mathrm{H}, \mathrm{H}-2^{\prime}\right)$; ${ }^{13} \mathrm{C}-\mathrm{NMR}\left(\mathrm{CDCl}_{3}\right) \delta 55.9,56.2,56.4,61.5,95.0,95.5,111.3,113.4,115.3,116.3,120.3,122.7,123.8,137.0$, $137.5,144.0,146.1,149.5,151.0,153.7,172.4$.

8, $3^{\prime}, 4^{\prime}$-Trimethoxy-7-(methoxymethoxy)flavonol (10f): ( $0.15 \mathrm{~g}, 0.38 \mathrm{mmol}, 38 \%$ yield); light yellow solid, 163-166 ${ }^{\circ} \mathrm{C} ;{ }^{1} \mathrm{H}-\mathrm{NMR}\left(\mathrm{CDCl}_{3}\right) \delta 3.56\left(\mathrm{~s}, 3 \mathrm{H}, \mathrm{OCH}_{3}\right), 3.98\left(\mathrm{~s}, 3 \mathrm{H}, \mathrm{OCH}_{3}\right), 4.01\left(\mathrm{~s}, 3 \mathrm{H}, \mathrm{OCH}_{3}\right), 4.08$ $\left(\mathrm{s}, 3 \mathrm{H}, \mathrm{OCH}_{3}\right), 5.37\left(\mathrm{~s}, 2 \mathrm{H}, \mathrm{OCH}_{2}\right), 7.00(\mathrm{~s}, 1 \mathrm{H}, \mathrm{OH}), 7.05(\mathrm{~d}, J=8.5 \mathrm{~Hz}, 1 \mathrm{H}, \mathrm{H}-6), 7.28(\mathrm{~d}, J=7.6 \mathrm{~Hz}$, $\left.1 \mathrm{H}, \mathrm{H}-5^{\prime}\right), 7.93\left(\mathrm{~s}, 1 \mathrm{H}, \mathrm{H}-2^{\prime}\right), 7.94(\mathrm{~d}, J=8.8 \mathrm{~Hz}, 1 \mathrm{H}, \mathrm{H}-5), 7.96\left(\mathrm{dd}, J=2.0 \mathrm{~Hz}\right.$ and $\left.8.1 \mathrm{~Hz}, 1 \mathrm{H}, \mathrm{H}-6^{\prime}\right)$; ${ }^{13} \mathrm{C}-\mathrm{NMR}\left(\mathrm{CDCl}_{3}\right) \delta 55.7,55.8,56.5,61.5,94.9,110.1,110.7,113.3,116.2,120.4,121.0,123.6,136.9,137.3$, $144.2,148.4,149.5,150.2,153.6,172.3$.

7,8-Dimethoxy-4'-(methoxymethoxy)flavonol (10g): (0.16 g, $0.45 \mathrm{mmol}, 45 \%$ yield); ${ }^{1} \mathrm{H}-\mathrm{NMR}\left(\mathrm{CDCl}_{3}\right)$ $\delta 3.51\left(\mathrm{~s}, 3 \mathrm{H}, \mathrm{OCH}_{3}\right), 4.02\left(\mathrm{~s}, 3 \mathrm{H}, \mathrm{OCH}_{3}\right), 4.04\left(\mathrm{~s}, 3 \mathrm{H}, \mathrm{OCH}_{3}\right), 5.27\left(\mathrm{~s}, 2 \mathrm{H}, \mathrm{OCH}_{2}\right), 6.94(\mathrm{~s}, 1 \mathrm{H}, \mathrm{OH})$, $7.07(\mathrm{~d}, J=9.0 \mathrm{~Hz}, 1 \mathrm{H}, \mathrm{H}-6), 7.20\left(\mathrm{~d}, J=9.0 \mathrm{~Hz}, 2 \mathrm{H}, \mathrm{H}-3^{\prime}\right.$ and H-5'), $7.97(\mathrm{~d}, J=9.0 \mathrm{~Hz}, 1 \mathrm{H}, \mathrm{H}-5), 8.26$ $\left(\mathrm{d}, J=9.0 \mathrm{~Hz}, 2 \mathrm{H}, \mathrm{H}-2^{\prime}\right.$ and $\left.\mathrm{H}-6^{\prime}\right) ;{ }^{13} \mathrm{C}-\mathrm{NMR}\left(\mathrm{CDCl}_{3}\right) \delta 56.0,56.4,61.4,94.0,109.8,115.4,115.9,120.5$, 124.6, 129.0, 136.7, 144.3, 149.4, 156.0, 158.1, 172.5 .

7,8-Dimethoxy-3' $4^{\prime}$-di(methoxymethoxy)flavonol (10h): $\left(0.12 \mathrm{~g}, 0.28 \mathrm{mmol}, 28 \%\right.$ yield); ${ }^{1} \mathrm{H}-\mathrm{NMR}$ $\left(\mathrm{CDCl}_{3}\right) \delta 3.55\left(\mathrm{~s}, 3 \mathrm{H}, \mathrm{OCH}_{3}\right), 3.58\left(\mathrm{~s}, 3 \mathrm{H}, \mathrm{OCH}_{3}\right), 4.02\left(\mathrm{~s}, 3 \mathrm{H}, \mathrm{OCH}_{3}\right), 4.05\left(\mathrm{~s}, 3 \mathrm{H}, \mathrm{OCH}_{3}\right), 5.33(\mathrm{~s}, 2 \mathrm{H}$, $\left.\mathrm{OCH}_{2}\right), 5.34\left(\mathrm{~s}, 2 \mathrm{H}, \mathrm{OCH}_{2}\right), 6.97(\mathrm{~s}, 1 \mathrm{H}, \mathrm{OH}), 7.07(\mathrm{~d}, J=9.3 \mathrm{~Hz}, 1 \mathrm{H}, \mathrm{H}-6), 7.33\left(\mathrm{~d}, J=8.8 \mathrm{~Hz}, 1 \mathrm{H}, \mathrm{H}-5^{\prime}\right)$, $7.96(\mathrm{~d}, J=9.0 \mathrm{~Hz}, 1 \mathrm{H}, \mathrm{H}-5), 7.98\left(\mathrm{dd}, J=2.2 \mathrm{~Hz}\right.$ and $\left.8.8 \mathrm{~Hz}, 1 \mathrm{H}, \mathrm{H}-6^{\prime}\right), 8.18\left(\mathrm{~d}, J=2.2 \mathrm{~Hz}, 1 \mathrm{H}, \mathrm{H}-2^{\prime}\right)$; ${ }^{13} \mathrm{C}-\mathrm{NMR}\left(\mathrm{CDCl}_{3}\right) \delta 56.2,56.2,56.4,61.4,94.9,95.5,109.8,115.3,115.7,115.8,120.5,122.5,125.2,136.5$, $136.9,143.8,146.7,148.4,149.4,156.1,172.5$.

7,8-Dimethoxy-2' $4^{\prime}$-di(methoxymethoxy)flavonol (10i): $\left(0.07 \mathrm{~g}, 0.17 \mathrm{mmol}, 17 \%\right.$ yield); ${ }^{1} \mathrm{H}-\mathrm{NMR}$ $\left(\mathrm{CDCl}_{3}\right) \delta 3.48\left(\mathrm{~s}, 3 \mathrm{H}, \mathrm{OCH}_{3}\right), 3.51\left(\mathrm{~s}, 3 \mathrm{H}, \mathrm{OCH}_{3}\right), 3.96\left(\mathrm{~s}, 3 \mathrm{H}, \mathrm{OCH}_{3}\right), 4.01\left(\mathrm{~s}, 3 \mathrm{H}, \mathrm{OCH}_{3}\right), 5.20$ $\left(\mathrm{s}, 2 \mathrm{H}, \mathrm{OCH}_{2}\right), 5.23\left(\mathrm{~s}, 2 \mathrm{H}, \mathrm{OCH}_{2}\right), 6.42(\mathrm{~s}, 1 \mathrm{H}, \mathrm{OH}), 6.85\left(\mathrm{dd}, J=2.2 \mathrm{~Hz}\right.$ and $\left.8.8 \mathrm{~Hz}, 1 \mathrm{H}, \mathrm{H}-6^{\prime}\right), 7.00$ $\left(\mathrm{d}, J=2.2 \mathrm{~Hz}, 1 \mathrm{H}, \mathrm{H}-2^{\prime}\right), 7.08(\mathrm{~d}, J=9.0 \mathrm{~Hz}, 1 \mathrm{H}, \mathrm{H}-6), 7.54\left(\mathrm{~d}, J=8.8 \mathrm{~Hz}, 1 \mathrm{H}, \mathrm{H}-5^{\prime}\right), 8.00(\mathrm{~d}, J=9.0 \mathrm{~Hz}$, 1H, H-5); ${ }^{13} \mathrm{C}-\mathrm{NMR}\left(\mathrm{CDCl}_{3}\right) \delta 56.1,56.4,61.3,94.1,94.8,104.0,108.8,109.6,114.0,116.1,120.5,131.4$, $136.5,137.6,145.0,150.0,155.7,156.2,159.8,172.5$. 
7,8,3'-Trimethoxy-4' -(methoxymethoxy)flavonol (10j): (0.22 g, $0.56 \mathrm{mmol}, 56 \%$ yield); ${ }^{1} \mathrm{H}-\mathrm{NMR}\left(\mathrm{CDCl}_{3}\right)$ $\delta 3.55\left(\mathrm{~s}, 3 \mathrm{H}, \mathrm{OCH}_{3}\right), 4.00\left(\mathrm{~s}, 3 \mathrm{H}, \mathrm{OCH}_{3}\right), 4.02\left(\mathrm{~s}, 3 \mathrm{H}, \mathrm{OCH}_{3}\right), 4.05\left(\mathrm{~s}, 3 \mathrm{H}, \mathrm{OCH}_{3}\right), 5.33\left(\mathrm{~s}, 2 \mathrm{H}, \mathrm{OCH}_{2}\right)$, $7.00(\mathrm{~s}, 1 \mathrm{H}, \mathrm{OH}), 7.08(\mathrm{~d}, J=9.0 \mathrm{~Hz}, 1 \mathrm{H}, \mathrm{H}-6), 7.32\left(\mathrm{~d}, J=8.8 \mathrm{~Hz}, 1 \mathrm{H}, \mathrm{H}-5^{\prime}\right), 7.90(\mathrm{dd}, J=2.0 \mathrm{~Hz}$ and $\left.8.8 \mathrm{~Hz}, 1 \mathrm{H}, \mathrm{H}-6^{\prime}\right), 7.95\left(\mathrm{~d}, J=2.0 \mathrm{~Hz}, 1 \mathrm{H}, \mathrm{H}-2^{\prime}\right), 7.97$ (d, J = 9.0 Hz, 1H, H-5); ${ }^{13} \mathrm{C}-\mathrm{NMR}\left(\mathrm{CDCl}_{3}\right) \delta 55.8$, 56.2, 56.4, 61.3, 94.9, 109.8, 110.8, 115.3, 115.4, 120.6, 120.8, 125.1, 136.4, 136.9, 144.0, 147.7, 149.0, 149.4, 156.1, 172.5 .

7,8,4'-Trimethoxy-3'-(methoxymethoxy)flavonol (10k): (0.24 g, $0.61 \mathrm{mmol}, 61 \%$ yield); ${ }^{1} \mathrm{H}-\mathrm{NMR}$ $\left(\mathrm{CDCl}_{3}\right) \delta 3.58\left(\mathrm{~s}, 3 \mathrm{H}, \mathrm{OCH}_{3}\right), 3.98\left(\mathrm{~s}, 3 \mathrm{H}, \mathrm{OCH}_{3}\right), 4.02\left(\mathrm{~s}, 3 \mathrm{H}, \mathrm{OCH}_{3}\right), 4.06\left(\mathrm{~s}, 3 \mathrm{H}, \mathrm{OCH}_{3}\right), 5.34$ $\left(\mathrm{s}, 2 \mathrm{H}, \mathrm{OCH}_{2}\right), 7.00(\mathrm{~s}, 1 \mathrm{H}, \mathrm{OH}), 7.06\left(\mathrm{~d}, J=8.5 \mathrm{~Hz}, 1 \mathrm{H}, \mathrm{H}-5^{\prime}\right), 7.07(\mathrm{~d}, J=9.0 \mathrm{~Hz}, 1 \mathrm{H}, \mathrm{H}-6), 7.96$ $(\mathrm{d}, J=9.0 \mathrm{~Hz}, 1 \mathrm{H}, \mathrm{H}-5), 8.04\left(\mathrm{dd}, J=2.2 \mathrm{~Hz}\right.$ and $\left.8.8 \mathrm{~Hz}, 1 \mathrm{H}, \mathrm{H}-6^{\prime}\right), 8.18\left(\mathrm{~d}, J=2.0 \mathrm{~Hz}, 1 \mathrm{H}, \mathrm{H}-2^{\prime}\right)$; ${ }^{13}$ C-NMR $\left(\mathrm{CDCl}_{3}\right)$ 8 56.0, 56.4, 56.6, 61.6, 95.7, 109.9, 111.4, 115.5, 116.0, 120.7, 122.9, 124.0, 136.6, 137.0, $144.2,146.2,149.5,151.1,156.2,172.6$.

7,8, $3^{\prime}, 4^{\prime}$-Tetramethoxyflavonol (101): $\left(0.12 \mathrm{~g}, 0.33 \mathrm{mmol}, 33 \%\right.$ yield); pale yellow solid, $215-217{ }^{\circ} \mathrm{C}$; ${ }^{1} \mathrm{H}-\mathrm{NMR}\left(\mathrm{CDCl}_{3}\right) \delta 3.98\left(\mathrm{~s}, 3 \mathrm{H}, \mathrm{OCH}_{3}\right), 4.00\left(\mathrm{~s}, 3 \mathrm{H}, \mathrm{OCH}_{3}\right), 4.02\left(\mathrm{~s}, 3 \mathrm{H}, \mathrm{OCH}_{3}\right), 4.05\left(\mathrm{~s}, 3 \mathrm{H}, \mathrm{OCH}_{3}\right), 7.01$ $(\mathrm{s}, 1 \mathrm{H}, \mathrm{OH}), 7.04\left(\mathrm{~d}, J=8.5 \mathrm{~Hz}, 1 \mathrm{H}, \mathrm{H}-5^{\prime}\right), 7.08(\mathrm{~d}, J=9.0 \mathrm{~Hz}, 1 \mathrm{H}, \mathrm{H}-6), 7.92\left(\mathrm{~d}, J=2.0 \mathrm{~Hz}, 1 \mathrm{H}, \mathrm{H}-2^{\prime}\right)$, $7.95\left(\mathrm{dd}, J=2.0 \mathrm{~Hz}\right.$ and $\left.8.1 \mathrm{~Hz}, 1 \mathrm{H}, \mathrm{H}-6^{\prime}\right), 7.97(\mathrm{~d}, J=8.8 \mathrm{~Hz}, 1 \mathrm{H}, \mathrm{H}-5) ;{ }^{13} \mathrm{C}-\mathrm{NMR}\left(\mathrm{CDCl}_{3}\right) \delta 55.7,55.8$, 56.4, 61.3, 109.7, 110.2, 110.7, 115.3, 120.5, 121.0, 123.7, 136.4, 136.7, 144.2, 148.5, 149.3, 150.2, 156.0, 172.4; $\mathrm{UV} /$ Vis $\left(2.1 \times 10^{-5} \mathrm{M}, \mathrm{CHCl}_{3}\right) ; \lambda=363.6 \mathrm{~nm}\left(\varepsilon, 2.8 \times 10^{4}\right)$.

\subsection{The General Procedure for the Deprotection of Flavonols $\mathbf{1 0 a - k}$}

A solution of 10a-k $(1.0 \mathrm{mmol})$ in methanol $(5 \mathrm{~mL})$ and $3 \mathrm{M}$ hydrochloric acid $(5 \mathrm{~mL})$ was refluxed for $1 \mathrm{~h}$. The mixture was extracted with EtOAc. The organic layer was washed with water and brine and dried over anhydrous $\mathrm{MgSO}_{4}$. The solvent was evaporated in vacuo and the residue was chromatographed on a preparative thin layer chromatography (hexane:EtOAc $=2: 3$ ) to produce flavonols 11a-k.

7,4'-Dihydroxy-8-methoxyflavonol (11a): ( $0.18 \mathrm{~g}, 0.45 \mathrm{mmol}, 80 \%$ yield); pale yellowish brown solid, 263-267 ${ }^{\circ} \mathrm{C} ;{ }^{1} \mathrm{H}-\mathrm{NMR}\left(\mathrm{DMSO}-d_{6}\right) \delta 3.93\left(\mathrm{~s}, 3 \mathrm{H}, \mathrm{OCH}_{3}\right), 6.96\left(\mathrm{~d}, J=9.0 \mathrm{~Hz}, 2 \mathrm{H}, \mathrm{H}-3^{\prime}\right.$ and $\left.\mathrm{H}-5^{\prime}\right), 6.98$ $(\mathrm{d}, J=8.8 \mathrm{~Hz}, 1 \mathrm{H}, \mathrm{H}-6), 7.68(\mathrm{~d}, J=8.8 \mathrm{~Hz}, 1 \mathrm{H}, \mathrm{H}-5), 8.06\left(\mathrm{~d}, J=8.8 \mathrm{~Hz}, 2 \mathrm{H}, \mathrm{H}-2^{\prime}\right.$ and $\left.\mathrm{H}-6^{\prime}\right), 9.14(\mathrm{~s}, 1 \mathrm{H}$, $\mathrm{OH}), 10.07$ (s, $1 \mathrm{H}, \mathrm{OH}) ;{ }^{13} \mathrm{C}-\mathrm{NMR}$ (DMSO- $d_{6}$ ) $\delta 60.8,114.6,114.9,115.3,119.8,122.1,128.8,134.4,136.8$, 144.7, 149.1, 154.1, 158.5, 171.8; UV/Vis $\left(2.8 \times 10^{-5} \mathrm{M}, \mathrm{CH}_{3} \mathrm{OH}\right) ; \lambda=358.5 \mathrm{~nm}\left(\varepsilon, 1.8 \times 10^{4}\right)$.

7,3' ${ }^{\prime} 4^{\prime}$-Trihydroxy-8-methoxyflavonol (11b): (0.16 g, $0.49 \mathrm{mmol}, 98 \%$ yield); yellow solid, $257-258{ }^{\circ} \mathrm{C}$; ${ }^{1} \mathrm{H}-\mathrm{NMR}\left(\mathrm{DMSO}-d_{6}\right) \delta 3.94\left(\mathrm{~s}, 3 \mathrm{H}, \mathrm{OCH}_{3}\right), 6.91\left(\mathrm{~d}, J=8.5 \mathrm{~Hz}, 1 \mathrm{H}, \mathrm{H}-5^{\prime}\right), 6.98(\mathrm{~d}, J=9.0 \mathrm{~Hz}, 1 \mathrm{H}, \mathrm{H}-6)$, $7.59\left(\mathrm{dd}, J=2.2\right.$ and $\left.8.5 \mathrm{~Hz}, 1 \mathrm{H}, \mathrm{H}-6^{\prime}\right), 7.67(\mathrm{~d}, J=8.8 \mathrm{~Hz}, 1 \mathrm{H}, \mathrm{H}-5), 7.72\left(\mathrm{~d}, J=2.2 \mathrm{~Hz}, 1 \mathrm{H}, \mathrm{H}-2^{\prime}\right)$, $9.10(\mathrm{~s}, 1 \mathrm{H}, \mathrm{OH}), 9.35(\mathrm{~s}, 1 \mathrm{H}, \mathrm{OH}), 9.52(\mathrm{~s}, 1 \mathrm{H}, \mathrm{OH}), 10.51(\mathrm{~s}, 1 \mathrm{H}, \mathrm{OH}) ;{ }^{13} \mathrm{C}-\mathrm{NMR}\left(\mathrm{DMSO}-d_{6}\right) \delta 60.9$, 114.5, 114.6, 114.9, 115.4, 119.4, 119.8, 122.4, 134.4, 136.8, 144.7, 144.8, 147.0, 149.1, 154.0, 171.7; UV/Vis $\left(2.5 \times 10^{-5} \mathrm{M}, \mathrm{CH}_{3} \mathrm{OH}\right) ; \lambda=366.0 \mathrm{~nm}\left(\varepsilon, 2.1 \times 10^{4}\right)$.

$7,2^{\prime}, 4^{\prime}$-Trihydroxy-8-methoxyflavonol (11c): (0.06 g, $0.18 \mathrm{mmol}, 36 \%$ yield); pale green-yellow solid, $265{ }^{\circ} \mathrm{C}$ (decomp.); ${ }^{1} \mathrm{H}-\mathrm{NMR}$ (DMSO- $\left.d_{6}\right) \delta 3.90\left(\mathrm{~s}, 3 \mathrm{H}, \mathrm{OCH}_{3}\right), 6.17\left(\mathrm{~d}, J=1.7 \mathrm{~Hz}, 1 \mathrm{H}, \mathrm{H}-3^{\prime}\right), 6.31$ $\left(\mathrm{dd}, J=2.0 \mathrm{~Hz}\right.$ and $\left.8.8 \mathrm{~Hz}, 1 \mathrm{H}, \mathrm{H}-5^{\prime}\right), 6.95(\mathrm{~d}, J=8.8 \mathrm{~Hz}, 1 \mathrm{H}, \mathrm{H}-6), 7.52\left(\mathrm{~d}, J=8.3 \mathrm{~Hz}, 1 \mathrm{H}, \mathrm{H}-6^{\prime}\right)$, $7.68(\mathrm{~d}, J=8.8 \mathrm{~Hz}, 1 \mathrm{H}, \mathrm{H}-5), 9.46(\mathrm{~s}, 1 \mathrm{H}, \mathrm{OH}), 10.32(\mathrm{~s}, 1 \mathrm{H}, \mathrm{OH}) ;{ }^{13} \mathrm{C}-\mathrm{NMR}\left(\mathrm{DMSO}-d_{6}\right) \delta 60.8,104.8$, 106.1, 113.2, 114.1, 115.0, 119.7, 127.9, 134.4, 142.9, 146.8, 149.4, 153.1, 159.8, 160.6, 175.9; UV/Vis $\left(2.7 \times 10^{-5} \mathrm{M}, \mathrm{CH}_{3} \mathrm{OH}\right) ; \lambda=395.0 \mathrm{~nm}\left(\varepsilon, 1.5 \times 10^{4}\right)$.

7,4'-Dihydroxy-8,3'-dimethoxyflavonol (11d): (0.14 g, $0.43 \mathrm{mmol}, 85 \%$ yield); pale yellow solid, 281-282 ${ }^{\circ} \mathrm{C} ;{ }^{1} \mathrm{H}-\mathrm{NMR}$ (DMSO-d 6 ) $\delta 3.85\left(\mathrm{~s}, 3 \mathrm{H}, \mathrm{OCH}_{3}\right), 3.95\left(\mathrm{~s}, 3 \mathrm{H}, \mathrm{OCH}_{3}\right), 6.97\left(\mathrm{~d}, J=8.5 \mathrm{~Hz}, 1 \mathrm{H}, \mathrm{H}-5^{\prime}\right)$, $6.99(\mathrm{~d}, J=8.8 \mathrm{~Hz}, 1 \mathrm{H}, \mathrm{H}-6), 7.68(\mathrm{~d}, J=8.8 \mathrm{~Hz}, 1 \mathrm{H}, \mathrm{H}-5), 7.74\left(\mathrm{dd}, J=2.0 \mathrm{~Hz}\right.$ and $\left.8.5 \mathrm{~Hz}, 1 \mathrm{H}, \mathrm{H}-6^{\prime}\right), 7.78$ $\left(\mathrm{d}, J=2.0 \mathrm{~Hz}, 1 \mathrm{H}, \mathrm{H}-2^{\prime}\right), 9.25(\mathrm{~s}, 1 \mathrm{H}, \mathrm{OH}), 9.75(\mathrm{~s}, 1 \mathrm{H}, \mathrm{OH}), 10.56(\mathrm{~s}, 1 \mathrm{H}, \mathrm{OH}) ;{ }^{13} \mathrm{C}-\mathrm{NMR}\left(\mathrm{DMSO}-d_{6}\right)$ 
$\delta 55.6,60.9,111.0,114.7,114.9,115.5,119.9,121.2,122.5,134.4,137.0,144.6,147.2,148.2,149.2,154.2$, 171.9; $\mathrm{UV} / \mathrm{Vis}\left(2.7 \times 10^{-5} \mathrm{M}\right.$, acetone $) ; \lambda=353.0 \mathrm{~nm}\left(\varepsilon, 1.8 \times 10^{4}\right)$.

7,3'-Dihydroxy-8,4'-dimethoxyflavonol (11e): $\left(0.14 \mathrm{~g}, 0.43 \mathrm{mmol}, 86 \%\right.$ yield); yellow solid, $241-244{ }^{\circ} \mathrm{C}$; ${ }^{1} \mathrm{H}-\mathrm{NMR}\left(\mathrm{DMSO}-d_{6}\right) \delta 3.86\left(\mathrm{~s}, 3 \mathrm{H}, \mathrm{OCH}_{3}\right), 3.95\left(\mathrm{~s}, 3 \mathrm{H}, \mathrm{OCH}_{3}\right), 7.00(\mathrm{~d}, J=8.8 \mathrm{~Hz}, 1 \mathrm{H}, \mathrm{H}-6), 7.13$ $\left(\mathrm{d}, J=8.5 \mathrm{~Hz}, 1 \mathrm{H}, \mathrm{H}-5^{\prime}\right), 7.69(\mathrm{~d}, J=8.8 \mathrm{~Hz}, 1 \mathrm{H}, \mathrm{H}-5), 7.71\left(\mathrm{dd}, J=2.2 \mathrm{~Hz}\right.$ and $\left.8.5 \mathrm{~Hz}, 1 \mathrm{H}, \mathrm{H}-6^{\prime}\right), 7.74$ $\left(\mathrm{d}, J=2.2 \mathrm{~Hz}, 1 \mathrm{H}, \mathrm{H}-2^{\prime}\right), 9.21(\mathrm{~s}, 1 \mathrm{H}, \mathrm{OH}), 9.39(\mathrm{~s}, 1 \mathrm{H}, \mathrm{OH}), 10.54(\mathrm{~s}, 1 \mathrm{H}, \mathrm{OH}) ;{ }^{13} \mathrm{C}-\mathrm{NMR}\left(\mathrm{DMSO}-d_{6}\right)$ $\delta 55.5,60.9,111.7,114.2,114.7,114.9,119.1,119.8,123.9,134.4,137.2,144.2,146.0,148.7,149.1,154.1$, 171.8; UV/Vis $\left(2.8 \times 10^{-5} \mathrm{M}, \mathrm{CH}_{3} \mathrm{OH}\right) ; \lambda=361.5 \mathrm{~nm}\left(\varepsilon, 2.2 \times 10^{4}\right)$.

7-Hydroxy-8, $3^{\prime}, 4^{\prime}$-trimethoxyflavonol (11f): $\left(0.07 \mathrm{~g}, 0.19 \mathrm{mmol}, 38 \%\right.$ yield); ocher solid, $202-206{ }^{\circ} \mathrm{C}$; ${ }^{1} \mathrm{H}-\mathrm{NMR}\left(\mathrm{DMSO}-d_{6}\right) \delta 3.85\left(\mathrm{~s}, 3 \mathrm{H}, \mathrm{OCH}_{3}\right), 3.86\left(\mathrm{~s}, 3 \mathrm{H}, \mathrm{OCH}_{3}\right), 3.96\left(\mathrm{~s}, 3 \mathrm{H}, \mathrm{OCH}_{3}\right), 7.00(\mathrm{~d}, J=8.8 \mathrm{~Hz}$, $1 \mathrm{H}, \mathrm{H}-6), 7.18\left(\mathrm{~d}, J=8.5 \mathrm{~Hz}, 1 \mathrm{H}, \mathrm{H}-5^{\prime}\right), 7.69(\mathrm{~d}, J=8.8 \mathrm{~Hz}, 1 \mathrm{H}, \mathrm{H}-5), 7.80\left(\mathrm{~d}, J=2.0 \mathrm{~Hz}, 1 \mathrm{H}, \mathrm{H}-2^{\prime}\right), 7.85$ $\left(\mathrm{dd}, J=2.0 \mathrm{~Hz}\right.$ and $\left.8.5 \mathrm{~Hz}, 1 \mathrm{H}, \mathrm{H}-6^{\prime}\right), 9.29(\mathrm{~s}, 1 \mathrm{H}, \mathrm{OH}), 10.56(\mathrm{~s}, 1 \mathrm{H}, \mathrm{OH}) ;{ }^{13} \mathrm{C}-\mathrm{NMR}\left(\mathrm{DMSO}-d_{6}\right) \delta 55.4$, 55.6, 60.8, 110.3, 111.5, 114.8, 114.9, 119.9, 120.8, 123.8, 134.4, 137.4, 144.1, 148.2, 149.2, 149.8, 154.3, 171.9; $\mathrm{UV} / \mathrm{Vis}\left(2.4 \times 10^{-5} \mathrm{M}, \mathrm{CHCl}_{3}\right) ; \lambda=359.0 \mathrm{~nm}\left(\varepsilon, 1.9 \times 10^{4}\right)$.

4'-Hydroxy-7,8,dimethoxyflavonol (11g): (0.09 $\mathrm{g}, 0.29 \mathrm{mmol}, 57 \%$ yield); pale yellow solid, $235-236$ ${ }^{\circ} \mathrm{C} ;{ }^{1} \mathrm{H}-\mathrm{NMR}$ (DMSO- $\left.d_{6}\right) \delta 3.93\left(\mathrm{~s}, 3 \mathrm{H}, \mathrm{OCH}_{3}\right), 3.96\left(\mathrm{~s}, 3 \mathrm{H}, \mathrm{OCH}_{3}\right), 6.97\left(\mathrm{~d}, J=8.8 \mathrm{~Hz}, 2 \mathrm{H}, \mathrm{H}-3^{\prime}\right.$ and H-5') $7.27(\mathrm{~d}, J=9.0 \mathrm{~Hz}, 1 \mathrm{H}, \mathrm{H}-6), 7.83(\mathrm{~d}, J=9.0 \mathrm{~Hz}, 1 \mathrm{H}, \mathrm{H}-5), 8.08\left(\mathrm{~d}, J=8.8 \mathrm{~Hz}, 2 \mathrm{H}, \mathrm{H}-2^{\prime}\right.$ and H-6' $), 9.26(\mathrm{~s}, 1 \mathrm{H}, \mathrm{OH}), 10.12(\mathrm{~s}, 1 \mathrm{H}, \mathrm{OH}) ;{ }^{13} \mathrm{C}-\mathrm{NMR}$ (DMSO-d $\left.\mathrm{d}_{6}\right) \delta 56.5,61.0,110.4,115.3,116.1,119.9$, 122.0, 129.0, 135.9, $136.9145 .3,148.4,155.5,158.7,171.9 ; \mathrm{UV} / \mathrm{Vis}\left(2.7 \times 10^{-5} \mathrm{M}, \mathrm{CH}_{3} \mathrm{OH}\right) ; \lambda=361.5 \mathrm{~nm}$ $\left(\varepsilon, 2.5 \times 10^{4}\right)$.

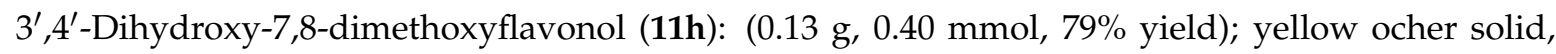
261-263 ${ }^{\circ} \mathrm{C} ;{ }^{1} \mathrm{H}-\mathrm{NMR}\left(\mathrm{DMSO}-d_{6}\right) \delta 3.84\left(\mathrm{~s}, 3 \mathrm{H}, \mathrm{OCH}_{3}\right), 3.94\left(\mathrm{~s}, 3 \mathrm{H}, \mathrm{OCH}_{3}\right), 6.37(\mathrm{dd}, J=2.0 \mathrm{~Hz}$ and $\left.8.3 \mathrm{~Hz}, 1 \mathrm{H}, \mathrm{H}-5^{\prime}\right), 6.42\left(\mathrm{~d}, J=2.0 \mathrm{~Hz}, 1 \mathrm{H}, \mathrm{H}-3^{\prime}\right), 7.25(\mathrm{~d}, J=9.0 \mathrm{~Hz}, 1 \mathrm{H}, \mathrm{H}-6), 7.26(\mathrm{~d}, J=8.3 \mathrm{~Hz}, 1 \mathrm{H}$, H-6 $\left.{ }^{\prime}\right), 7.83(\mathrm{~d}, J=9.0 \mathrm{~Hz}, 1 \mathrm{H}, \mathrm{H}-5), 9.68(\mathrm{~s}, 1 \mathrm{H}, \mathrm{OH}), 9.78(\mathrm{~s}, 1 \mathrm{H}, \mathrm{OH}) ;{ }^{13} \mathrm{C}-\mathrm{NMR}$ (DMSO- $\left.d_{6}\right) \delta 56.4,60.9$, $102.9,106.6,109.5,110.3,116.8,119.9,131.6,136.0,137.4,147.5,149.2,155.3,156.7,160.1,172.1$; UV/Vis $\left(2.5 \times 10^{-5} \mathrm{M}, \mathrm{CH}_{3} \mathrm{OH}\right) ; \lambda=369.0 \mathrm{~nm}\left(\varepsilon, 2.4 \times 10^{4}\right)$.

$2^{\prime}, 4^{\prime}$-Dihydroxy-7,8,3'-trimethoxyflavonol (11i): (0.07 g, $0.22 \mathrm{mmol}, 43 \%$ yield); red-clay solid, $192-196^{\circ} \mathrm{C}$; ${ }^{1} \mathrm{H}-\mathrm{NMR}\left(\mathrm{DMSO}-\mathrm{d}_{6}\right) \delta 3.95\left(\mathrm{~s}, 3 \mathrm{H}, \mathrm{OCH}_{3}\right), 3.96\left(\mathrm{~s}, 3 \mathrm{H}, \mathrm{OCH}_{3}\right), 6.92\left(\mathrm{~d}, J=8.5 \mathrm{~Hz}, 1 \mathrm{H}, \mathrm{H}-5^{\prime}\right), 7.26$ $(\mathrm{d}, J=9.0 \mathrm{~Hz}, 1 \mathrm{H}, \mathrm{H}-6), 7.62\left(\mathrm{dd}, J=2.0 \mathrm{~Hz}\right.$ and $\left.8.5 \mathrm{~Hz}, 1 \mathrm{H}, \mathrm{H}-6^{\prime}\right), 7.75\left(\mathrm{~d}, J=2.0 \mathrm{~Hz}, 1 \mathrm{H}, \mathrm{H}-2^{\prime}\right), 7.82$ $(\mathrm{d}, J=9.0 \mathrm{~Hz}, 1 \mathrm{H}, \mathrm{H}-5), 9.22$ (s, $1 \mathrm{H}, \mathrm{OH}), 9.40(\mathrm{~s}, 1 \mathrm{H}, \mathrm{OH}), 9.56(\mathrm{~s}, 1 \mathrm{H}, \mathrm{OH}) ;{ }^{13} \mathrm{C}-\mathrm{NMR}$ (DMSO-d 6 ) $\delta 56.4$, 61.1, 110.3, 114.6, 115.4, 116.0, 119.6, 119.9, 122.3, 135.8, 136.9, 144.8, 145.2, 147.2, 148.3, 155.4, 171.8.

4'-Hydroxy-7,8,3'-trimethoxyflavonol (11j): (0.08 g, $0.24 \mathrm{mmol}, 48 \%$ yield); ocher solid, $177-181^{\circ} \mathrm{C}$; ${ }^{1} \mathrm{H}-\mathrm{NMR}\left(\mathrm{CDCl}_{3}\right) \delta 4.01\left(\mathrm{~s}, 3 \mathrm{H}, \mathrm{OCH}_{3}\right), 4.02\left(\mathrm{~s}, 3 \mathrm{H}, \mathrm{OCH}_{3}\right), 4.05\left(\mathrm{~s}, 3 \mathrm{H}, \mathrm{OCH}_{3}\right), 6.01(\mathrm{~s}, 1 \mathrm{H}, \mathrm{OH}), 7.00$ $(\mathrm{s}, 1 \mathrm{H}, \mathrm{OH}), 7.07(\mathrm{~d}, J=9.0 \mathrm{~Hz}, 1 \mathrm{H}, \mathrm{H}-6), 7.09\left(\mathrm{~d}, J=8.3 \mathrm{~Hz}, 1 \mathrm{H}, \mathrm{H}-5^{\prime}\right), 7.88(\mathrm{dd}, J=2.0 \mathrm{~Hz}$ and $8.5 \mathrm{~Hz}$, $\left.1 \mathrm{H}, \mathrm{H}-6^{\prime}\right), 7.93\left(\mathrm{~d}, J=2.0 \mathrm{~Hz}, 1 \mathrm{H}, \mathrm{H}-2^{\prime}\right), 7.97(\mathrm{~d}, J=9.0 \mathrm{~Hz}, 1 \mathrm{H}, \mathrm{H}-5) ;{ }^{13} \mathrm{C}-\mathrm{NMR}\left(\mathrm{CDCl}_{3}\right) \delta 55.8,56.4$, 61.3, 109.7, 109.9, 114.4, 115.3, 120.5, 121.4, 123.2, 136.4, 136.6, 144.3, 146.1, 147.1, 149.3, 156.0, 172.4; $\mathrm{UV} / \mathrm{Vis}\left(2.8 \times 10^{-5} \mathrm{M}, \mathrm{CHCl}_{3}\right) ; \lambda=362.5 \mathrm{~nm}\left(\varepsilon, 2.3 \times 10^{4}\right)$.

3'-Hydroxy-7,8,4'-trimethoxyflavonol (11k): ( $0.09 \mathrm{~g}, 0.27 \mathrm{mmol}, 53 \%$ yield); pale yellow solid, $231-234{ }^{\circ} \mathrm{C}$; ${ }^{1} \mathrm{H}-\mathrm{NMR}\left(\mathrm{DMSO}_{6}\right) \delta 3.86\left(\mathrm{~s}, 3 \mathrm{H}, \mathrm{OCH}_{3}\right), 3.95\left(\mathrm{~s}, 3 \mathrm{H}, \mathrm{OCH}_{3}\right), 3.97\left(\mathrm{~s}, 3 \mathrm{H}, \mathrm{OCH}_{3}\right), 7.13(\mathrm{~d}, J=8.5 \mathrm{~Hz}, 1 \mathrm{H}$, $\left.\mathrm{H}-5^{\prime}\right), 7.27(\mathrm{~d}, J=9.0 \mathrm{~Hz}, 1 \mathrm{H}, \mathrm{H}-6), 7.72\left(\mathrm{dd}, J=2.2 \mathrm{~Hz}\right.$ and $\left.8.5 \mathrm{~Hz}, 1 \mathrm{H}, \mathrm{H}-6^{\prime}\right), 7.75\left(\mathrm{~d}, J=2.2 \mathrm{~Hz}, 1 \mathrm{H}, \mathrm{H}-2^{\prime}\right)$, $7.83(\mathrm{~d}, J=9.0 \mathrm{~Hz}, 1 \mathrm{H}, \mathrm{H}-5), 9.33(\mathrm{~s}, 1 \mathrm{H}, \mathrm{OH}), 9.42(\mathrm{~s}, 1 \mathrm{H}, \mathrm{OH}) ;{ }^{13} \mathrm{C}-\mathrm{NMR}$ (DMSO-d $\left.d_{6}\right) \delta 55.5,56.4,61.0$, $110.3,111.7,114.2,116.0,119.3,119.9,123.8,135.8,137.3,144.7,146.0,148.4,148.8,155.5,171.9$; UV/Vis $\left(2.3 \times 10^{-5} \mathrm{M}, \mathrm{CHCl}_{3}\right) ; \lambda=360.5 \mathrm{~nm}\left(\varepsilon, 2.6 \times 10^{4}\right)$.

\subsection{The General Procedure for the Preparation of 4-Chloroacetylpyrogallols 12a, $\mathbf{b}$}

Chloroacetyl chloride $(4.3 \mathrm{~mL}, 54.0 \mathrm{mmol})$ was added to a suspension of anhydrous aluminum chloride $(8.00 \mathrm{~g}, 60.0 \mathrm{mmol})$ and 1,2-dichloroethane $(100 \mathrm{~mL})$ was added under an argon atmosphere 
at room temperature. A solution of $\mathbf{1 a}, \mathbf{b}(30.0 \mathrm{mmol})$ in 1,2-dichloroethane $(30 \mathrm{~mL})$ was added to the mixture and the reaction mixture was stirred at room temperature for $12 \mathrm{~h}$. The mixture was poured into ice and a $2 \mathrm{M} \mathrm{HCl}$ solution and extracted with $\mathrm{CHCl}$. The organic layer was washed with water and dried over anhydrous $\mathrm{MgSO}_{4}$. The solvent was evaporated in vacuo and the residue was chromatographed on silica gel with $\mathrm{CHCl}_{3}-\mathrm{Et}_{2} \mathrm{O}(9: 1)$ to produce 12a,b.

1-Chloroacetyl-2,4-dihydroxy-3-methoxybenzene (12a): (3.77 g, $17.4 \mathrm{mmol}, 58 \%$ yield); ${ }^{1} \mathrm{H}-\mathrm{NMR}\left(\mathrm{CDCl}_{3}\right)$ $\delta 4.00\left(\mathrm{~s}, 3 \mathrm{H}, \mathrm{OCH}_{3}\right), 4.64(\mathrm{~s}, 2 \mathrm{H}, \mathrm{CH} 2), 6.56(\mathrm{~d}, J=9.0 \mathrm{~Hz}, 1 \mathrm{H}, \mathrm{H}-5), 6.57(\mathrm{~s}, 1 \mathrm{H}, \mathrm{OH}), 7.41(\mathrm{~d}, J=9.0 \mathrm{~Hz}$, $1 \mathrm{H}, \mathrm{H}-6), 12.24$ (s, $1 \mathrm{H}, \mathrm{OH}) ;{ }^{13} \mathrm{C}-\mathrm{NMR}\left(\mathrm{CDCl}_{3}\right) \delta$ 44.8, 60.9, 107.2, 112.2, 126.3, 134.3, 155.9, 156.8, 195.2.

1-Chloroacetyl-2-hydroxy-3,4-dimethoxybenzene (12b): (3.74 g, $16.2 \mathrm{mmol}, 54 \%$ yield); colorless solid, 155-158 ${ }^{\circ} \mathrm{C} ;{ }^{1} \mathrm{H}-\mathrm{NMR}\left(\mathrm{CDCl}_{3}\right) \delta 3.89\left(\mathrm{~s}, 3 \mathrm{H}, \mathrm{OCH}_{3}\right), 3.95\left(\mathrm{~s}, 3 \mathrm{H}, \mathrm{OCH}_{3}\right), 4.65(\mathrm{~s}, 2 \mathrm{H}, \mathrm{CH} 2), 6.54$ $(\mathrm{d}, J=9.0 \mathrm{~Hz}, 1 \mathrm{H}, \mathrm{H}-5), 7.49(\mathrm{~d}, J=9.0 \mathrm{~Hz}, 1 \mathrm{H}, \mathrm{H}-6), 11.85(\mathrm{~s}, 1 \mathrm{H}, \mathrm{OH}) ;{ }^{13} \mathrm{C}-\mathrm{NMR}\left(\mathrm{CDCl}_{3}\right) \delta$ 45.0, 56.2, $60.7,103.5,112.7,126.1,136.6,157.2,159.1,195.0$.

\subsection{The General Procedure for the Preparation of Benzofuranones $\mathbf{1 3 a}, \mathbf{b}$}

A solution of 12a,b $(20.0 \mathrm{mmol})$ and sodium acetate $(6.56 \mathrm{~g}, 80.0 \mathrm{mmol}$ or $3.28 \mathrm{~g}, 40.0 \mathrm{mmol})$ in methanol $(100 \mathrm{~mL})$ was refluxed for $2 \mathrm{~h}$. Water was added to the mixture and extracted with $\mathrm{Et}_{2} \mathrm{O}$. The organic layer was washed with brine and dried over anhydrous $\mathrm{MgSO}_{4}$. The solvent was evaporated in vacuo and the residue was chromatographed on silica gel with $\mathrm{CHCl}_{3}-\mathrm{Et}_{2} \mathrm{O}$ (9:1) to produce $13 \mathbf{a}, \mathbf{b}$.

6-Hydroxy-7-methoxy-3(2H)-benzofuranone (13a): (2.77 g, $15.4 \mathrm{mmol}, 77 \%$ yield); ${ }^{1} \mathrm{H}-\mathrm{NMR}$ (DMSO- $d_{6}$ ) $\delta 3.89\left(\mathrm{~s}, 3 \mathrm{H}, \mathrm{OCH}_{3}\right), 4.76\left(\mathrm{~s}, 2 \mathrm{H}, \mathrm{CH}_{2}\right), 6.85(\mathrm{~d}, J=8.5 \mathrm{~Hz}, 1 \mathrm{H}, \mathrm{H}-5), 7.12(\mathrm{~d}, J=8.5 \mathrm{~Hz}, 1 \mathrm{H}, \mathrm{H}-4), 9.37$ (s, 1H, OH); ${ }^{13} \mathrm{C}-\mathrm{NMR}$ (DMSO- $\left.d_{6}\right) \delta 56.5,75.2,107.4,113.7,115.5,131.7,154.6,162.1,198.0$.

6,7-Dimethoxy-3(2H)-benzofuranone (13b): (3.22 g, $16.6 \mathrm{mmol}, 83 \%$ yield); reddish yellow solid, 119-123 ${ }^{\circ} \mathrm{C} ;{ }^{1} \mathrm{H}-\mathrm{NMR}\left(\mathrm{CDCl}_{3}\right) \delta 3.97\left(\mathrm{~s}, 3 \mathrm{H}, \mathrm{OCH}_{3}\right), 4.01\left(\mathrm{~s}, 3 \mathrm{H}, \mathrm{OCH}_{3}\right), 4.67\left(\mathrm{~s}, 2 \mathrm{H}, \mathrm{CH}_{2}\right), 6.72$ $(\mathrm{d}, J=8.5 \mathrm{~Hz}, 1 \mathrm{H}, \mathrm{H}-5), 7.41(\mathrm{~d}, J=8.5 \mathrm{~Hz}, 1 \mathrm{H}, \mathrm{H}-4) ;{ }^{13} \mathrm{C}-\mathrm{NMR}\left(\mathrm{CDCl}_{3}\right) \delta 56.7,61.0,75.5,107.3,116.3$, $119.1,134.2,159.4,166.0,197.8$.

\subsection{The General Procedure for the Protection of 13a with a Chloromethyl Methyl Ether}

A solution of 13a $(0.90 \mathrm{~g}, 5.0 \mathrm{mmol})$ in DMF $(5 \mathrm{~mL})$ was added to a suspension of sodium hydride $(60 \%$ in mineral oil, $0.24 \mathrm{~g}, 6.0 \mathrm{mmol})$ in DMF $(15 \mathrm{~mL})$ at $0{ }^{\circ} \mathrm{C}$. After being stirred at room temperature for $30 \mathrm{~min}$, a chloromethyl methyl ether $(0.57 \mathrm{~mL}, 7.5 \mathrm{mmol})$ was added to the mixture at $0{ }^{\circ} \mathrm{C}$. After being stirred at room temperature for $6 \mathrm{~h}, \mathrm{Et}_{2} \mathrm{O}(20 \mathrm{~mL})$ was added to the mixture. The reaction mixture was poured into ice water $(200 \mathrm{~mL})$. The mixture was extracted with $\mathrm{Et}_{2} \mathrm{O}$. The organic layer was washed with water and brine and dried over anhydrous $\mathrm{MgSO}_{4}$. The solvent was evaporated in vacuo and the residue was chromatographed on silica gel with $\mathrm{CHCl}_{3}-\mathrm{Et}_{2} \mathrm{O}(9: 1)$ to produce $13 \mathrm{c}$.

7-Methoxy-6-(methoxymethoxy)-3(2H)-benzofuranone (13c): (0.81 g, $3.6 \mathrm{mmol}, 72 \%$ yield); dark brown solid, 203-210 ${ }^{\circ} \mathrm{C} ;{ }^{1} \mathrm{H}-\mathrm{NMR}\left(\mathrm{CDCl}_{3}\right) \delta 3.53\left(\mathrm{~s}, 3 \mathrm{H}, \mathrm{OCH}_{3}\right), 4.03\left(\mathrm{~s}, 3 \mathrm{H}, \mathrm{OCH}_{3}\right), 4.68\left(\mathrm{~s}, 2 \mathrm{H}, \mathrm{OCH}_{2}\right), 5.32$ $\left(\mathrm{s}, 2 \mathrm{H}, \mathrm{OCH}_{2}\right), 6.94(\mathrm{~d}, J=8.5 \mathrm{~Hz}, 1 \mathrm{H}, \mathrm{H}-5), 7.37(\mathrm{~d}, J=8.5 \mathrm{~Hz}, 1 \mathrm{H}, \mathrm{H}-4) ;{ }^{13} \mathrm{C}-\mathrm{NMR}\left(\mathrm{CDCl}_{3}\right) \delta 56.6,61.0$, 75.4, 95.0, 110.8, 117.0, 118.8, 156.9, 166.3, 197.9.

\subsection{The General Procedure for the Synthesis of Aurones 14a-1}

Aluminum oxide (basic, $2.00 \mathrm{~g}, 19.6 \mathrm{mmol}$ ) was added to a solution of benzofuranones $\mathbf{1 3 b}$,c $(1.0 \mathrm{mmol})$ and benzaldehydes $\mathbf{5 a}-\mathbf{f}(1.2 \mathrm{mmol})$ in dichloromethane $(5 \mathrm{~mL})$. The mixture was thoroughly stirred for 2 days at room temperature. The suspension was filtered off and the residue was washed with $\mathrm{CHCl}_{3}$. The filtrate was concentrated in vacuo and the residue was chromatographed on a preparative thin layer chromatography $\left(\mathrm{CHCl}_{3}: \mathrm{Et}_{2} \mathrm{O}=9: 1\right)$ to produce $(\mathrm{Z})$-aurones 14a-1. 
(Z)-7-Methoxy-6,4'-di(methoxymethoxy)aurone (14a): (0.32 g, $0.86 \mathrm{mmol}, 86 \%$ yield); reddish yellow solid, 92-94 ${ }^{\circ} \mathrm{C} ;{ }^{1} \mathrm{H}-\mathrm{NMR}\left(\mathrm{CDCl}_{3}\right) \delta 3.50\left(\mathrm{~s}, 3 \mathrm{H}, \mathrm{OCH}_{3}\right), 3.55\left(\mathrm{~s}, 3 \mathrm{H}, \mathrm{OCH}_{3}\right), 4.19\left(\mathrm{~s}, 3 \mathrm{H}, \mathrm{OCH}_{3}\right), 5.24$ $\left(\mathrm{s}, 2 \mathrm{H}, \mathrm{OCH}_{2}\right), 5.33\left(\mathrm{~s}, 2 \mathrm{H}, \mathrm{OCH}_{2}\right), 6.84(\mathrm{~s}, 1 \mathrm{H}, \mathrm{H}-10), 7.03(\mathrm{~d}, J=8.5 \mathrm{~Hz}, 1 \mathrm{H}, \mathrm{H}-5), 7.12(\mathrm{~d}, J=9.0 \mathrm{~Hz}$, 2H, H-3' and H-5'), $7.48(\mathrm{~d}, J=8.3 \mathrm{~Hz}, 1 \mathrm{H}, \mathrm{H}-4), 7.87\left(\mathrm{~d}, J=8.8 \mathrm{~Hz}, 2 \mathrm{H}, \mathrm{H}-2^{\prime}\right.$ and $\left.\mathrm{H}-6^{\prime}\right) ;{ }^{13} \mathrm{C}-\mathrm{NMR} \delta$ $\left(\mathrm{CDCl}_{3}\right)$ 56.1, 56.5, 61.0, 93.9, 95.1, 111.7, 112.2, 116.3, 117.6, 119.0, 125.7, 132.7, 134.6, 146.1, 155.9, 157.4, 158.1, 182.7.

(Z)-7-Methoxy-6, $3^{\prime}, 4^{\prime}$-tri(methoxymethoxy)aurone (14b): $(0.23 \mathrm{~g}, 0.54 \mathrm{mmol}, 54 \%$ yield); light yellow solid, 85-86 ${ }^{\circ} \mathrm{C} ;{ }^{1} \mathrm{H}-\mathrm{NMR}\left(\mathrm{CDCl}_{3}\right) \delta 3.54\left(\mathrm{~s}, 3 \mathrm{H}, \mathrm{OCH}_{3}\right), 3.55\left(\mathrm{~s}, 3 \mathrm{H}, \mathrm{OCH}_{3}\right), 3.56\left(\mathrm{~s}, 3 \mathrm{H}, \mathrm{OCH}_{3}\right), 4.21$ $\left(\mathrm{s}, 3 \mathrm{H}, \mathrm{OCH}_{3}\right), 5.32\left(\mathrm{~s}, 4 \mathrm{H}, \mathrm{OCH}_{2}\right), 5.34\left(\mathrm{~s}, 2 \mathrm{H}, \mathrm{OCH}_{2}\right), 6.82(\mathrm{~s}, 1 \mathrm{H}, \mathrm{H}-10), 7.04(\mathrm{~d}, J=8.5 \mathrm{~Hz}, 1 \mathrm{H}, \mathrm{H}-5)$, $7.24\left(\mathrm{~d}, J=8.5 \mathrm{~Hz}, 1 \mathrm{H}, \mathrm{H}-5^{\prime}\right), 7.47\left(\mathrm{dd}, J=2.0 \mathrm{~Hz}\right.$ and $\left.8.3 \mathrm{~Hz}, 1 \mathrm{H}, \mathrm{H}-6^{\prime}\right), 7.48(\mathrm{~d}, J=8.5 \mathrm{~Hz}, 1 \mathrm{H}, \mathrm{H}-4)$, $7.88\left(\mathrm{~d}, J=2.0 \mathrm{~Hz}, 1 \mathrm{H}, \mathrm{H}-2^{\prime}\right) ;{ }^{13} \mathrm{C}-\mathrm{NMR}\left(\mathrm{CDCl}_{3}\right) \delta 56.1,56.2,56.5,61.0,94.7,95.0,95.1,111.5,112.2$, $115.7,117.5,118.4,118.9,126.2,126.5,134.5,146.1,146.8,148.3,155.8,157.3,182.8$.

(Z)-7-Methoxy-6,2', 4'-tri(methoxymethoxy)aurone (14c): (0.29 g, $0.67 \mathrm{mmol}, 67 \%$ yield); yellow solid, $105-110{ }^{\circ} \mathrm{C} ;{ }^{1} \mathrm{H}-\mathrm{NMR}\left(\mathrm{CDCl}_{3}\right) \delta 3.50\left(\mathrm{~s}, 3 \mathrm{H}, \mathrm{OCH}_{3}\right), 3.52\left(\mathrm{~s}, 3 \mathrm{H}, \mathrm{OCH}_{3}\right), 3.67\left(\mathrm{~s}, 3 \mathrm{H}, \mathrm{OCH}_{3}\right), 3.99(\mathrm{~s}, 3 \mathrm{H}$, $\left.\mathrm{OCH}_{3}\right), 5.22\left(\mathrm{~s}, 2 \mathrm{H}, \mathrm{OCH}_{2}\right), 5.27\left(\mathrm{~s}, 2 \mathrm{H}, \mathrm{OCH}_{2}\right), 5.33\left(\mathrm{~s}, 2 \mathrm{H}, \mathrm{OCH}_{2}\right), 6.78(\mathrm{dd}, J=2.2 \mathrm{~Hz}$ and $9.0 \mathrm{~Hz}, 1 \mathrm{H}$, H-5') 6.81, (d, J = 8.8 Hz, 1H, H-5), $6.87\left(\mathrm{~d}, J=2.2 \mathrm{~Hz}, 1 \mathrm{H}, \mathrm{H}-3^{\prime}\right), 7.38$ (s, 1H, H-10), 7.58 (d, J = $8.5 \mathrm{~Hz}$, $1 \mathrm{H}, \mathrm{H}-4), 8.27$ (d, $\left.J=8.8 \mathrm{~Hz}, 1 \mathrm{H}, \mathrm{H}-6{ }^{\prime}\right) ;{ }^{13} \mathrm{C}-\mathrm{NMR}\left(\mathrm{CDCl}_{3}\right) \delta 56.2,56.3,56.5,61.0,93.9,94.4,95.1,102.7$, $106.5,109.1,111.4,115.5,117.8,118.9,132.4,133.6,146.2,155.6,157.2,157.6,159.5,182.8$.

(Z)-7,3'-Dimethoxy-6,4'-di(methoxymethoxy)aurone (14d): (0.28 g, $0.69 \mathrm{mmol}, 69 \%$ yield); reddish yellow solid, $95-100{ }^{\circ} \mathrm{C} ;{ }^{1} \mathrm{H}-\mathrm{NMR}\left(\mathrm{CDCl}_{3}\right) \delta 3.54\left(\mathrm{~s}, 3 \mathrm{H}, \mathrm{OCH}_{3}\right), 3.55\left(\mathrm{~s}, 3 \mathrm{H}, \mathrm{OCH}_{3}\right), 3.98\left(\mathrm{~s}, 3 \mathrm{H}, \mathrm{OCH}_{3}\right)$, $4.18\left(\mathrm{~s}, 3 \mathrm{H}, \mathrm{OCH}_{3}\right), 5.32\left(\mathrm{~s}, 2 \mathrm{H}, \mathrm{OCH}_{2}\right), 5.34\left(\mathrm{~s}, 2 \mathrm{H}, \mathrm{OCH}_{2}\right), 6.84(\mathrm{~s}, 1 \mathrm{H}, \mathrm{H}-10), 7.04(\mathrm{~d}, J=8.5 \mathrm{~Hz}, 1 \mathrm{H}$, $\mathrm{H}-5), 7.24\left(\mathrm{~d}, J=8.5 \mathrm{~Hz}, 1 \mathrm{H}, \mathrm{H}-5^{\prime}\right), 7.44\left(\mathrm{dd}, J=2.0 \mathrm{~Hz}\right.$ and $\left.8.5 \mathrm{~Hz}, 1 \mathrm{H}, \mathrm{H}-6^{\prime}\right), 7.50(\mathrm{~d}, J=8.5 \mathrm{~Hz}, 1 \mathrm{H}$, $\mathrm{H}-4), 7.60\left(\mathrm{~d}, J=2.0 \mathrm{~Hz}, 1 \mathrm{H}, \mathrm{H}-2^{\prime}\right) ;{ }^{13} \mathrm{C}-\mathrm{NMR}\left(\mathrm{CDCl}_{3}\right) \delta 55.6,56.2,56.5,60.8,94.8,95.1,111.6,112.4$, $113.5,115.4,117.5,119.2,125.2,126.2,134.4,146.2,147.7,149.2,155.9,157.5,182.7$.

(Z)-7,4'-Dimethoxy-6,3'-di(methoxymethoxy)aurone (14e): (0.34 g, $0.85 \mathrm{mmol}, 85 \%$ yield); light yellow solid, $130-133{ }^{\circ} \mathrm{C} ;{ }^{1} \mathrm{H}-\mathrm{NMR}\left(\mathrm{CDCl}_{3}\right) \delta 3.55\left(\mathrm{~s}, 3 \mathrm{H}, \mathrm{OCH}_{3}\right), 3.56\left(\mathrm{~s}, 3 \mathrm{H}, \mathrm{OCH}_{3}\right), 3.95\left(\mathrm{~s}, 3 \mathrm{H}, \mathrm{OCH}_{3}\right), 4.20$ $\left(\mathrm{s}, 3 \mathrm{H}, \mathrm{OCH}_{3}\right), 5.30\left(\mathrm{~s}, 2 \mathrm{H}, \mathrm{OCH}_{2}\right), 5.33\left(\mathrm{~s}, 2 \mathrm{H}, \mathrm{OCH}_{2}\right), 6.82(\mathrm{~s}, 1 \mathrm{H}, \mathrm{H}-10), 6.97\left(\mathrm{~d}, J=8.5 \mathrm{~Hz}, 1 \mathrm{H}, \mathrm{H}-5^{\prime}\right)$, $7.03(\mathrm{~d}, J=8.5 \mathrm{~Hz}, 1 \mathrm{H}, \mathrm{H}-5), 7.48\left(\mathrm{dd}, J=2.0 \mathrm{~Hz}\right.$ and $\left.8.5 \mathrm{~Hz}, 1 \mathrm{H}, \mathrm{H}-6^{\prime}\right), 7.48(\mathrm{~d}, J=8.5 \mathrm{~Hz}, 1 \mathrm{H}, \mathrm{H}-4), 7.89$ $\left(\mathrm{d}, J=2.0 \mathrm{~Hz}, 1 \mathrm{H}, \mathrm{H}-2^{\prime}\right) ;{ }^{13} \mathrm{C}-\mathrm{NMR}\left(\mathrm{CDCl}_{3}\right) \delta 55.8,56.1,56.5,61.0,95.2,95.3,111.4,111.7,112.5,117.7$, 118.1, 118.9, 125.0, 126.9, 134.6, 146.0, 146.4, 151.0, 155.8, 157.3, 182.7.

(Z)-7,3', $4^{\prime}$-Trimethoxy-6-(methoxymethoxy)aurone (14f): (0.12 g, $0.31 \mathrm{mmol}, 31 \%$ yield); light yellow solid, 157-161 ${ }^{\circ} \mathrm{C} ;{ }^{1} \mathrm{H}-\mathrm{NMR}\left(\mathrm{CDCl}_{3}\right) \delta 3.55\left(\mathrm{~s}, 3 \mathrm{H}, \mathrm{OCH}_{3}\right), 3.95\left(\mathrm{~s}, 3 \mathrm{H}, \mathrm{OCH}_{3}\right), 3.98\left(\mathrm{~s}, 3 \mathrm{H}, \mathrm{OCH}_{3}\right), 4.18$ $\left(\mathrm{s}, 3 \mathrm{H}, \mathrm{OCH}_{3}\right), 5.34\left(\mathrm{~s}, 2 \mathrm{H}, \mathrm{OCH}_{2}\right), 6.84(\mathrm{~s}, 1 \mathrm{H}, \mathrm{H}-10), 6.95\left(\mathrm{~d}, J=8.3 \mathrm{~Hz}, 1 \mathrm{H}, \mathrm{H}-5^{\prime}\right), 7.04(\mathrm{~d}, J=8.5 \mathrm{~Hz}$, $1 \mathrm{H}, \mathrm{H}-5), 7.44\left(\mathrm{dd}, J=1.7 \mathrm{~Hz}\right.$ and $\left.8.5 \mathrm{~Hz}, 1 \mathrm{H}, \mathrm{H}-6^{\prime}\right), 7.49(\mathrm{~d}, J=8.3 \mathrm{~Hz}, 1 \mathrm{H}, \mathrm{H}-4), 7.60(\mathrm{~d}, J=1.7 \mathrm{~Hz}, 1 \mathrm{H}$, $\left.\mathrm{H}-2^{\prime}\right) ;{ }^{13} \mathrm{C}-\mathrm{NMR}\left(\mathrm{CDCl}_{3}\right) \delta 55.7,55.9,56.6,60.9,95.2,111.0,111.7,112.9,113.1,117.7,119.3,125.1,125.7$, 134.6, 146.1, 148.8, 150.5, 156.1, 157.6, 182.9 .

(Z)-6,7-Dimethoxy-4'-(methoxymethoxy)aurone (14g): (0.31 g, $0.89 \mathrm{mmol}, 89 \%$ yield); ${ }^{1} \mathrm{H}-\mathrm{NMR}\left(\mathrm{CDCl}_{3}\right)$ $\delta 3.50\left(\mathrm{~s}, 3 \mathrm{H}, \mathrm{OCH}_{3}\right), 3.99\left(\mathrm{~s}, 3 \mathrm{H}, \mathrm{OCH}_{3}\right), 4.18\left(\mathrm{~s}, 3 \mathrm{H}, \mathrm{OCH}_{3}\right), 5.24\left(\mathrm{~s}, 2 \mathrm{H}, \mathrm{OCH}_{2}\right), 6.80(\mathrm{~d}, J=8.5 \mathrm{~Hz}$, $1 \mathrm{H}, \mathrm{H}-5), 6.83(\mathrm{~s}, 1 \mathrm{H}, \mathrm{H}-10), 7.12\left(\mathrm{~d}, J=8.5 \mathrm{~Hz}, 2 \mathrm{H}, \mathrm{H}-3^{\prime}\right.$ and $\left.\mathrm{H}-5^{\prime}\right), 7.52(\mathrm{~d}, J=8.5 \mathrm{~Hz}, 1 \mathrm{H}, \mathrm{H}-4), 7.87$ $\left(\mathrm{d}, J=8.8 \mathrm{~Hz}, 2 \mathrm{H}, \mathrm{H}-2^{\prime}\right.$ and $\left.\mathrm{H}-6^{\prime}\right) ;{ }^{13} \mathrm{C}-\mathrm{NMR}\left(\mathrm{CDCl}_{3}\right) \delta 56.2,56.8,61.1,94.2,108.0,112.1,116.6,117.1$, 119.5, 126.0, 132.9, 133.9, 146.6, 157.4, 158.4, 158.6, 183.0.

(Z)-6,7-Dimethoxy-3' $4^{\prime}$-di(methoxymethoxy)aurone (14h): ( $0.31 \mathrm{~g}, 0.78 \mathrm{mmol}, 78 \%$ yield); yellow solid, 133-135 ${ }^{\circ} \mathrm{C} ;{ }^{1} \mathrm{H}-\mathrm{NMR}\left(\mathrm{CDCl}_{3}\right) \delta 3.53\left(\mathrm{~s}, 3 \mathrm{H}, \mathrm{OCH}_{3}\right), 3.56\left(\mathrm{~s}, 3 \mathrm{H}, \mathrm{OCH}_{3}\right), 3.99\left(\mathrm{~s}, 3 \mathrm{H}, \mathrm{OCH}_{3}\right), 4.19(\mathrm{~s}, 3 \mathrm{H}$, $\left.\mathrm{OCH}_{3}\right), 5.31\left(\mathrm{~s}, 4 \mathrm{H}, \mathrm{OCH}_{2}\right), 6.80(\mathrm{~s}, 1 \mathrm{H}, \mathrm{H}-10), 6.80(\mathrm{~d}, J=8.5 \mathrm{~Hz}, 1 \mathrm{H}, \mathrm{H}-5), 7.24\left(\mathrm{~d}, J=8.3 \mathrm{~Hz}, 1 \mathrm{H}, \mathrm{H}-5^{\prime}\right)$, $7.47\left(\mathrm{dd}, J=2.0 \mathrm{~Hz}\right.$ and $\left.8.3 \mathrm{~Hz}, 1 \mathrm{H}, \mathrm{H}-6^{\prime}\right), 7.52(\mathrm{~d}, J=8.5 \mathrm{~Hz}, 1 \mathrm{H}, \mathrm{H}-4), 7.87\left(\mathrm{~d}, J=2.0 \mathrm{~Hz}, 1 \mathrm{H}, \mathrm{H}-2^{\prime}\right)$; ${ }^{13} \mathrm{C}-\mathrm{NMR}\left(\mathrm{CDCl}_{3}\right) \delta 56.1,56.2,56.7,61.0,94.8,95.2,107.7,111.9,115.8,116.7,118.6,119.2,126.4,126.5$, 133.6, 146.3, 146.9, 148.4, 157.0, 158.3, 182.7 . 
(Z)-6,7-Dimethoxy-2', 4'-di(methoxymethoxy)aurone (14i): (0.36 g, $0.89 \mathrm{mmol}, 89 \%$ yield); light yellow solid, $115-120{ }^{\circ} \mathrm{C} ;{ }^{1} \mathrm{H}-\mathrm{NMR}\left(\mathrm{CDCl}_{3}\right) \delta 3.50\left(\mathrm{~s}, 3 \mathrm{H}, \mathrm{OCH}_{3}\right), 3.52\left(\mathrm{~s}, 3 \mathrm{H}, \mathrm{OCH}_{3}\right), 3.99\left(\mathrm{~s}, 3 \mathrm{H}, \mathrm{OCH}_{3}\right), 4.16$ $\left(\mathrm{s}, 3 \mathrm{H}, \mathrm{OCH}_{3}\right), 5.22\left(\mathrm{~s}, 2 \mathrm{H}, \mathrm{OCH}_{2}\right), 5.27\left(\mathrm{~s}, 2 \mathrm{H}, \mathrm{OCH}_{2}\right), 6.80(\mathrm{~d}, J=8.5 \mathrm{~Hz}, 1 \mathrm{H}, \mathrm{H}-5), 6.83(\mathrm{dd}, J=2.2 \mathrm{~Hz}$ and $\left.8.8 \mathrm{~Hz}, 1 \mathrm{H}, \mathrm{H}-5^{\prime}\right), 6.88\left(\mathrm{~d}, J=2.2 \mathrm{~Hz}, 1 \mathrm{H}, \mathrm{H}-3^{\prime}\right), 7.38(\mathrm{~s}, 1 \mathrm{H}, \mathrm{H}-10), 7.52(\mathrm{~d}, J=8.3 \mathrm{~Hz}, 1 \mathrm{H}, \mathrm{H}-4), 8.26$ $\left(\mathrm{d}, J=8.5 \mathrm{~Hz}, 1 \mathrm{H}, \mathrm{H}-6^{\prime}\right) ;{ }^{13} \mathrm{C}-\mathrm{NMR}\left(\mathrm{CDCl}_{3}\right) \delta 56.1,56.3,56.6,60.9,94.0,94.5,102.8,106.2,107.6,109.2$, $115.7,117.0,119.2,132.4,133.6,146.4,156.9,157.6,158.1,159.5,182.7$.

(Z)-6,7,3'-Trimethoxy-4'-(methoxymethoxy)aurone (14j): (0.30 g, $0.81 \mathrm{mmol}, 81 \%$ yield); yellow solid, 158-162 ${ }^{\circ} \mathrm{C} ;{ }^{1} \mathrm{H}-\mathrm{NMR}\left(\mathrm{CDCl}_{3}\right) \delta 3.53\left(\mathrm{~s}, 3 \mathrm{H}, \mathrm{OCH}_{3}\right), 3.98\left(\mathrm{~s}, 3 \mathrm{H}, \mathrm{OCH}_{3}\right), 4.00\left(\mathrm{~s}, 3 \mathrm{H}, \mathrm{OCH}_{3}\right), 4.16(\mathrm{~s}, 3 \mathrm{H}$, $\left.\mathrm{OCH}_{3}\right), 5.31\left(\mathrm{~s}, 2 \mathrm{H}, \mathrm{OCH}_{2}\right), 6.81(\mathrm{~d}, J=8.1 \mathrm{~Hz}, 1 \mathrm{H}, \mathrm{H}-5), 6.82(\mathrm{~s}, 1 \mathrm{H}, \mathrm{H}-10), 7.23\left(\mathrm{~d}, J=8.5 \mathrm{~Hz}, 1 \mathrm{H}, \mathrm{H}-5^{\prime}\right)$, $7.43\left(\mathrm{dd}, J=2.0 \mathrm{~Hz}\right.$ and $\left.8.5 \mathrm{~Hz}, 1 \mathrm{H}, \mathrm{H}-6^{\prime}\right), 7.53(\mathrm{~d}, J=8.5 \mathrm{~Hz}, 1 \mathrm{H}, \mathrm{H}-4), 7.59\left(\mathrm{~d}, J=1.7 \mathrm{~Hz}, 1 \mathrm{H}, \mathrm{H}-2^{\prime}\right)$; ${ }^{13} \mathrm{C}-\mathrm{NMR}\left(\mathrm{CDCl}_{3}\right) \delta 55.7,56.2,56.7,60.8,94.9,107.8$ 112.2, 113.6, 115.5, 116.7, 119.4, 125.2, 126.3, 133.5, $146.4,147.7,149.2,157.2,158.4,182.6$.

(Z)-6,7,4'-Trimethoxy-3'-(methoxymethoxy)aurone (14k): ( $0.29 \mathrm{~g}, 0.78 \mathrm{mmol}, 78 \%$ yield); yellow solid, $162-167^{\circ} \mathrm{C} ;{ }^{1} \mathrm{H}-\mathrm{NMR}\left(\mathrm{CDCl}_{3}\right) \delta 3.55\left(\mathrm{~s}, 3 \mathrm{H}, \mathrm{OCH}_{3}\right), 3.94\left(\mathrm{~s}, 3 \mathrm{H}, \mathrm{OCH}_{3}\right), 4.00\left(\mathrm{~s}, 3 \mathrm{H}, \mathrm{OCH}_{3}\right), 4.19(\mathrm{~s}, 3 \mathrm{H}$, $\left.\mathrm{OCH}_{3}\right), 5.30\left(\mathrm{~s}, 2 \mathrm{H}, \mathrm{OCH}_{2}\right), 6.80(\mathrm{~d}, J=8.3 \mathrm{~Hz}, 1 \mathrm{H}, \mathrm{H}-5), 6.80(\mathrm{~s}, 1 \mathrm{H}, \mathrm{H}-10), 6.97\left(\mathrm{~d}, J=8.3 \mathrm{~Hz}, 1 \mathrm{H}, \mathrm{H}-5^{\prime}\right)$, $7.48\left(\mathrm{dd}, J=2.0 \mathrm{~Hz}\right.$ and $\left.8.5 \mathrm{~Hz}, 1 \mathrm{H}, \mathrm{H}-6^{\prime}\right), 7.51(\mathrm{~d}, J=8.5 \mathrm{~Hz}, 1 \mathrm{H}, \mathrm{H}-4), 7.88\left(\mathrm{~d}, J=2.2 \mathrm{~Hz}, 1 \mathrm{H}, \mathrm{H}-2^{\prime}\right)$; ${ }^{13} \mathrm{C}-\mathrm{NMR}\left(\mathrm{CDCl}_{3}\right) \delta 56.0,56.3,56.8,61.1,95.4,107.9$ 111.6, 112.3, 117.0, 118.3, 119.3, 125.2, 126.9, 133.8, $146.3,146.5,151.1,157.1,158.4,182.8$.

(Z)-6,7,3'4'-Tetramethoxyaurone (14l): $\left(0.27 \mathrm{~g}, 0.80 \mathrm{mmol}, 80 \%\right.$ yield); yellow solid, $156-157{ }^{\circ} \mathrm{C}$; ${ }^{1} \mathrm{H}-\mathrm{NMR}\left(\mathrm{CDCl}_{3}\right) \delta 3.95\left(\mathrm{~s}, 3 \mathrm{H}, \mathrm{OCH}_{3}\right), 3.98\left(\mathrm{~s}, 3 \mathrm{H}, \mathrm{OCH}_{3}\right), 3.99\left(\mathrm{~s}, 3 \mathrm{H}, \mathrm{OCH}_{3}\right), 4.16\left(\mathrm{~s}, 3 \mathrm{H}, \mathrm{OCH}_{3}\right)$, $6.80(\mathrm{~d}, J=8.5 \mathrm{~Hz}, 1 \mathrm{H}, \mathrm{H}-5), 6.82(\mathrm{~s}, 1 \mathrm{H}, \mathrm{H}-10), 6.95\left(\mathrm{~d}, J=8.3 \mathrm{~Hz}, 1 \mathrm{H}, \mathrm{H}-5^{\prime}\right), 7.44(\mathrm{dd}, J=2.0 \mathrm{~Hz}$ and $\left.8.5 \mathrm{~Hz}, 1 \mathrm{H}, \mathrm{H}-6^{\prime}\right), 7.53(\mathrm{~d}, J=8.3 \mathrm{~Hz}, 1 \mathrm{H}, \mathrm{H}-4), 7.60\left(\mathrm{~d}, J=2.0 \mathrm{~Hz}, 1 \mathrm{H}, \mathrm{H}-2^{\prime}\right) ;{ }^{13} \mathrm{C}-\mathrm{NMR}\left(\mathrm{CDCl}_{3}\right) \delta 55.6$, $55.8,56.6,60.8,107.8,110.9,112.4,113.0,116.8,119.4,125.0,125.5,133.5,146.2,148.7,150.3,157.1,158.4$, 182.6; UV/Vis $\left(2.2 \times 10^{-5} \mathrm{M}, \mathrm{CHCl}_{3}\right) ; \lambda=406.8 \mathrm{~nm}\left(\varepsilon, 2.3 \times 10^{4}\right)$.

\subsection{The General Procedure for the Deprotection of $\mathbf{1 4 a - k}$}

A solution of 14a-k $(1.0 \mathrm{mmol})$ in methanol $(5 \mathrm{~mL})$ and $3 \mathrm{M}$ hydrochloric acid $(5 \mathrm{~mL})$ was refluxed for $1 \mathrm{~h}$. The mixture was extracted with EtOAc. The organic layer was washed with water and brine and dried over anhydrous $\mathrm{MgSO}_{4}$. The solvent was evaporated in vacuo and the residue was chromatographed on a preparative thin layer chromatography (hexane:EtOAc $=2: 3$ ) to produce aurones 15a-k.

(Z)-6,4'-Dihydroxy-7-methoxyaurone (15a): $(0.18 \mathrm{~g}, 0.63 \mathrm{mmol}, 63 \%$ yield); yellow brown solid, 240-241 ${ }^{\circ} \mathrm{C} ;{ }^{1} \mathrm{H}-\mathrm{NMR}\left(\mathrm{CDCl}_{3}: \mathrm{CD}_{3} \mathrm{OD}=1: 1\right) \delta 4.15\left(\mathrm{~s}, 3 \mathrm{H}, \mathrm{OCH}_{3}\right), 6.75(\mathrm{~d}, J=8.5 \mathrm{~Hz}, 1 \mathrm{H}, \mathrm{H}-5)$, $6.80(\mathrm{~s}, 1 \mathrm{H}, \mathrm{H}-10), 6.90\left(\mathrm{~d}, J=8.5 \mathrm{~Hz}, 2 \mathrm{H}, \mathrm{H}-3^{\prime}\right.$ and H-5'), $7.37(\mathrm{~d}, J=8.3 \mathrm{~Hz}, 1 \mathrm{H}, \mathrm{H}-4), 7.81(\mathrm{~d}, J=8.8 \mathrm{~Hz}$, $2 \mathrm{H}, \mathrm{H}-2^{\prime}$ and $\left.\mathrm{H}-6\right) ;{ }^{13} \mathrm{C}-\mathrm{NMR}\left(\mathrm{CDCl}_{3}: \mathrm{CD}_{3} \mathrm{OD}=1: 1\right) \delta 61.1,113.8,114.2,116.0,116.5,120.1,124.2,132.8$, $133.9,146.7,158.5,158.8,160.0,183.8$; UV/Vis $\left(3.0 \times 10^{-5} \mathrm{M}, \mathrm{CH}_{3} \mathrm{OH}\right) ; \lambda=394.6 \mathrm{~nm}\left(\varepsilon, 2.6 \times 10^{4}\right)$.

(Z)-6,3' , $^{\prime}$-Trihydroxy-7-methoxyaurone (15b): $(0.27 \mathrm{~g}, 0.91 \mathrm{mmol}, 91 \%$ yield); reddish ocher solid, 235-238 ${ }^{\circ} \mathrm{C} ;{ }^{1} \mathrm{H}-\mathrm{NMR}\left(\mathrm{DMSO}_{6} \mathrm{~d}_{6}\right) \delta 4.04\left(\mathrm{~s}, 3 \mathrm{H}, \mathrm{OCH}_{3}\right), 6.70(\mathrm{~s}, 1 \mathrm{H}, \mathrm{H}-10), 6.79(\mathrm{~d}, J=8.3 \mathrm{~Hz}, 1 \mathrm{H}, \mathrm{H}-5)$, $6.87\left(\mathrm{~d}, J=8.3 \mathrm{~Hz}, 1 \mathrm{H}, \mathrm{H}-5^{\prime}\right), 7.27\left(\mathrm{dd}, J=2.0 \mathrm{~Hz}\right.$ and $\left.8.3 \mathrm{~Hz}, 1 \mathrm{H}, \mathrm{H}-6^{\prime}\right), 7.35(\mathrm{~d}, J=8.3 \mathrm{~Hz}, 1 \mathrm{H}, \mathrm{H}-4)$, $7.46\left(\mathrm{~d}, J=1.7 \mathrm{~Hz}, 1 \mathrm{H}, \mathrm{H}-2^{\prime}\right), 9.45(\mathrm{~s}, 1 \mathrm{H}, \mathrm{OH}), 9.84(\mathrm{~s}, 1 \mathrm{H}, \mathrm{OH}), 10.96(\mathrm{~s}, 1 \mathrm{H}, \mathrm{OH}) ;{ }^{13} \mathrm{C}-\mathrm{NMR}\left(\mathrm{DMSO}-d_{6}\right)$ $\delta 60.8,112.3,113.3,114.7,115.9,117.8,119.3,123.2,124.6,132.1,145.3,145.4,148.0,157.6,157.8,181.1$; $\mathrm{UV} /$ Vis $\left(2.9 \times 10^{-5} \mathrm{M}, \mathrm{DMSO}\right) ; \lambda=411.2 \mathrm{~nm}\left(\varepsilon, 2.1 \times 10^{4}\right)$.

(Z)-6,2', 4' -Trihydroxy-7-methoxyaurone (15c): (0.25 g, $0.84 \mathrm{mmol}, 84 \%$ yield); ocher solid, $288-290{ }^{\circ} \mathrm{C}$; ${ }^{1} \mathrm{H}-\mathrm{NMR}\left(\mathrm{DMSO}-d_{6}\right) \delta 3.94\left(\mathrm{~s}, 3 \mathrm{H}, \mathrm{OCH}_{3}\right), 6.43\left(\mathrm{~d}, J=2.0 \mathrm{~Hz}, 1 \mathrm{H}, \mathrm{H}-3^{\prime}\right), 6.45(\mathrm{dd}, J=2.2 \mathrm{~Hz}$ and $\left.9.3 \mathrm{~Hz}, 1 \mathrm{H}, \mathrm{H}-5^{\prime}\right), 6.96$ (d, J = 8.5 Hz, 1H, H-5), 7.12 (s, 1H, H-10), 7.26 (d, J = 8.5 Hz, 1H, H-4), 8.16 $\left(\mathrm{d}, J=8.3 \mathrm{~Hz}, 1 \mathrm{H}, \mathrm{H}-6^{\prime}\right), 9.82(\mathrm{~s}, 1 \mathrm{H}, \mathrm{OH}), 10.16(\mathrm{~s}, 1 \mathrm{H}, \mathrm{OH}), 10.42(\mathrm{~s}, 1 \mathrm{H}, \mathrm{OH}) ;{ }^{13} \mathrm{C}-\mathrm{NMR}\left(\mathrm{DMSO}-d_{6}\right)$ 
¿ 56.6, 102.1, 106.3, 108.3, 108.3, 110.6, 114.6, 116.1, 131.3, 132.8, 145.0, 153.3, 154.5, 159.0, 160.8, 181.9; $\mathrm{UV} / \mathrm{Vis}\left(2.8 \times 10^{-5} \mathrm{M}, \mathrm{DMSO}\right) ; \lambda=428.2 \mathrm{~nm}\left(\varepsilon, 3.3 \times 10^{4}\right)$.

(Z)-6,4'-Dihydroxy-7,3'-dimethoxyaurone (15d): (0.24 g, $0.75 \mathrm{mmol}, 75 \%$ yield); yellow solid, $218-220^{\circ} \mathrm{C}$; ${ }^{1} \mathrm{H}-\mathrm{NMR}\left(\mathrm{DMSO}-d_{6}\right) \delta 3.87\left(\mathrm{~s}, 3 \mathrm{H}, \mathrm{OCH}_{3}\right), 4.04\left(\mathrm{~s}, 3 \mathrm{H}, \mathrm{OCH}_{3}\right), 6.79(\mathrm{~d}, J=8.5 \mathrm{~Hz}, 1 \mathrm{H}, \mathrm{H}-5), 6.79(\mathrm{~s}, 1 \mathrm{H}$, $\mathrm{H}-10), 6.92\left(\mathrm{~d}, J=8.3 \mathrm{~Hz}, 1 \mathrm{H}, \mathrm{H}-5^{\prime}\right), 7.36(\mathrm{~d}, J=8.5 \mathrm{~Hz}, 1 \mathrm{H}, \mathrm{H}-4), 7.42\left(\mathrm{dd}, J=1.7 \mathrm{~Hz}\right.$ and $\left.8.3 \mathrm{~Hz}, 1 \mathrm{H}, \mathrm{H}-6^{\prime}\right)$, $7.63\left(\mathrm{~d}, J=1.7 \mathrm{~Hz}, 1 \mathrm{H}, \mathrm{H}-2^{\prime}\right)$; ${ }^{13} \mathrm{C}-\mathrm{NMR}$ (DMSO- $d_{6}$ ) $\delta 55.6,60.7,112.3,113.5,114.3,114.7,116.0,119.5$, 123.4, 125.9, 132.1, 145.6, 147.7, 148.9, 157.8, 157.9, 181.2; UV/Vis $\left(2.4 \times 10^{-5} \mathrm{M}, \mathrm{DMSO}\right) ; \lambda=407.2 \mathrm{~nm}$ $\left(\varepsilon, 2.9 \times 10^{4}\right)$.

(Z)-6,3'-Dihydroxy-7,4'-dimethoxyaurone (15e): (0.31 g, $0.97 \mathrm{mmol}, 97 \%$ yield); yellow brown solid, 241-243 ${ }^{\circ} \mathrm{C} ;{ }^{1} \mathrm{H}-\mathrm{NMR}\left(\mathrm{DMSO}-d_{6}\right) \delta 3.82\left(\mathrm{~s}, 3 \mathrm{H}, \mathrm{OCH}_{3}\right), 4.01\left(\mathrm{~s}, 3 \mathrm{H}, \mathrm{OCH}_{3}\right), 6.70(\mathrm{~s}, 1 \mathrm{H}, \mathrm{H}-10), 6.77$ $(\mathrm{d}, J=8.5 \mathrm{~Hz}, 1 \mathrm{H}, \mathrm{H}-5), 7.05\left(\mathrm{~d}, J=8.5 \mathrm{~Hz}, 1 \mathrm{H}, \mathrm{H}-5^{\prime}\right), 7.33(\mathrm{~d}, J=8.3 \mathrm{~Hz}, 1 \mathrm{H}, \mathrm{H}-4), 7.37(\mathrm{dd}, J=1.5 \mathrm{~Hz}$ and $\left.8.5 \mathrm{~Hz}, 1 \mathrm{H}, \mathrm{H}-6^{\prime}\right), 7.45\left(\mathrm{~d}, J=1.5 \mathrm{~Hz}, 1 \mathrm{H}, \mathrm{H}-2^{\prime}\right), 9.44(\mathrm{~s}, 1 \mathrm{H}, \mathrm{OH}), 10.97(\mathrm{~s}, 1 \mathrm{H}, \mathrm{OH}) ;{ }^{13} \mathrm{C}-\mathrm{NMR}$ $\left(\right.$ DMSO- $d_{6}$ ) $\delta 55.7,60.8,111.7,112.1,113.4,114.5,117.3,119.4,124.2,124.5,132.1,145.7,146.4,149.5$, $157.8,157.9,181.2 ; \mathrm{UV} / \mathrm{Vis}\left(2.7 \times 10^{-5} \mathrm{M}, \mathrm{DMSO}\right) ; \lambda=405.4 \mathrm{~nm}\left(\varepsilon, 2.1 \times 10^{4}\right)$.

(Z)-6-Hydroxy-7, $3^{\prime}, 4^{\prime}$-trimethoxyaurone (15f): (0.21 g, $0.65 \mathrm{mmol}, 65 \%$ yield); yellow solid, 204-205 ${ }^{\circ} \mathrm{C}$; ${ }^{1} \mathrm{H}-\mathrm{NMR}\left(\mathrm{CDCl}_{3}\right) \delta 3.95\left(\mathrm{~s}, 3 \mathrm{H}, \mathrm{OCH}_{3}\right), 3.96\left(\mathrm{~s}, 3 \mathrm{H}, \mathrm{OCH}_{3}\right), 4.27\left(\mathrm{~s}, 3 \mathrm{H}, \mathrm{OCH}_{3}\right), 6.65(\mathrm{~s}, 1 \mathrm{H}, \mathrm{OH}), 6.82$ $(\mathrm{d}, J=8.5 \mathrm{~Hz}, 1 \mathrm{H}, \mathrm{H}-5), 6.83(\mathrm{~s}, 1 \mathrm{H}, \mathrm{H}-10), 6.94\left(\mathrm{~d}, J=8.5 \mathrm{~Hz}, 1 \mathrm{H}, \mathrm{H}-5^{\prime}\right), 7.42(\mathrm{dd}, J=2.0 \mathrm{~Hz}$ and $8.3 \mathrm{~Hz}$, $\left.1 \mathrm{H}, \mathrm{H}-6^{\prime}\right), 7.46(\mathrm{~d}, J=8.3 \mathrm{~Hz}, 1 \mathrm{H}, \mathrm{H}-4), 7.51\left(\mathrm{~d}, J=2.0 \mathrm{~Hz}, \mathrm{H}-2^{\prime}\right) ;{ }^{13} \mathrm{C}-\mathrm{NMR}\left(\mathrm{CDCl}_{3}\right) \delta 55.7,55.8,60.6$, 111.0, 111.7, 112.6, 113.0, 116.3, 119.7, 124.9, 125.4, 130.9, 146.0, 148.7, 150.4, 154.9, 115.9, 182.1; UV/Vis $\left(2.4 \times 10^{-5} \mathrm{M}, \mathrm{CHCl}_{3}\right) ; \lambda=400.0 \mathrm{~nm}\left(\varepsilon, 2.6 \times 10^{4}\right)$.

(Z)-4'-Hydroxy-6,7-dimethoxyaurone (15g): $\left(0.27 \mathrm{~g}, 0.89 \mathrm{mmol}, 89 \%\right.$ yield); dark yellow solid, $230-231^{\circ} \mathrm{C}$; ${ }^{1} \mathrm{H}-\mathrm{NMR}\left(\mathrm{DMSO}-d_{6}\right) \delta 4.00\left(\mathrm{~s}, 3 \mathrm{H}, \mathrm{OCH}_{3}\right), 4.17\left(\mathrm{~s}, 3 \mathrm{H}, \mathrm{OCH}_{3}\right), 5.76(\mathrm{~s}, 1 \mathrm{H}, \mathrm{OH}), 6.81(\mathrm{~d}, J=8.3 \mathrm{~Hz}$, $1 \mathrm{H}, \mathrm{H}-5), 6.84(\mathrm{~s}, 1 \mathrm{H}, \mathrm{H}-10), 6.95\left(\mathrm{~d}, J=8.3 \mathrm{~Hz}, 2 \mathrm{H}, \mathrm{H}-3^{\prime}\right.$ and $\left.\mathrm{H}-5^{\prime}\right), 7.54(\mathrm{~d}, J=8.5 \mathrm{~Hz}, 1 \mathrm{H}, \mathrm{H}-4), 7.83$ $\left(\mathrm{d}, J=8.3 \mathrm{~Hz}, 2 \mathrm{H}, \mathrm{H}-2^{\prime}\right.$ and $\left.\mathrm{H}-6^{\prime}\right) ;{ }^{13} \mathrm{C}-\mathrm{NMR}\left(\mathrm{DMSO}-\mathrm{d}_{6}\right) \delta 56.6,60.6,108.7,112.0,114.9,116.0,119.0,119.1$, 122.7, 133.1, 154.1, 156.5, 158.3, 159.2, 181.3; UV/Vis $\left(3.0 \times 10^{-5} \mathrm{M}\right.$, DMSO); $\lambda=404.2 \mathrm{~nm}\left(\varepsilon, 2.5 \times 10^{4}\right)$.

(Z)-3', $4^{\prime}$-Dihydroxy-6,7-dimethoxyaurone (15h): (0.16 g, $0.51 \mathrm{mmol}, 51 \%$ yield); dark yellow solid, 219-220 ${ }^{\circ} \mathrm{C} ;{ }^{1} \mathrm{H}-\mathrm{NMR}\left(\mathrm{CD}_{3} \mathrm{OD}\right) \delta 3.97\left(\mathrm{~s}, 3 \mathrm{H}, \mathrm{OCH}_{3}\right), 4.08\left(\mathrm{~s}, 3 \mathrm{H}, \mathrm{OCH}_{3}\right), 6.71(\mathrm{~s}, 1 \mathrm{H}, \mathrm{H}-10), 6.84$ $(\mathrm{d}, J=8.3 \mathrm{~Hz}, 1 \mathrm{H}, \mathrm{H}-5), 6.94\left(\mathrm{~d}, J=8.5 \mathrm{~Hz}, 1 \mathrm{H}, \mathrm{H}-5^{\prime}\right), 7.26\left(\mathrm{dd}, J=2.2 \mathrm{~Hz}\right.$ and $\left.8.3 \mathrm{~Hz}, 1 \mathrm{H}, \mathrm{H}-6^{\prime}\right), 7.46$ $(\mathrm{d}, J=8.5 \mathrm{~Hz}, 1 \mathrm{H}, \mathrm{H}-4), 7.46\left(\mathrm{~d}, J=2.2 \mathrm{~Hz}, 1 \mathrm{H}, \mathrm{H}-2^{\prime}\right) ;{ }^{13} \mathrm{C}-\mathrm{NMR}\left(\mathrm{CD}_{3} \mathrm{OD}\right) \delta 57.2,61.5,109.7,115.0,116.4$, $117.6,118.8,120.3,125.1,126.3,135.0,146.4,147.0,149.3,158.7,160.5,184.3 ; \mathrm{UV} / \mathrm{Vis}\left(2.5 \times 10^{-5} \mathrm{M}\right.$, $\left.\mathrm{CH}_{3} \mathrm{OH}\right) ; \lambda=408.2 \mathrm{~nm}\left(\varepsilon, 2.6 \times 10^{4}\right)$.

(Z)-2' $4^{\prime}$-Dihydroxy-6,7-dimethoxyaurone (15i): (0.25 g, $0.78 \mathrm{mmol}, 78 \%$ yield); reddish clay solid, $245{ }^{\circ} \mathrm{C}$ (decomp.); ${ }^{1} \mathrm{H}-\mathrm{NMR}$ (DMSO- $\left.d_{6}\right) \delta 3.94\left(\mathrm{~s}, 3 \mathrm{H}, \mathrm{OCH}_{3}\right), 4.02\left(\mathrm{~s}, 3 \mathrm{H}, \mathrm{OCH}_{3}\right), 6.43(\mathrm{~s}, 1 \mathrm{H}, \mathrm{H}-10)$, $6.44(\mathrm{~d}, \mathrm{~J}=7.1 \mathrm{~Hz}, 1 \mathrm{H}, \mathrm{H}-5), 7.01\left(\mathrm{~d}, J=8.3 \mathrm{~Hz}, 1 \mathrm{H}, \mathrm{H}-5^{\prime}\right), 7.14\left(\mathrm{~s}, 1 \mathrm{H}, \mathrm{H}-3^{\prime}\right), 7.48(\mathrm{~d}, J=8.3 \mathrm{~Hz}, 1 \mathrm{H}$, $\mathrm{H}-4), 7.98\left(\mathrm{~d}, J=8.5 \mathrm{~Hz}, 1 \mathrm{H}, \mathrm{H}-6^{\prime}\right), 10.17(\mathrm{~s}, 1 \mathrm{H}, \mathrm{OH}), 10.36(\mathrm{~s}, 1 \mathrm{H}, \mathrm{OH}) ;{ }^{13} \mathrm{C}-\mathrm{NMR}\left(\mathrm{DMSO}-d_{6}\right) \delta 56.8$, 60.7, 102.3, 106.8, 108.5, 108.9, 110.4, 116.4, 119.0, 132.2, 133.3, 144.7, 156.5, 158.2, 159.2, 161.0, 181.2; $\mathrm{UV} / \mathrm{Vis}\left(2.4 \times 10^{-5} \mathrm{M}, \mathrm{DMSO}\right) ; \lambda=424.6 \mathrm{~nm}\left(\varepsilon, 2.9 \times 10^{4}\right)$.

(Z)-4'-Hydroxy-6,7,3'-trimethoxyaurone (15j): $(0.27 \mathrm{~g}, 0.81 \mathrm{mmol}, 81 \%$ yield); dark yellow solid, 171-176 ${ }^{\circ} \mathrm{C} ;{ }^{1} \mathrm{H}-\mathrm{NMR}\left(\mathrm{CDCl}_{3}\right) \delta 3.97\left(\mathrm{~s}, 3 \mathrm{H}, \mathrm{OCH}_{3}\right), 3.99\left(\mathrm{~s}, 3 \mathrm{H}, \mathrm{OCH}_{3}\right), 4.16\left(\mathrm{~s}, 3 \mathrm{H}, \mathrm{OCH}_{3}\right), 6.13(\mathrm{~s}, 1 \mathrm{H}$, $\mathrm{OH}), 6.80(\mathrm{~d}, J=8.3 \mathrm{~Hz}, 1 \mathrm{H}, \mathrm{H}-5), 6.81(\mathrm{~s}, 1 \mathrm{H}, \mathrm{H}-10), 6.99\left(\mathrm{~d}, J=8.3 \mathrm{~Hz}, 1 \mathrm{H}, \mathrm{H}-5^{\prime}\right), 7.39(\mathrm{dd}, J=1.7 \mathrm{~Hz}$ and $\left.8.3 \mathrm{~Hz}, 1 \mathrm{H}, \mathrm{H}-6^{\prime}\right), 7.52(\mathrm{~d}, J=8.5 \mathrm{~Hz}, 1 \mathrm{H}, \mathrm{H}-4), 7.56\left(\mathrm{~d}, J=1.7 \mathrm{~Hz}, 1 \mathrm{H}, \mathrm{H}-2^{\prime}\right) ;{ }^{13} \mathrm{C}-\mathrm{NMR}\left(\mathrm{CDCl}_{3}\right)$

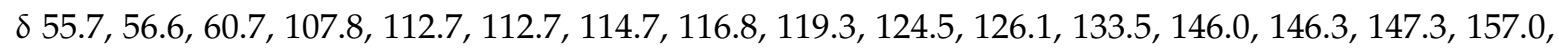
158.3, 182.5; UV/Vis $\left(2.8 \times 10^{-5} \mathrm{M}, \mathrm{CHCl}_{3}\right) ; \lambda=405.4 \mathrm{~nm}\left(\varepsilon, 1.7 \times 10^{4}\right)$.

(Z)-3'-Hydroxy-6,7,4'-trimethoxyaurone (15k): $(0.30 \mathrm{~g}, 0.91 \mathrm{mmol}, 91 \%$ yield); dark yellow solid, 196-200 ${ }^{\circ} \mathrm{C} ;{ }^{1} \mathrm{H}-\mathrm{NMR}\left(\mathrm{CDCl}_{3}\right) \delta 3.94\left(\mathrm{~s}, 3 \mathrm{H}, \mathrm{OCH}_{3}\right), 3.98\left(\mathrm{~s}, 3 \mathrm{H}, \mathrm{OCH}_{3}\right), 4.20\left(\mathrm{~s}, 3 \mathrm{H}, \mathrm{OCH}_{3}\right), 5.86(\mathrm{~s}, 1 \mathrm{H}$, $\mathrm{OH}), 6.78(\mathrm{~s}, 1 \mathrm{H}, \mathrm{H}-10), 6.79(\mathrm{~d}, J=9.3 \mathrm{~Hz}, 1 \mathrm{H}, \mathrm{H}-5), 6.92\left(\mathrm{~d}, J=8.3 \mathrm{~Hz}, 1 \mathrm{H}, \mathrm{H}-5^{\prime}\right), 7.39(\mathrm{dd}, J=2.0 \mathrm{~Hz}$ and $\left.8.3 \mathrm{~Hz}, 1 \mathrm{H}, \mathrm{H}-6^{\prime}\right), 7.51(\mathrm{~d}, J=8.5 \mathrm{~Hz}, 1 \mathrm{H}, \mathrm{H}-4), 7.57\left(\mathrm{~d}, J=2.2 \mathrm{~Hz}, 1 \mathrm{H}, \mathrm{H}-2^{\prime}\right) ;{ }^{13} \mathrm{C}-\mathrm{NMR}\left(\mathrm{CDCl}_{3}\right)$ 
$\delta \delta 56.0,56.8,61.1,107.9,110.6,112.4,116.7,116.9,119.3,124.7,125.6,133.8,145.6,146.4,148.0,157.1$, 158.4, 182.9; UV/Vis $\left(2.6 \times 10^{-5} \mathrm{M}_{1} \mathrm{CHCl}_{3}\right) ; \lambda=405.0 \mathrm{~nm}\left(\varepsilon, 1.8 \times 10^{4}\right)$.

\subsection{The DPPH Radical Scavenging Assay}

The measurement of the 2,2-Diphenyl-1-picrylhydrazyl (DPPH) radical scavenging effect was performed according to the established procedure [8]. Sample compounds were dissolved in ethanol to obtain a $0.1 \mathrm{mM}$ concentration. The DPPH free radical was dissolved in ethanol to obtain a concentration of $0.2 \mathrm{mM}$. The ethanol $(100 \mu \mathrm{L})$ and DPPH solutions $(50 \mu \mathrm{L})$ were added to a sample solution $(100 \mu \mathrm{L})$ on a $96-$-well transparent microplate. The mix solution was mixed on a plate-mixer for $1 \mathrm{~min}$. The mix solution was allowed to stand at $25^{\circ} \mathrm{C}$ for $30 \mathrm{~min}$ in the dark, followed by measuring the absorbance with a microplate reader at $517 \mathrm{~nm}$. The sample blank test (B) was performed with ethanol instead of the sample solution using a similar procedure. The blank test of the sample (C) was performed similarly, with ethanol instead of the DPPH solution. The blank test of the sample blank (D) was performed similarly, but with ethanol instead of the sample and DPPH solution. The DPPH radical scavenging rate was calculated as follows:

$$
\text { DPPH Radical Scavenging Rate }(\%)=\{(B-D)-(A-C)\} /(B-D) \times 100
$$

where $\mathrm{A}$ is the absorbance of the sample, $\mathrm{B}$ is the absorbance of the sample blank, $\mathrm{C}$ is the absorbance of the blank of the sample, and D is the absorbance of the blank of the sample blank.

\subsection{Tyrosinase Activity Inhibition Assay}

The Tyrosinase activity was determined using the dopachrome method with L-3-(3,4-dihydroxyphenyl) alanine (L-DOPA) as the substrate [9]. Sample compounds were dissolved in DMSO to obtain a concentration of $3.0 \mathrm{mM}$. L-DOPA was dissolved in a $0.2 \mathrm{M}$ phosphate buffer solution (PBS, pH 6.8) to obtain a concentration of $1.66 \mathrm{mM}$. The enzyme tyrosinase from mushrooms was dissolved in PBS to obtain a concentration of 600 units $/ \mathrm{mL}$. The sample solution $(10 \mu \mathrm{L})$ was added to a L-DOPA solution $(280 \mu \mathrm{L})$ on a 96-well transparent microplate. The mix solution was mixed on a plate-mixer for $1 \mathrm{~min}$. The mix solution was left to stand at $25^{\circ} \mathrm{C}$ for $5 \mathrm{~min}$. The tyrosinase solution $(10 \mu \mathrm{L})$ was added to the mixture and the mixture was incubated at $25^{\circ} \mathrm{C}$ for $10 \mathrm{~min}$, followed by measuring the absorbance with a microplate reader at $475 \mathrm{~nm}$. The sample blank test (B) was performed with DMSO instead of the sample solution with similar procedure. The blank test of sample (C) was similarly performed with PBS instead of the enzyme solution. The blank test of the sample blank (D) was similarly performed with the DMSO and PBS instead of the sample and enzyme solutions, respectively. The percentage inhibition of tyrosinase activity was calculated as follows.

$$
\text { Tyrosinase Activity Inhibition Rate }(\%)=\{(B-D)-(A-C)\} /(B-D) \times 100
$$

where $\mathrm{A}$ is the absorbance of the sample, $\mathrm{B}$ is the absorbance of the sample blank, $\mathrm{C}$ is the absorbance of the blank of the sample, and D is the absorbance of the blank of the sample blank.

\section{Conclusions}

In this study, chalcones, flavanones, and flavonols were easily synthesized, including 8-methoxybutin, which is a naturally occurring product from Coreopsis lanceolata L., using the HWE reaction as the key reaction in five to seven steps with overall yields of $18-59 \%, 13-53 \%$, and $2-21 \%$ from $O$-methylpyrogallol $\mathbf{4 a}, \mathbf{b}$, respectively. The synthesis of aurones including leptosidin was achieved in four to five steps with overall yields of $5-36 \%$ from $\mathbf{4 a , b}$ using the aldol condensation reaction as a key reaction.

We found a correlation between the physiological activity and structures of the A- and B-rings of chalcone, flavanone, flavonol, and aurone. Each of chalcones $7 \mathbf{b}, \mathbf{h}$; flavanones $\mathbf{8 b}, \mathbf{h}$; flavonols 
$\mathbf{1 1 b}, \mathbf{h}$; and aurones 15b,h with the 3,4-dihydroxy groups on the B-ring had high antioxidant activity. The antioxidant activity in decreasing order was flavonol, chalcone, aurone, and flavanone.

The chalcones 7c,i and aurones 15c,i bearing the 2,4-dihydroxy groups on the B-ring had a high inhibitory activity potential. The whitening effect in decreasing order was chalcone, aurone, flavonol, and flavanone.

Author Contributions: D.N. and Y.O. (Yoshiharu Okada) conceived and designed the experiments; D.N., Y.O. (Yuka Okano), N.K. (Naomi Kandori), T.S., N.K. (Naoya Kataoka) and J.A. performed the experiments; D.N., Y.O. (Yuka Okano), N. Kandori, and Y.O. (Yoshiharu Okada) analyzed the data; Y.O. (Yoshiharu Okada) wrote the paper.

Funding: This research received no external funding.

Conflicts of Interest: The authors declare no conflict of interest.

\section{References}

1. Tanimoto, S.; Miyazawa, M.; Inoue, T.; Okada, Y.; Nomura, M. Chemical constituents of Coreopsis lanceolata L. and their physiological activities. J. Oleo Sci. 2009, 58, 141-146. [CrossRef] [PubMed]

2. Okada, Y.; Okita, M.; Murai, Y.; Okano, Y.; Nomura, M. Isolation and identification of flavonoids from Coreopsis lanceolata L. petals. Nat. Prod. Res. 2014, 28, 201-204. [CrossRef] [PubMed]

3. Pardede, A.; Mashita, K.; Ninomiya, M.; Tanaka, K. Kouketsu, Flavonoid profile and antileukemic activity of Coreopsis lanceolata flowers. Bioorg. Med. Chem. Lett. 2016, 26, 2784-2787. [CrossRef] [PubMed]

4. Rao, Y.K.; Rao, V.C.; Kishore, P.H.; Gunasekar, D. Total synthesis of heliannone A and (R,S)-heliannone B, two bioactive flavonoids from Helianthus annuus Cultivars. J. Nat. Prod. 2001, 64, 368-369. [CrossRef] [PubMed]

5. Oyamada, T. A new general method for the synthesis of the derivatives of flavonol. Bull. Chem. Soc. Jpn. 1935, 10, 182-186. [CrossRef]

6. Bolek, D.; Gütschow, M. Preparation of 4,6,3', $4^{\prime}$-tetrasubstituted aurones via aluminium oxide-catalyzed condensation. J. Heterocycl. Chem. 2005, 42, 1399-1403. [CrossRef]

7. Pelter, A.; Ward, R.S.; Heller, H.G. Carbon-13 nuclear magnetic resonance spectra of (Z)- and (E)-aurones. J. Chem. Soc. Perkin Trans. 1 1979, 0, 328-329. [CrossRef]

8. Tominaga, H.; Kobayashi, Y.; Goto, T.; Kasemura, K.; Nomura, M. DPPH radical-scavenging effect of several phenylpropanoid compounds and their glycoside derivatives. Yakugaku Zasshi 2005, 125, 371-375. [CrossRef] [PubMed]

9. Tada, T.; Nomura, M.; Shimomura, K.; Fujihara, Y. Synthesis of karahanaenone derivatives and their inhibition properties toward tyrosinase and superoxide scavenging activity. Biosci. Biotechnol. Biochem. 1996, 60, 1421-1424. [CrossRef]

10. Stratford, M.R.L.; Ramsden, C.A.; Riley, P.A. Mechanistic studies of the inactivation of tyrosinase by resorcinol. Bioorg. Med. Chem. 2013, 21, 1166-1173. [CrossRef] [PubMed]

Sample Availability: Samples of the compounds 4a,b, 6a-c,g,i-k, 7a-1, 8a-j,1, 9b,g,i, 10f,l, 11a-k, 12b, 13b,c, $\mathbf{1 4} \mathbf{a}-\mathbf{f}, \mathbf{h}-\mathbf{l}$, and $\mathbf{1 5} \mathbf{a}-\mathbf{k}$ are available from the authors. 